\title{
Evaluation of Nondestructive Methods for Determining Pavement Thickness
}

Lulu Edwards and Quint Mason

September 2011

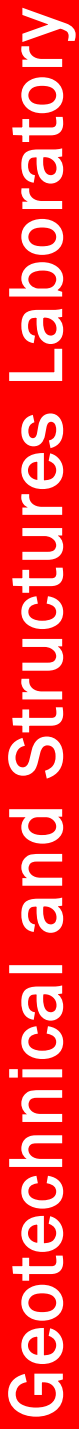
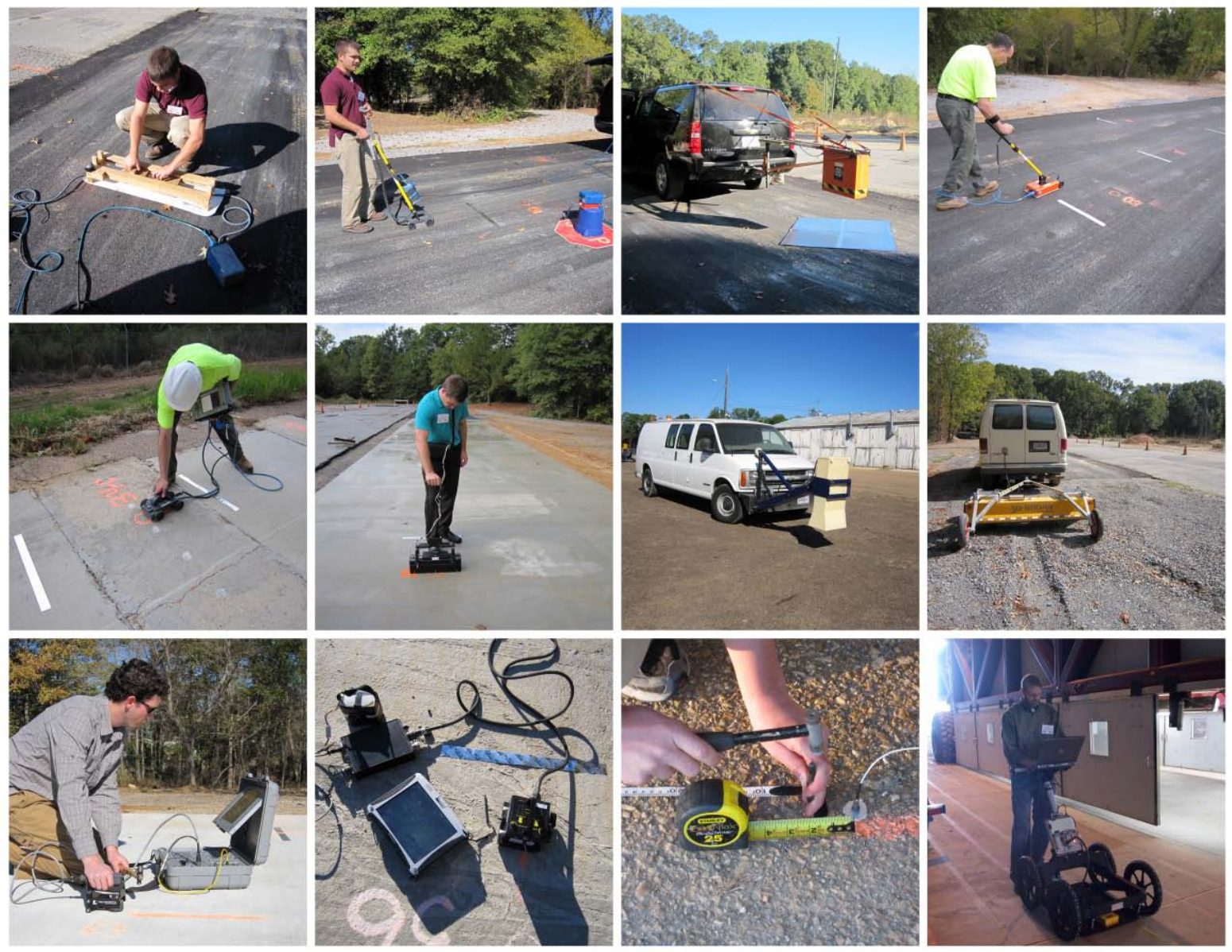


\section{Evaluation of Nondestructive Methods for Determining Pavement Thickness}

Lulu Edwards and Quint Mason

Geotechnical and Structures Laboratory

U.S. Army Engineer Research and Development Center

3909 Halls Ferry Road

Vicksburg, MS 39180-6199

Final report

Approved for public release; distribution is unlimited.

Prepared for Headquarters, Air Force Civil Engineer Support Agency

139 Barnes Avenue, Suite 1

Tyndall AFB, FL 32403-5319 


\begin{abstract}
The ERDC was tasked by the U.S. Air Force to evaluate emerging nondestructive thickness measuring devices to determine their ability to accurately estimate the pavement surface thickness without requiring large footprint equipment or repairs. Companies with products using nondestructive technology were down-selected to participate in a study requiring them to estimate the thickness of 40 asphalt and concrete locations with nondestructive devices. For each of the different pavement types, a single core was extracted to provide vendors with calibration points. Vendors provided initial thickness estimates, and upon receiving the calibration core thicknesses, vendors provided final thickness estimates. The results were compared to determine the accuracy and feasibility of the devices tested.
\end{abstract}




\section{Contents}

Figures and Tables........................................................................................................................

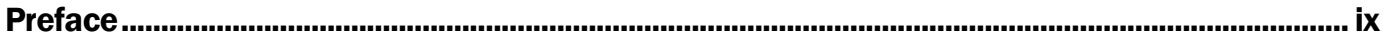

Unit Conversion Factors ....................................................................................................................... xi

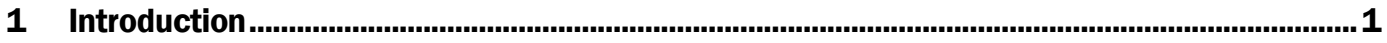

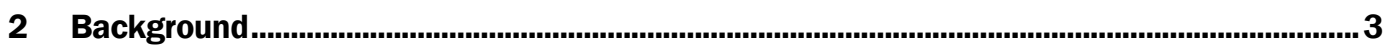

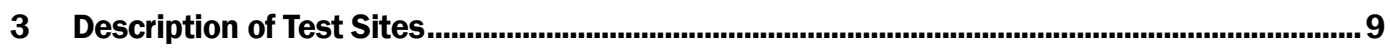

Custom test section construction at the Poor House Test Area …...................................... 10

Forest Service Road test section............................................................................ 19

Minimum PCC thickness test section at Hangar 4 …..................................................... 21

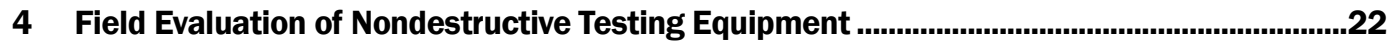

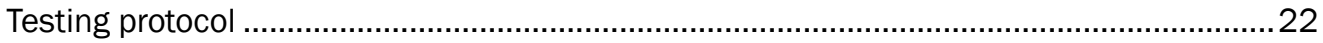

MIRA

Olson Engineering: multiple impact surface waves...................................................... 27

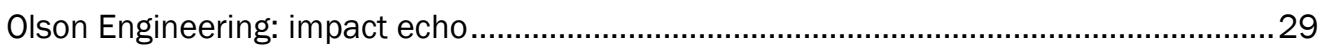

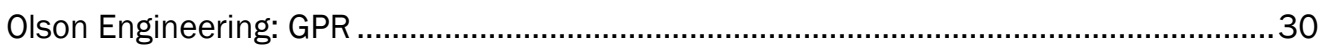

Infrasense, Inc.: single 1.5-GHz ground-coupled GSSI antenna...................................... 31

Infrasense, Inc.: CMP method with two 1.5-GHz ground-coupled GSSI antennas ..............34

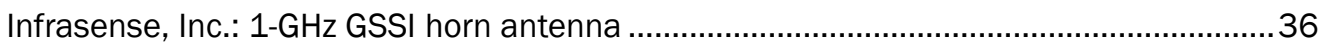

Resource International: $900-\mathrm{MHz}$ and 1.5-GHz ground-coupled GSSI antennas................38

MALÅ: 800-MHz, 1.2-GHz, 1.6-GHz, and 2.3-GHz ground-coupled MALÅ antennas .......... 41

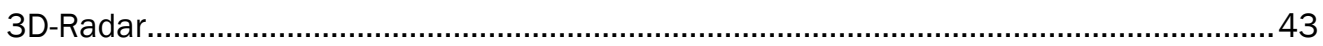

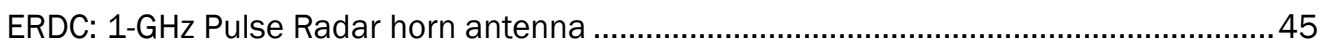

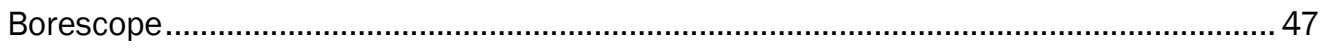

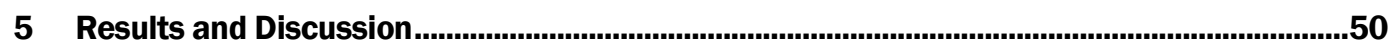

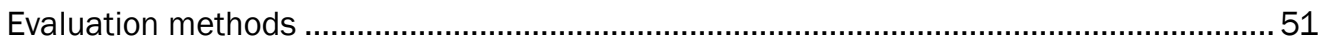

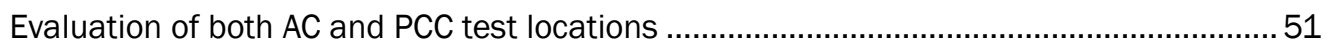

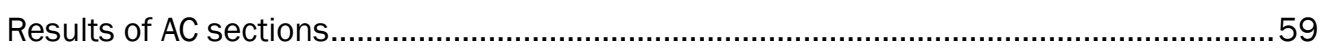

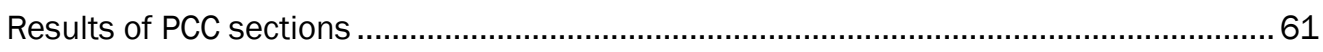

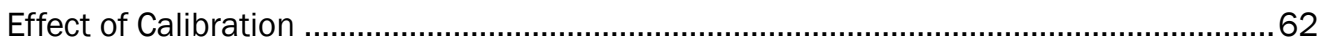

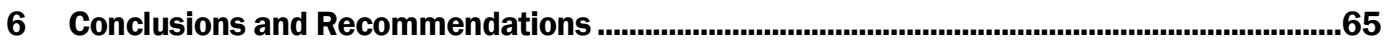

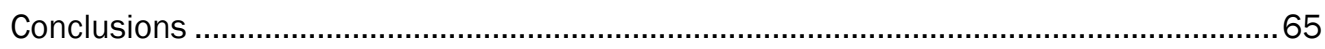

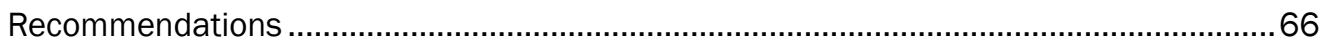

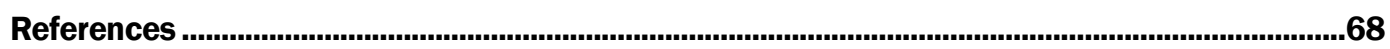




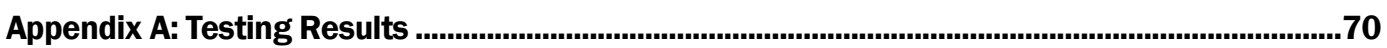

Report Documentation Page 


\section{Figures and Tables}

\section{Figures}

Figure 1. Current method of extracting cores during an airfield evaluation ...................................... 1

Figure 2. Layers of the AC portion of the custom test section .............................................................11

Figure 3. Layers of the PCC portion of the custom test section............................................................11

Figure 4. Overview photo of the custom test section constructed at the Poor House Test

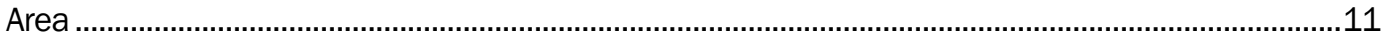

Figure 5. Excavation for test site construction preparation ..............................................................12

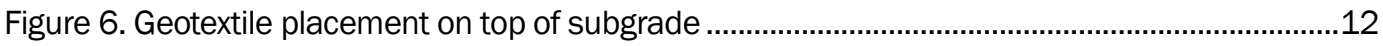

Figure 7. Drainage construction .................................................................................................13

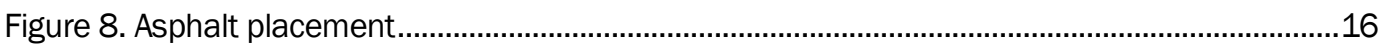

Figure 9. Compaction with a double drum vibratory compactor .......................................................17

Figure 10. Compaction with a rubber tire roller ................................................................................17

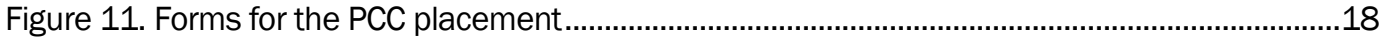

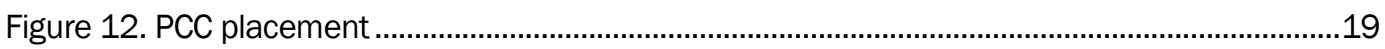

Figure 13. Saw cutting .....................................................................................................................19

Figure 14. Construction map of the Forest Service Road ..............................................................20

Figure 15. The flowable fill section is shown here on the right and was located within the Forest Service Road.......................................................................................................21

Figure 16. Test location marked with a circle to indicate location of the core hole and metallic tape spaced $2 \mathrm{ft}$ away from the center of the core hole ......................................................2.

Figure 17. Bottom of the MIRA device, where the 40 transducers are located..................................25

Figure 18. Testing a PCC slab with the MIRA............................................................................25

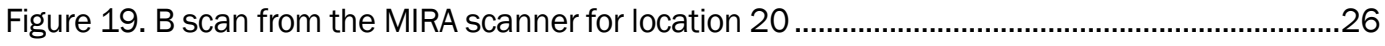

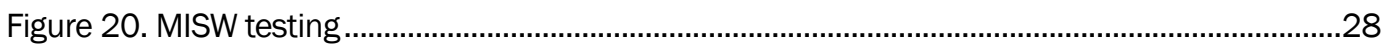

Figure 21. Impact echo testing...........................................................................................30

Figure 22. 2-GHz Ground-Coupled IDS Aladdin GPR testing ..............................................................31

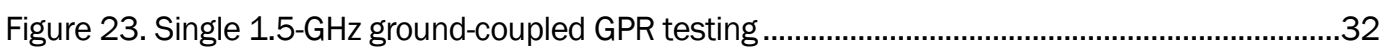

Figure 24. Example of the single ground-coupled GPR data from test location 8 .............................33

Figure 25. Common midpoint testing using two 1.5-GHz GSSI antennas ........................................34

Figure 26. Description of the variables in the CMP method and the hyperbolic pattern

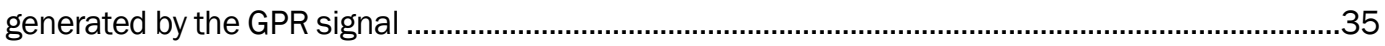

Figure 27. Infrasense testing of GSSI 1-GHz horn antenna............................................................36

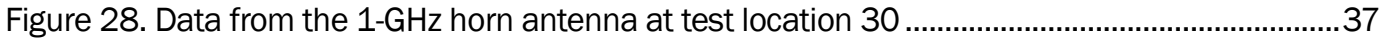

Figure 29. 900-MHz GSSI GPR system ......................................................................................39

Figure 30. Testing with the 1.5-GHz GSSI antenna ....................................................................39

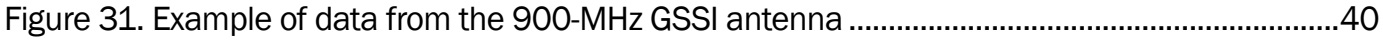


Figure 32. Example of data from the 1.5-GHz antenna................................................................ 41

Figure 33. MALÅ equipment on a utility cart ..............................................................................

Figure 34. Testing during intermittent rain .................................................................................. 42

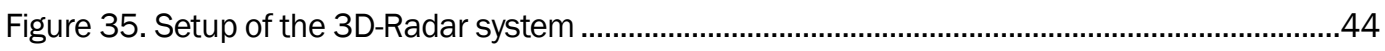

Figure 36. Testing with the 3D-Radar system ............................................................................4

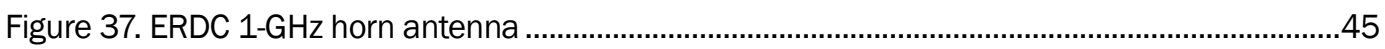

Figure 38. Data processing with the 1-GHz Pulse Radar horn antenna system ...............................46

Figure 39. Drilling a 2-in. hole and vacuuming the fines out of the hole ...........................................4 47

Figure 40. Using the borescope and measuring tape inside the drilled hole....................................48

Figure 41. Washing the drilled hole .............................................................................................. 48

Figure 42. Snapshot from borescope camera ……………………………………………......49

Figure 43. Measurement of PCC pavement layer for test location 19 .............................................50

Figure 44. Measurement of pavement layers for test location 31 .................................................51

Figure 45. Correlation of actual core thickness and estimated thickness from the MIRA ................53

Figure 46. Correlation of actual core thickness and estimated thickness from impact echo............53

Figure 47. Correlation of actual core thickness and estimated thickness from the MISW ................54

Figure 48. Correlation of actual core thickness and estimated thickness from the 2-GHz ground-coupled IDS Aladdin GPR

Figure 49. Correlation of actual core thickness and estimated thickness from the single 1.5-GHz ground-coupled GSSI antenna

Figure 50. Correlation of actual core thickness and estimated thickness from the CMP method with two 1.5-GHz ground-coupled GSSI antennas

Figure 51. Correlation of actual core thickness and estimated thickness from the 1-GHz GSSI horn antenna

Figure 52. Correlation of actual core thickness and estimated thickness from the 900-MHz and 1.5-GHz ground-coupled GSSI antennas

Figure 53. Correlation of actual core thickness and estimated thickness from the 800-MHz, 1.2-GHz, 1.6-GHz, and 2.3-GHz ground-coupled antennas.

Figure 54. Correlation of actual core thickness and estimated thickness from 3D-Radar's GPR system

Figure 55. Correlation of actual core thickness and estimated thickness from the 1-GHz Pulse Radar horn antenna

Figure A1. Comparison of the estimated thicknesses using the MIRA to actual core thicknesses

Figure A2. Comparison of the estimated thicknesses using the impact echo device to actual core thicknesses.

Figure A3. Comparison of the estimated thicknesses using the MISW device to actual core thicknesses

Figure A4. Comparison of the estimated thicknesses using the 2-GHz ground-coupled IDS Alladin GPR to actual core thicknesses.

Figure A5. Comparison of the estimated thicknesses using the single 1.5-GHz groundcoupled GSSI antenna to actual core thicknesses.

Figure A6. Comparison of the estimated thicknesses using the CMP method with two 1.5-GHz ground-coupled GSSI antennas to actual core thicknesses 
Figure A7. Comparison of the estimated thicknesses using the 1-GHz GSSI horn antenna to actual core thicknesses.

Figure A8. Comparison of the estimated thicknesses using the $900-\mathrm{MHz}$ and $1.5-\mathrm{GHz}$

ground-coupled GSSI antennas to actual core thicknesses

Figure A9. Comparison of the estimated thicknesses using the $800-\mathrm{MHz}, 1.2-\mathrm{GHz}$, 1.6-GHz , and 2.3-GHz ground-coupled GSSI antennas to actual core thicknesses

Figure A10. Comparison of the estimated thicknesses using the 3D-Radar device to actual core thicknesses.

Figure A11. Comparison of the estimated thicknesses using the 1-GHz Pulse Radar horn antenna to actual core thicknesses

\section{Tables}

Table 1. Constructed/reported thicknesses of test points ................................................................... 9

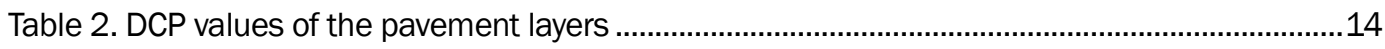

Table 3. Nuclear density gauge test results on the subgrade...........................................................14

Table 4. Nuclear density gauge test results on the clay gravel subbase ..........................................15

Table 5. Nuclear density gauge test results on the crushed limestone base course ..........................15

Table 6. Nuclear density gauge test results on Lift 1 of the AC section ........................................16

Table 7. Laboratory data on concrete placement ................................................................................18

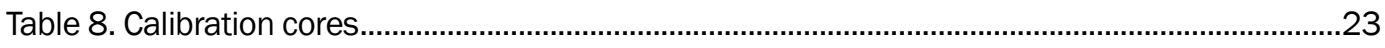

Table 9. Comparison of measured core data to GPR data at the calibration locations for the single 1.5-GHz ground-coupled GPR antenna .............................................................................33

Table 10. Comparison of measured core data to GPR data at the calibration locations for the CMP method using dual 1.5-GHz ground-coupled GPR antennas .............................................35

Table 11. Comparison of measured core data to GPR data at the calibration locations for

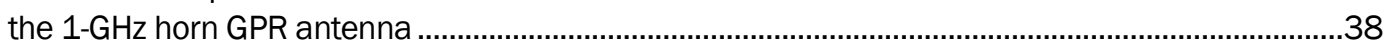

Table 12. Results for all test locations, ranked from highest to lowest $\mathrm{R}^{2}$......................................52

Table 13. Results for AC test locations, ranked from lowest error to highest error .............................59

Table 14. Results for PCC test locations, ranked from lowest error to highest error ..........................61

Table 15. Comparison of estimated data before and after calibration for AC test locations.............63

Table 16. Comparison of estimated data before and after calibration for PCC test

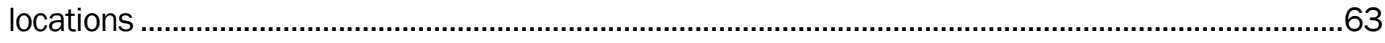

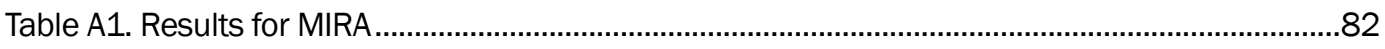

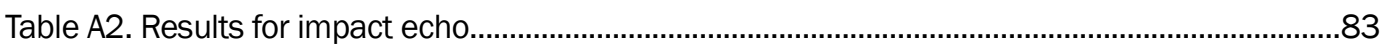

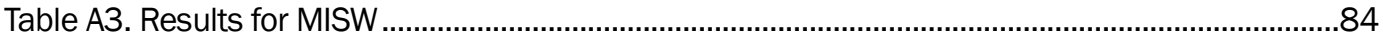

Table A4. Results for the 2-GHz ground-coupled IDS Aladdin GPR ...................................................85

Table A5. Results for the single 1.5-GHz ground-coupled GSSI antenna ........................................86

Table A6. Results for the CMP Method with two 1.5-GHz ground-coupled GSSI antennas ...............87

Table A7. 1-GHz GSSI horn antenna .............................................................................................8

Table A8. Results for the 900-MHz and 1.5-GHz ground-coupled GSSI antennas ...........................89

Table A9. Results for the 800-MHz, 1.2-GHz, 1.6-GHz, and 2.3-GHz ground-coupled antennas 


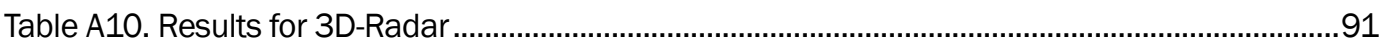

Table A11. Results for the 1-GHz Pulse Radar horn antenna ..........................................................92 


\section{Preface}

The purpose of this report is to present results of field evaluations of emerging nondestructive thickness measuring devices to determine their ability to accurately estimate the pavement surface thickness without requiring large footprint equipment or repairs. This report includes the following:

1. Literature review of current research related to nondestructive thickness determination

2. Review of candidate technologies

3. Evaluation of potential solutions

4. Specification of required capabilities

Projected users of this report include military personnel who evaluate airfields for suitability and performance capability, which includes the U.S. Air Force Airfield Pavement Evaluation Team. Other potential users include Army, Navy, and Marine Corps units assigned with similar tasks.

This publication was prepared by personnel of the U.S. Army Engineer Research and Development Center (ERDC), Geotechnical and Structures Laboratory (GSL), Vicksburg, MS. The findings and recommendations presented in this report are based upon field tests conducted at Vicksburg, MS, from October to December 2010. The principal investigator for this project was Lulu Edwards of the GSL, and the construction of the custom test section was performed by Quint Mason, GSL. Additional assistance was provided by the ERDC Vicksburg Directorate of Public Works. This report was prepared by Edwards and Mason. J eb S. Tingle, Engineering Systems and Materials Division (ESMD), GSL, served as the Program Manager and provided general technical oversight. The testing and analyses were conducted under the supervision of Dr. Gary L. Anderton, Chief, Airfields and Pavements Branch; Dr. Larry N. Lynch, Chief, ESMD; and Dr. David W. Pittman, Director, GSL.

COL Kevin J . Wilson was Commander and Executive Director of ERDC. Dr. J effery P. Holland was Director. 
Recommended changes for improving this publication in content and/ or format should be submitted on DA Form 2028 (Recommended Changes to Publications and Blank Forms) and forwarded to Headquarters, U.S. Army Corps of Engineers, ATTN: CECW-EWS, Kingman Building, Room 321, 7701 Telegraph Road, Alexandria, VA 22315. 


\section{Unit Conversion Factors}

\begin{tabular}{|l|c|l|}
\hline Multiply & By & To Obtain \\
\hline degrees Fahrenheit & (F-32)/1.8 & degrees Celsius \\
\hline feet & 0.3048 & meters \\
\hline inches & 0.0254 & meters \\
\hline miles per hour & 0.44704 & meters per second \\
\hline ounces (mass) & 0.02834952 & kilograms \\
\hline pounds (force) per square inch & 6.894757 & kilopascals \\
\hline pounds (mass) & 0.45359237 & kilograms \\
\hline pounds (mass) per cubic foot & 16.01846 & kilograms per cubic meter \\
\hline
\end{tabular}




\section{Introduction}

The ERDC was tasked by the U.S. Air Force (USAF) to evaluate emerging nondestructive thickness measuring devices to determine their ability to accurately estimate pavement surface thickness without requiring large footprint equipment or repairs. The USAF must operate anywhere in the world that supports our nation's objectives. In order to support deployments, existing airfields must be evaluated for their potential suitability for use, and accurate estimates of their performance capability must be made. The Airfield Pavement Evaluation (APE) team of the USAF is tasked with deploying to airfields of interest, often with minimal resources, and quickly evaluating the condition and structural capacity of the airfield pavement infrastructure. The pavement surface thickness is a critical component of the data needed to accurately assess the structural capacity of the pavement. Currently, the APE team must core the pavement to determine its thickness. Coring is a destructive data collection method that requires bulky equipment, a water source, and patching materials to repair the hole left in the pavement (Figure 1).

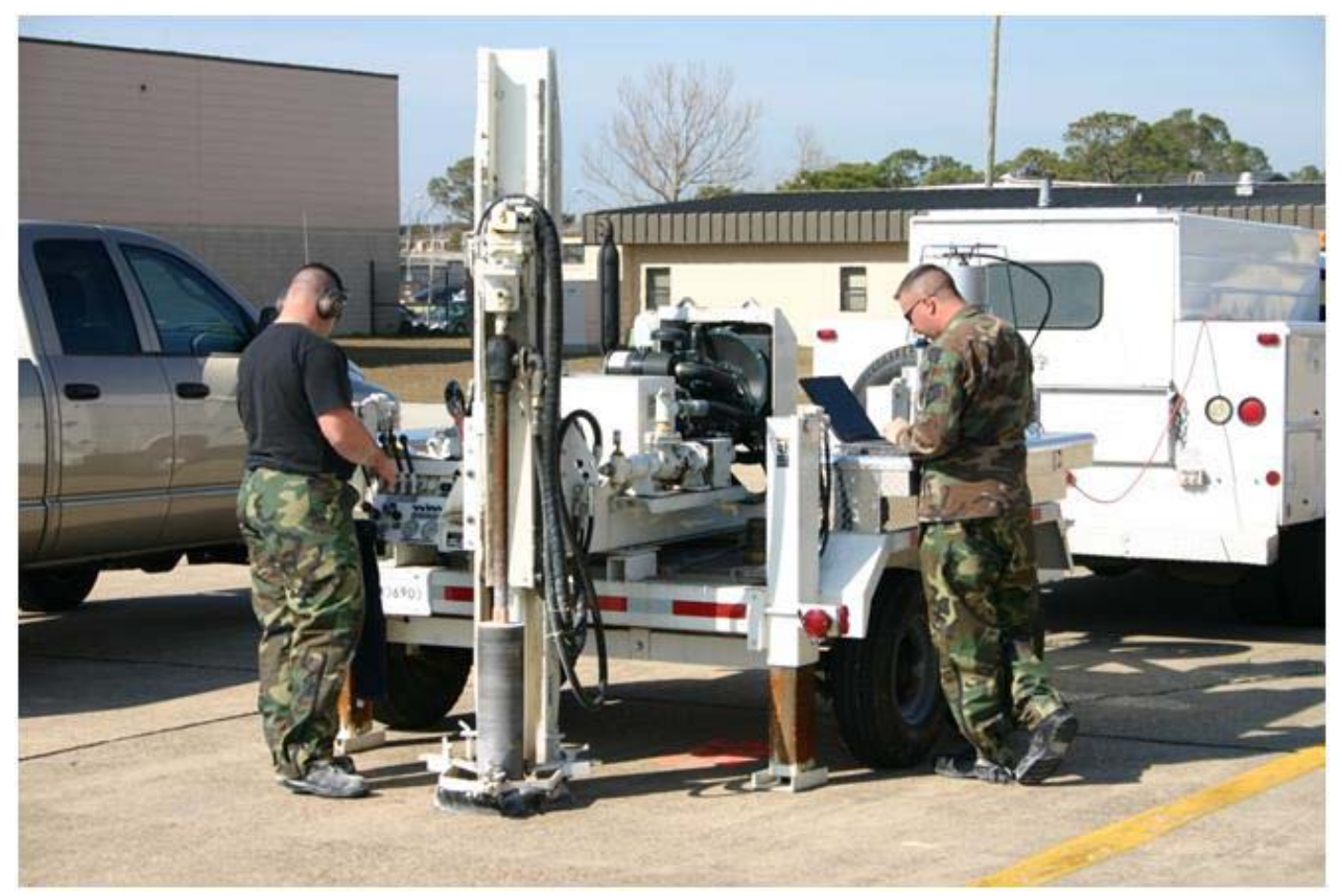

Figure 1. Current method of extracting cores during an airfield evaluation. 


\section{Objective and scope}

The objective of this study was to evaluate emerging thickness measuring devices to determine their ability to accurately estimate the pavement surface thickness without requiring large footprint equipment. This report provides information for the following:

1. Review of current technologies

2. Testing and evaluation of selected technologies

3. Specification of required capabilities

This report presents information on the types of sensor technology available to nondestructively measure pavement thickness, a description of the testing locations used to evaluate the down-selected technologies, and descriptions of the technologies evaluated and their results. Additionally, conclusions and recommendations for nondestructive pavement thickness evaluations are provided. 


\section{Background}

Emerging technology was reviewed for its potential use in accurately estimating pavement surface thickness. The current capability of the devices to determine pavement surface thickness was reviewed, and the potential for modification of the equipment to improve thickness prediction capability was considered.

\section{Sensor type}

Several sensors present possible solutions to the problem of nondestructively estimating pavement thickness.

\section{Ground penetrating radar (GPR)}

Since the 1970s, ground penetrating radar (GPR) has proven to be a valuable tool for applications such as the evaluation of highways, railroad tracks, and bridge decks. GPR has been used to locate pavement layer interfaces, buried utilities, voids, and items such as rebar within concrete. In particular, over ten state highway agencies have shown that GPR technology was successful in determining asphalt thicknesses; and the difference between the GPR measured thickness and core thicknesses ranged from $2 \%$ to $5 \%$ of the total thickness (Maser et al. 2006).

There are two major types of GPR, air-coupled systems and groundcoupled systems. Air-coupled systems are normally mounted above the ground, so that they can quickly collect data; and they can often move at highway speeds. They are often higher frequency ( $1 \mathrm{GHz}$ or higher) and can collect high resolution data. However, the depth of penetration is normally limited because of the high frequency. Ground-coupled systems are placed on the ground and require either manually moving the device or a cart to move the system along the pavement. These systems collect data at a much slower rate, but normally have a deeper penetration depth because they often come with antennas that are lower frequency $(<1 \mathrm{GHz})$.

To determine the pavement thickness for pulsed systems (air-coupled or ground-coupled), a short electromagnetic pulse is transmitted into the pavement. When the electromagnetic wave encounters an interface with a 
dielectric discontinuity, the electromagnetic wave is partially reflected back to the receiving antenna. The relationships between the layer thicknesses, dielectric constants, and the reflection amplitudes have been described by Scullion et al. (1994). The measured reflection time represents the two-way travel time of the electromagnetic wave. By utilizing the dielectric constant of the material, the thickness of the pavement can be calculated, as described in the following equation:

$$
\mathrm{h}=\frac{\mathrm{c} \times \Delta \mathrm{t}}{2 \sqrt{\varepsilon}}
$$

where:

$$
\begin{aligned}
\mathrm{h} & =\text { layer thickness } \\
\mathrm{C} & =\text { speed of light, in free space } \\
\Delta \mathrm{t} & =\text { two way travel time } \\
\varepsilon & =\text { dielectric constant of material. }
\end{aligned}
$$

If the reflection from a metal plate is also measured, the top pavement layer dielectric constant, $\varepsilon_{\mathrm{a}}$, can be calculated for each GPR signal, as shown in the following equation:

$$
\varepsilon_{\mathrm{a}}=\left[\frac{1+\frac{\mathrm{A}_{0}}{\mathrm{~A}_{\mathrm{m}}}}{1-\frac{\mathrm{A}_{0}}{\mathrm{~A}_{\mathrm{m}}}}\right]
$$

where:

$$
\begin{aligned}
\varepsilon_{\mathrm{a}} & =\text { dielectric constant of the first layer } \\
\mathrm{A}_{0} & =\text { surface reflection amplitude } \\
\mathrm{A}_{\mathrm{m}} & =\text { metal reflection amplitude. }
\end{aligned}
$$

The base dielectric constant, $\varepsilon_{\mathrm{b}}$, can also be calculated if the reflection amplitude from the base $\left(\mathrm{A}_{1}\right)$ is measured. This is described in the following equation: 


$$
\sqrt{\varepsilon_{\mathrm{b}}}=\sqrt{\varepsilon_{\mathrm{a}}}\left[\frac{1-\left[\frac{\mathrm{A}_{0}}{\mathrm{~A}_{\mathrm{m}}}\right]^{2}+\left[\frac{\mathrm{A}_{1}}{\mathrm{~A}_{\mathrm{m}}}\right]}{1-\left[\frac{\mathrm{A}_{0}}{\mathrm{~A}_{\mathrm{m}}}\right]^{2}-\left[\frac{\mathrm{A}_{1}}{\mathrm{~A}_{\mathrm{m}}}\right]}\right]
$$

where:

$$
\begin{aligned}
\varepsilon_{b} & =\text { dielectric constant of the second or base layer } \\
\mathrm{A}_{1} & =\text { base reflection amplitude. }
\end{aligned}
$$

Alternatively, the dielectric constants can be obtained either by using known values reported in literature, or by measuring the thickness in situ and using Equation 1 to back-calculate the dielectric constant.

The common midpoint method has been used as a method to estimate dielectric constants for ground-coupled methods. Two ground-coupled antennas are placed side by side and moved at equal distances away from each other from an initial starting point. The collected data from the bottom of the pavement result in a hyperbolic pattern, and the following equation is used with the common midpoint data:

$$
\mathrm{t}_{\mathrm{tot}}(\mathrm{i})=\frac{2}{\mathrm{~V}_{2}} \sqrt{\mathrm{x}(\mathrm{i})^{2}+\mathrm{d}^{2}}
$$

where:

$$
\begin{aligned}
\mathrm{t}_{\text {tot }}(\mathrm{i}) & =\text { arrival time of GPR pulse for spacing } \mathrm{x}(\mathrm{i}) \\
\mathrm{x}(\mathrm{i}) & =\text { antenna distance from common midpoint at scan } \mathrm{i} \\
\mathrm{i} & =\text { scan number } \\
\mathrm{V}_{2} & =\text { GPR velocity in pavement layer } \\
\mathrm{d} & =\text { thickness of pavement layer. }
\end{aligned}
$$

With this method, the pavement layer velocity and the layer thickness can be estimated, so that the dielectric constant does not have to be estimated or determined from a core hole (Maser et al. 2002). 
Another type of radar that has been recently developed is a step frequency GPR, which can provide three-dimensional data. Rather than using just one frequency as with the pulsed radar methods, described previously, this type of GPR uses a range of frequencies.

The following items should be considered, prior to using GPR:

- Only pavement layers with a difference in dielectric constants can be detected. If the dielectric constants are too similar, no distinction can be made between layers, leading to incorrect thickness predictions.

- GPR is often not used because automated software or processing has not advanced enough to be reliable for routine use, and manually processing GPR data can be time consuming (Lahouar and Al-Qadi 2008). A trained, experienced user is normally required to process GPR data.

- Higher frequency GPR systems yield better resolution data but are limited in penetration depth. Lower frequency GPR systems can penetrate deeper, but are limited in resolution.

- Concrete, especially newly constructed concrete, attenuates the GPR signal and reduces the penetration depth (Halabe et al. 1993). Freshly placed concrete has a high free water and dissolved salts content that result in high attenuation of the GPR signal in concrete. The free water content decreases as the concrete cures over time (De Souza et al. 2004).

- For Asphalt Concrete (AC) pavements, increasing age may decrease the accuracy of GPR, probably because there is a dielectric constant gradient within a pavement layer. Additionally, thin overlays would also cause a similar problem because the dielectric constants of the thin layers would vary, but the variation may be too small to detect as a layer (Al-Qadi et al. 2005).

\section{Wave propagation methods}

Wave propagation methods include those based on sonic, seismic, and vibration methods. These nondestructive methods measure dynamic properties that are related to physical conditions (Olson and Wright 1990).

Impact echo is a type of mechanical wave technique that was first used in 1983 by the National Bureau of Standards (Sansalone 1997). Impact echo methodology involves using an impact source on the surface of the pavement to create low frequency stress waves in the pavement and 
transducers on the surface of the pavement to measure the reflecting waves from layer interfaces or flaws of the structure imaged. A fast Fourier transform is used to convert the displacement versus time signals to the frequency domain to provide data about flaw location, such as at layer interfaces (Sansalone 1997). It is typically used for nondestructive testing of concrete because the thickness of concrete pavement is typically sufficient for the measurement range required by mechanical wave measurements. Additionally, the mechanical impedance contrast for concrete pavement and base material is normally strong enough to delineate the layer interface. However, mechanical wave techniques are not as successful in asphalt because of the lower modulus of asphalt, as well as the changes in modulus resulting from changes in temperature (Maser et al. 2006).

Ultrasonic tomographic imaging is another type of mechanical wave based technology that uses sound waves ( $>20 \mathrm{KHz}$ ) to penetrate pavement and generate images. Early ultrasonic methods were problematic because they required a coupling liquid and were not able to penetrate sufficiently. A new technology utilizing dry point contact (DPC) transducers has advanced the use of ultrasonic imaging in the civil field. This technology has been used extensively for Portland Cement Concrete (PCC)-related applications, such as for detecting reinforcement, thickness determinations, detection of delamination between layers, and the diagnostics of joints (Hoegh et al. 2011).

\section{Falling weight deflectometer}

The falling weight deflectometer (FWD) has been used to nondestructively measure pavement thicknesses by utilizing the deflection under an applied impulse load. The applied load and measured deflection can be used to backcalculate layer moduli. The same sensors that are used for calculating modulus values are also used to determine pavement layer thickness. According to Noureldin et al. (2005), the surface thickness can be calculated using the following equation:

$$
\mathrm{T}_{\text {surface }}=23.2379\left[\frac{\mathrm{D}_{0}-\mathrm{D}_{12}}{3 \mathrm{D}_{12}}\right]^{1 / 3}
$$


where:

$\mathrm{T}_{\text {surface }}=$ surface thickness

$\mathrm{D}_{0}=$ center deflection, mils

$\mathrm{D}_{12}=$ deflection of a sensor located at radii of $12 \mathrm{in}$.

However, using the FWD has proved to be difficult to implement because normally, the thicknesses are used to backcalculate layer moduli and not vice versa (Al-Qadi and Lahouar 2005).

\section{Borescope}

An alternative to coring and the previously mentioned nondestructive techniques is the use of borescopes to image through small diameter holes drilled into the pavement. Gopaldas et al. (2009) studied the usefulness of borescopes to determine pavement layer thicknesses. Drill bits to create small holes were not considered because experience had shown that the holes would not be clean enough to image because the heat generated during drilling caused a detrimental effect on the wall of the hole. Coring tools of different diameters ( $10 \mathrm{~mm}$ or $0.4 \mathrm{in} . ; 20 \mathrm{~mm}$ or $0.8 \mathrm{in}$; and $28 \mathrm{~mm}$ or $1.1 \mathrm{in}$.) were investigated and were found to have similar problems to drilling in that the bitumen was smeared and the cored material adhered to the coring tool interior. A coring tool to create a 52-mm (2.05-in.) diameter hole was also investigated and found to be as time consuming as a 150-mm (5.91-in.) diameter coring tool, but produced a core hole that was adequate for imaging. A rigid borescope was beneficial because a better image quality and field of view could be achieved using this device. The authors concluded that for this method to be successful, a better option to create a clean hole would be required, as well as the automation of the image collecting and data processing. 


\section{Description of Test Sites}

Devices were evaluated at three different sites at the ERDC, Vicksburg. The first site was located at the Poor House Test Area, where a custom test section was constructed specifically for this project with varying thicknesses of AC and PCC. The second site selected was the Forest Service Road Test Area, which was constructed in 1988 for traffic testing purposes and had several different AC thicknesses, as well as a newer test section constructed for testing flowable fill pavement repairs. The last site recycled a previously tested Air Force PCC test section constructed for a project to determine minimum PCC thickness for airfield pavement design, and this site was located in Hangar 4.

All test points with similar properties also had a calibration point associated with it. Once vendors provided their initial thickness estimate, they were given the calibration points to use, if necessary. The test points and their constructed/ reported thicknesses are listed in Table 1.

Table 1. Constructed/reported thicknesses of test points.

\begin{tabular}{|c|c|c|c|c|}
\hline Test & Site & Layer 1 & Layer 2 & Layer 3 \\
\hline 1 & Custom Test Section, AC Section 1 & 3-in. AC & 6-in. limestone & 10-in. clay gravel \\
\hline 2 & Custom Test Section, AC Section 1 & 3-in. AC & 6-in. limestone & 10-in. clay gravel \\
\hline 3 & Custom Test Section, AC Section 1 & 3-in. AC & 6-in. limestone & 10-in. clay gravel \\
\hline 4 & Custom Test Section, AC Section 2 & 5-in. AC & 12-in. PCC & 6-in. gravel \\
\hline 5 & Custom Test Section, AC Section 2 & 5-in. AC & 12-in. PCC & 6-in. gravel \\
\hline 6 & Custom Test Section, AC Section 2 & 5-in. AC & 12-in. PCC & 6-in. gravel \\
\hline 7 & Custom Test Section, AC Section 3 & 7-in. AC & 6-in. limestone & 6-in. gravel \\
\hline 8 & Custom Test Section, AC Section 3 & 7-in. AC & 6-in. limestone & 6-in. gravel \\
\hline 9 & Custom Test Section, AC Section 3 & 7-in. AC & 6-in. limestone & 6-in. gravel \\
\hline $10^{\text {cal }}$ & Custom Test Section, AC Buffer B & 3-in. AC & 6-in. limestone & 6-in. gravel \\
\hline 11 cal & Custom Test Section, PCC Buffer A & 8-in. PCC & 6-in. limestone & $\mathrm{N} / \mathrm{A}$ \\
\hline 12 & Custom Test Section & 24-in. PCC & 6-in. limestone & $\mathrm{N} / \mathrm{A}$ \\
\hline 13 & Custom Test Section & 24-in. PCC & 6-in. limestone & $\mathrm{N} / \mathrm{A}$ \\
\hline 14 & Custom Test Section & 24-in. PCC & 6-in. limestone & $\mathrm{N} / \mathrm{A}$ \\
\hline 15 & Custom Test Section & 15-in. PCC & 6-in. limestone & $\mathrm{N} / \mathrm{A}$ \\
\hline 16 & Custom Test Section & 15-in. PCC & 6-in. limestone & $\mathrm{N} / \mathrm{A}$ \\
\hline
\end{tabular}




\begin{tabular}{|c|c|c|c|c|}
\hline Test & Site & Layer 1 & Layer 2 & Layer 3 \\
\hline 17 & Custom Test Section & 15-in. PCC & 6-in. limestone & $\mathrm{N} / \mathrm{A}$ \\
\hline 18 & Custom Test Section & 8-in. PCC & 6-in. limestone & N/A \\
\hline 19 & Custom Test Section & 8-in. PCC & 6-in. limestone & $\mathrm{N} / \mathrm{A}$ \\
\hline 20 & Custom Test Section & 8-in. PCC & 6-in. limestone & $\mathrm{N} / \mathrm{A}$ \\
\hline $21^{\mathrm{cal}}$ & Forest Service Road & 5-in. AC & $\mathrm{N} / \mathrm{A}$ & $\mathrm{N} / \mathrm{A}$ \\
\hline 22 & Forest Service Road & 5-in. AC & N/A & N/A \\
\hline 23 & Forest Service Road & 4-in. AC & 4-in. limestone & $\mathrm{N} / \mathrm{A}$ \\
\hline 24 & Forest Service Road & 4-in. AC & 4-in. limestone & $\mathrm{N} / \mathrm{A}$ \\
\hline 25 & Forest Service Road & Unknown $\mathrm{AC}^{1}$ & 8-in. limestone & $\mathrm{N} / \mathrm{A}$ \\
\hline 26 cal & Forest Service Road & Unknown $\mathrm{AC}^{1}$ & 8-in. limestone & N/A \\
\hline 27 & Forest Service Road & Unknown $\mathrm{AC}^{1}$ & 6-in. limestone & $\mathrm{N} / \mathrm{A}$ \\
\hline 28 & Forest Service Road & Unknown $\mathrm{AC}^{1}$ & 6-in. limestone & $\mathrm{N} / \mathrm{A}$ \\
\hline 29 & Forest Service Road & Unknown $\mathrm{AC}^{1}$ & 4-in. limestone & $\mathrm{N} / \mathrm{A}$ \\
\hline 30 & Forest Service Road & Unknown $\mathrm{AC}^{1}$ & 4-in. limestone & $\mathrm{N} / \mathrm{A}$ \\
\hline 31 & Forest Service Road & Unknown $\mathrm{AC}^{2}$ & Unknown & $\mathrm{N} / \mathrm{A}$ \\
\hline 32 & Forest Service Road, Flowable Fill & 6-in. PCC & 30-in. flowable fill & N/A \\
\hline 33 & Forest Service Road, Flowable Fill & 6-in. PCC & 30-in. flowable fill & $\mathrm{N} / \mathrm{A}$ \\
\hline $34 \mathrm{cal}$ & Forest Service Road, Flowable Fill & 6-in. PCC & 30-in. flowable fill & $\mathrm{N} / \mathrm{A}$ \\
\hline 35 & Forest Service Road, Flowable Fill & 8-in. PCC & $\begin{array}{l}\text { 12-in. compacted } \\
\text { well-graded gravel }\end{array}$ & $\mathrm{N} / \mathrm{A}$ \\
\hline 36 & Forest Service Road, Flowable Fill & 8-in. PCC & $\begin{array}{l}\text { 12-in. compacted } \\
\text { well-graded gravel }\end{array}$ & N/A \\
\hline 37 & Hangar Test Section & 11-in. PCC & 13-in. limestone & $\mathrm{N} / \mathrm{A}$ \\
\hline 38 & Hangar Test Section & 11-in. PCC & 13-in. limestone & $\mathrm{N} / \mathrm{A}$ \\
\hline 39 & Hangar Test Section & 11-in. PCC & 13-in. limestone & $\mathrm{N} / \mathrm{A}$ \\
\hline $40^{\text {cal }}$ & Hangar Test Section & 8-in. PCC & 18-in. limestone & $\mathrm{N} / \mathrm{A}$ \\
\hline
\end{tabular}

Notes: cal $=$ calibration test point, N/A = not applicable.

1 This section of the Forest Service Road was rehabilitated, so the exact thickness of the AC is unknown.

2 This section was not part of the Forest Service Road test loop, so the thickness was not reported.

\section{Custom test section construction at the Poor House Test Area}

A 16-ft-wide custom test section was constructed of AC and PCC to provide a range of thicknesses found on airfields. Each section was 20-ft long with 15-ft buffers between the AC (Figure 2) and PCC sections (Figure 3), so the $\mathrm{AC}$ and $\mathrm{PCC}$ section were a total of 90 - $\mathrm{ft}$ long. Twenty test points, ten AC points, and ten PCC points were located in the custom test section at the 
Poor House Test Area (Figure 4). Three points were chosen for each thickness and a calibration point was chosen in the buffer zone for both the AC and PCC sections.

\begin{tabular}{|c|c|c|c|c|}
\hline $\begin{array}{l}15 \mathrm{FT} \\
16 \mathrm{FT}\end{array}$ & $\longleftarrow 20 \mathrm{FT}-$ & $\longleftarrow 20 \mathrm{FT}$ & $-20 \mathrm{FT}$ & $-15 \mathrm{FT} \longrightarrow$ \\
\hline $\begin{array}{l}\text { AC Buffer A: } \\
-3 \text { in. AC } \\
-6 \text { in. limestone } \\
-6 \text { in. gravel }\end{array}$ & $\begin{array}{l}\text { AC Section 1: } \\
-3 \text { in. AC } \\
-6 \text { in. limestone } \\
-10 \text { in. gravel }\end{array}$ & $\begin{array}{l}\text { AC Section 2: } \\
-5 \text { in. AC } \\
-12 \text { in. PCC } \\
-6 \text { in. gravel }\end{array}$ & $\begin{array}{l}\text { AC Section 3: } \\
-7 \text { in. AC } \\
-6 \text { in. limestone } \\
-6 \text { in. gravel }\end{array}$ & $\begin{array}{l}\text { AC Buffer B: } \\
-3 \text { in. AC } \\
-6 \text { in. limestone } \\
-6 \text { in. gravel }\end{array}$ \\
\hline
\end{tabular}

Figure 2. Layers of the AC portion of the custom test section. The * denotes where the $A C$ and PCC sections connect.

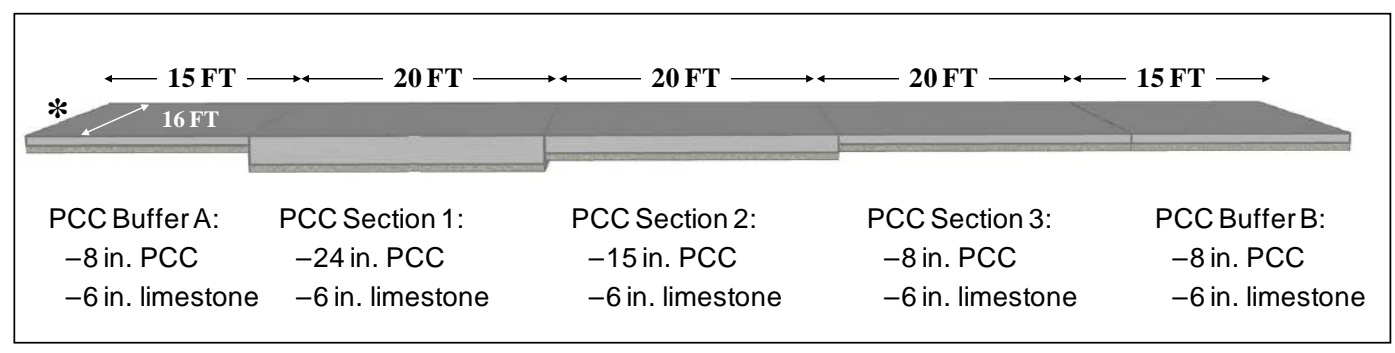

Figure 3. Layers of the PCC portion of the custom test section. The * denotes where the AC and PCC sections connect.

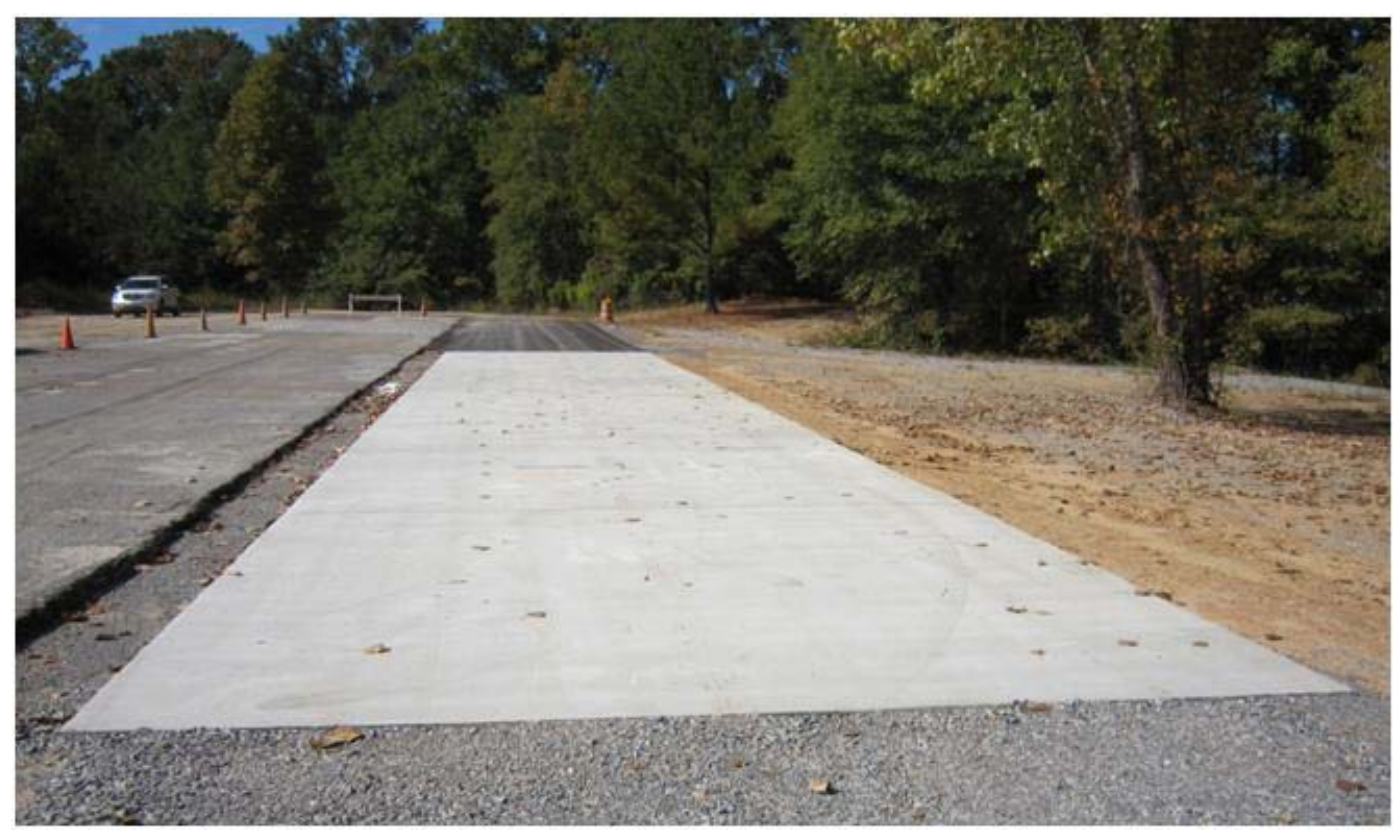

Figure 4. Overview photo of the custom test section constructed at the Poor House Test Area. 
The site for the custom test section was cleared of existing vegetation, and a prior test section was removed (Figure 5). The existing subgrade was leveled, prior to construction. A geotextile was placed on the subgrade, prior to placing the subbase and base layers (Figure 6). Drainage was also constructed in the center of the section (Figure 7). For both the AC and PCC sections, crushed limestone was used as the base, and clay gravel was used for the subbase. One lift of the crushed limestone was placed and compacted with a steel-wheel vibratory roller. The source for the crushed limestone was a 610 limestone base.

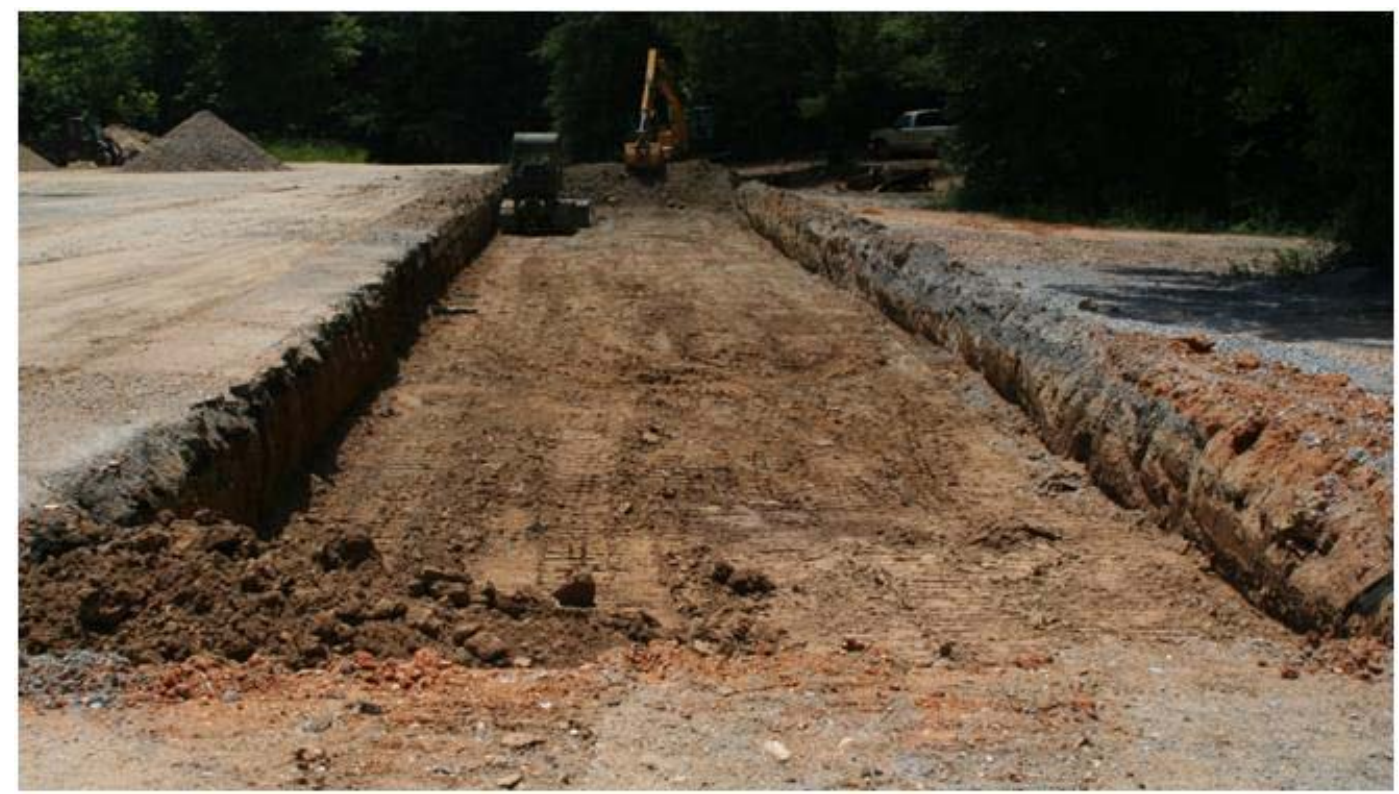

Figure 5. Excavation for test site construction preparation.

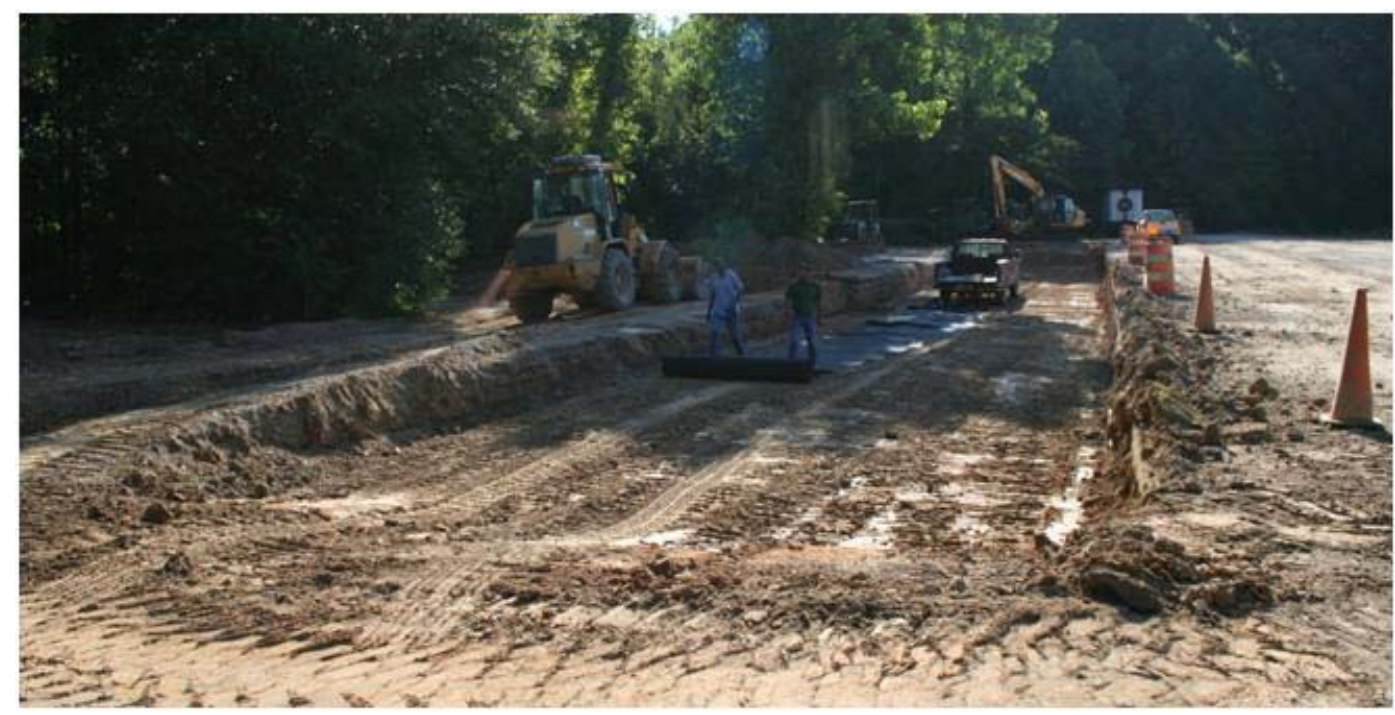

Figure 6. Geotextile placement on top of subgrade. 


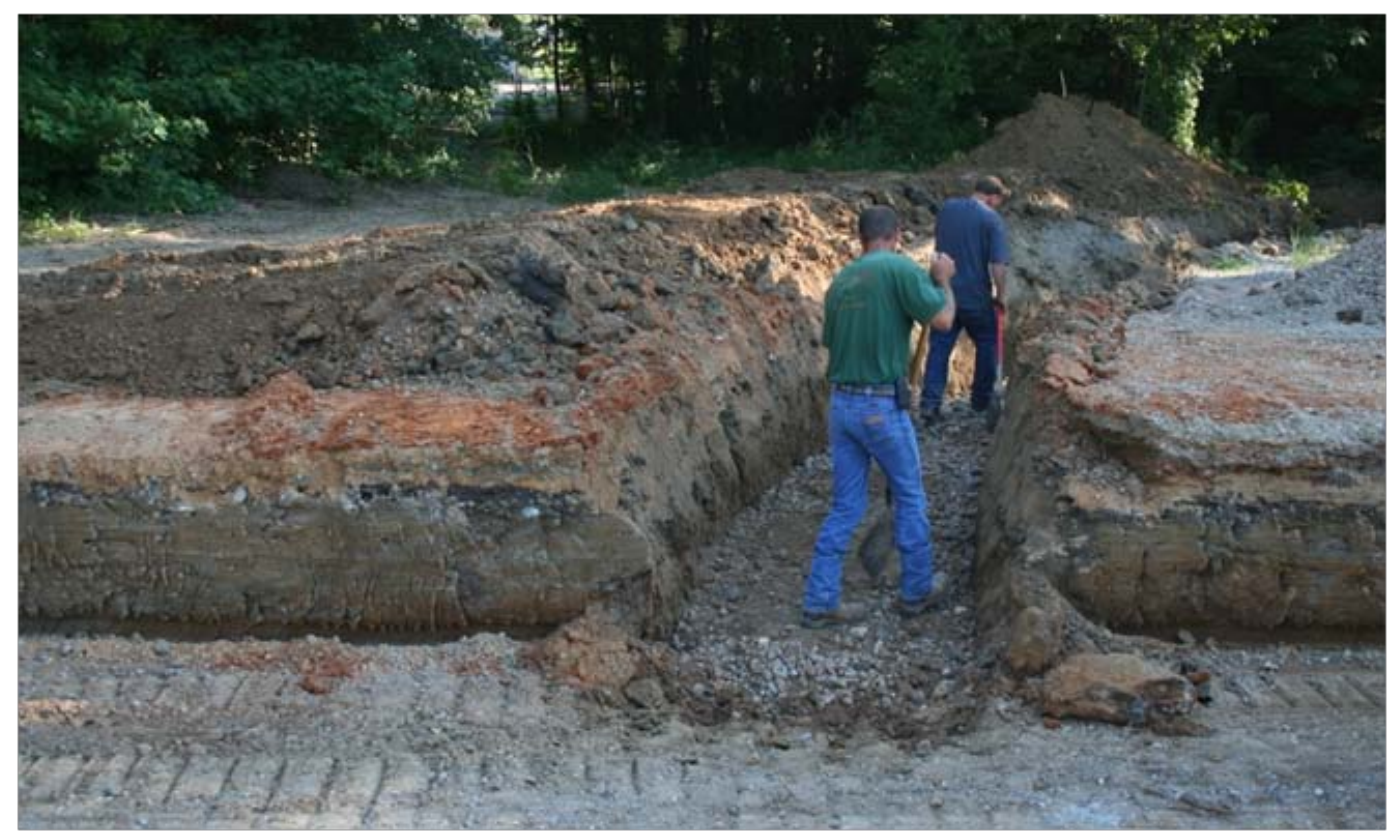

Figure 7. Drainage construction.

Dynamic cone penetrometer (DCP) measurements were taken to measure the in situ soil strength. The tests were conducted according to the procedure described by ASTM D6951 (2003). The DCP had a 60-deg cone with a base diameter of 0.79 in. The test procedure involved placing the DCP cone point on the surface and recording a baseline measurement to the nearest $5 \mathrm{~mm}$. The 17.6-lb hammer was then raised and dropped 22.6 in. onto the anvil, which drove the penetrometer rod and cone into the soil. Depth of cone penetration measurements and number of hammer blows were recorded approximately every inch $(25 \mathrm{~mm})$, or whenever any noticeable change in penetration rate occurred. A DCP strength index in terms of penetration per hammer blow was calculated for each measurement interval. The DCP index was then converted to the California Bearing Ratio (CBR) percentage using the correlation described in Equation 6. The CBR value provides an index of relative soil strength with depth. A CBR value of 100 is equivalent to the bearing capacity of a properly compacted, dense-graded, crushed aggregate. DCP data for this report were then entered into a Microsoft Excel spreadsheet formatted to automatically process the data.

$$
\operatorname{CBR}(\%)=\frac{292}{\mathrm{DCP}^{1.12}}
$$

Measurements were taken for each layer of the pavement sections and are tabulated in Table 2. 
Table 2. DCP values of the pavement layers (average of three replicates).

\begin{tabular}{|l|l|l|l|}
\hline Section & $\begin{array}{l}\text { Subgrade CBR } \\
\%\end{array}$ & $\begin{array}{l}\text { Subbase CBR } \\
\%\end{array}$ & $\begin{array}{l}\text { Base CBR } \\
\%\end{array}$ \\
\hline AC Buffer A & 23 & 82 & 35 \\
\hline AC Section 1 & 27 & 40 & 38 \\
\hline AC Section 2 & 26 & 43 & N/A \\
\hline AC Section 3 & 27 & 63 & 30 \\
\hline AC Buffer B & 15 & 20 & 18 \\
\hline PCC Buffer A & 21 & N/A & 35 \\
\hline PCC Section 1 & 25 & N/A & 26 \\
\hline PCC Section 2 & 37 & N/A & 33 \\
\hline PCC Section 3 & 40 & N/A & 47 \\
\hline PCC Buffer B & 62 & N/A & 68 \\
\hline
\end{tabular}

Nuclear density and moisture measurements were collected with a Troxler ${ }^{\circledR} 3430$ nuclear gauge. The gauge contains two radioactive sources: Cesium-137 for density measurement and Americium-241:Beryllium for determining moisture content. Density and moisture content of the subgrade (Table 3), subbase (Table 4), and base (Table 5) were measured, as specified by ASTM D6938-10 (ASTM 2010c).

Table 3. Nuclear density gauge test results on the subgrade.

\begin{tabular}{|l|l|l|l|l|l|}
\hline $\begin{array}{l}\text { Pavement } \\
\text { Section }\end{array}$ & $\begin{array}{l}\text { Depth } \\
\text { in. }\end{array}$ & $\begin{array}{l}\text { Wet Density } \\
\text { pcf }\end{array}$ & $\begin{array}{l}\text { Dry Density } \\
\text { pcf }\end{array}$ & $\begin{array}{l}\text { Moisture } \\
\text { pcf }\end{array}$ & $\begin{array}{l}\text { Moisture } \\
\%\end{array}$ \\
\hline AC Buffer A & 6 & 123.0 & 108.7 & 14.3 & 13.1 \\
\hline AC Section 1 & 6 & 120.0 & 106.0 & 14.0 & 13.2 \\
\hline AC Section 2 & 6 & 123.3 & 111.2 & 12.1 & 10.9 \\
\hline AC Section 3 & 6 & 121.7 & 110.1 & 11.5 & 10.5 \\
\hline AC Buffer B & 6 & 121.1 & 109.7 & 11.3 & 10.3 \\
\hline PCC Buffer A & 6 & 119.6 & 106.8 & 12.8 & 12.0 \\
\hline PCC Section 1 & 6 & 123.6 & 109.8 & 13.8 & 12.6 \\
\hline PCC Section 2 & 6 & 126.3 & 113.0 & 13.4 & 11.8 \\
\hline PCC Section 3 & 6 & 129.0 & 115.0 & 14.1 & 12.3 \\
\hline PCC Buffer B & 6 & 130.7 & 116.6 & 14.1 & 12.2 \\
\hline
\end{tabular}


Table 4. Nuclear density gauge test results on the clay gravel subbase.

\begin{tabular}{|l|l|l|l|l|l|}
\hline $\begin{array}{l}\text { Pavement } \\
\text { Section }\end{array}$ & $\begin{array}{l}\text { Depth } \\
\text { in. }\end{array}$ & $\begin{array}{l}\text { Wet Density } \\
\text { pcf }\end{array}$ & $\begin{array}{l}\text { Dry Density } \\
\text { pcf }\end{array}$ & $\begin{array}{l}\text { Moisture } \\
\text { pcf }\end{array}$ & $\begin{array}{l}\text { Moisture } \\
\%\end{array}$ \\
\hline AC Buffer A & 6 & 124.0 & 118.5 & 5.5 & 4.6 \\
\hline AC Section 1 & 6 & 132.1 & 125.9 & 6.3 & 5.0 \\
\hline AC Section 3 & 6 & 131.0 & 124.9 & 6.1 & 4.9 \\
\hline AC Buffer B & 6 & 130.5 & 125.7 & 4.7 & 3.8 \\
\hline
\end{tabular}

Table 5. Nuclear density gauge test results on the crushed limestone base course.

\begin{tabular}{|l|l|l|l|l|l|}
\hline $\begin{array}{l}\text { Pavement } \\
\text { Section }\end{array}$ & $\begin{array}{l}\text { Depth } \\
\text { in. }\end{array}$ & $\begin{array}{l}\text { Wet Density } \\
\text { pcf }\end{array}$ & $\begin{array}{l}\text { Dry Density } \\
\text { pcf }\end{array}$ & $\begin{array}{l}\text { Moisture } \\
\text { pcf }\end{array}$ & $\begin{array}{l}\text { Moisture } \\
\%\end{array}$ \\
\hline AC Buffer A & 6 & 128.6 & 126.1 & 2.5 & 2.0 \\
\hline AC Section 1 & 6 & 130.4 & 127.3 & 3.1 & 2.5 \\
\hline AC Section 2 & 6 & 134.9 & 128.0 & 6.8 & 5.3 \\
\hline AC Section 3 & 6 & 127.5 & 124.0 & 3.4 & 2.8 \\
\hline AC Buffer B & 6 & 139.9 & 136.2 & 3.7 & 2.7 \\
\hline PCC Buffer A & 6 & 122.0 & 120.4 & 2.7 & 2.2 \\
\hline PCC Section 1 & 6 & 132.5 & 129.0 & 3.5 & 2.7 \\
\hline PCC Section 2 & 6 & 133.9 & 131.0 & 2.9 & 2.2 \\
\hline PCC Section 3 & 6 & 135.4 & 132.5 & 2.9 & 2.2 \\
\hline PCC Buffer B & 6 & 130.2 & 127.9 & 2.3 & 1.8 \\
\hline
\end{tabular}

For the AC test section, as shown in Figure 2, the first section was constructed with a 3-in. AC, a 6-in. limestone base, and a 10-in. clay gravel subbase. The second section was a composite pavement section constructed with a 5-in. AC, a 12-in. PCC, and a 6-in. clay gravel base. The third section was constructed with a 7-in. AC, a 6-in. limestone base, and a 6-in. clay gravel subbase.

The AC hot mix was placed with an asphalt paving machine (Ingersoll Rand Blaw-Knox Pf-3172) in one 16-ft-wide lane. Two lifts were required for AC Sections 2 and 3; the AC Section 1 and the AC Buffers A and B only required one lift. The first lift for AC Section 2 was 2 in., and for AC Section 3, it was 4 in. A final 3-in. lift was placed over the entire AC portion of the test site. Compaction between lifts was completed with a double drum vibratory compactor (Caterpillar CB634-C) and an 8,500-lb rubber tire 
roller (Hyster C530A). Density was measured with the Troxler nuclear moisture-density gauge and was determined to be adequate for the purposes of this test (Table 6). Figures 8- 10 show the construction phases of the AC test section.

Table 6. Nuclear density gauge test results on Lift 1 of the AC section.

\begin{tabular}{|l|l|l|l|l|l|l|}
\hline $\begin{array}{l}\text { Pavement } \\
\text { Section }\end{array}$ & $\begin{array}{l}\text { Lift } \\
\text { Number }\end{array}$ & $\begin{array}{l}\text { Lift } \\
\text { Thickness } \\
\text { in. }\end{array}$ & $\begin{array}{l}\text { Wet } \\
\text { Density } \\
\text { pcf }\end{array}$ & $\begin{array}{l}\text { Dry } \\
\text { Density } \\
\text { pcf }\end{array}$ & $\begin{array}{l}\text { Moisture } \\
\text { pcf }\end{array}$ & $\begin{array}{l}\text { Moisture } \\
\%\end{array}$ \\
\hline AC Buffer A & 1 & 3 & 138.7 & 134.3 & 4.3 & 3.2 \\
\hline AC Section 1 & 1 & 3 & 137.4 & 132.3 & 5.2 & 3.9 \\
\hline AC Section 2 & 1 & 2 & 135.9 & 128.8 & 7.1 & 5.5 \\
\hline AC Section 2 & 2 & 3 & 140.9 & 134.6 & 6.2 & 4.7 \\
\hline AC Section 3 & 1 & 4 & 137.0 & 131.6 & 5.5 & 4.1 \\
\hline AC Section 3 & 2 & 3 & 137.5 & 130.7 & 6.8 & 5.2 \\
\hline AC Buffer B & 1 & 3 & 132.9 & 128.8 & 4.0 & 3.0 \\
\hline PCC Buffer A & 1 & 3 & 132.9 & 126.8 & 6.0 & 4.8 \\
\hline
\end{tabular}

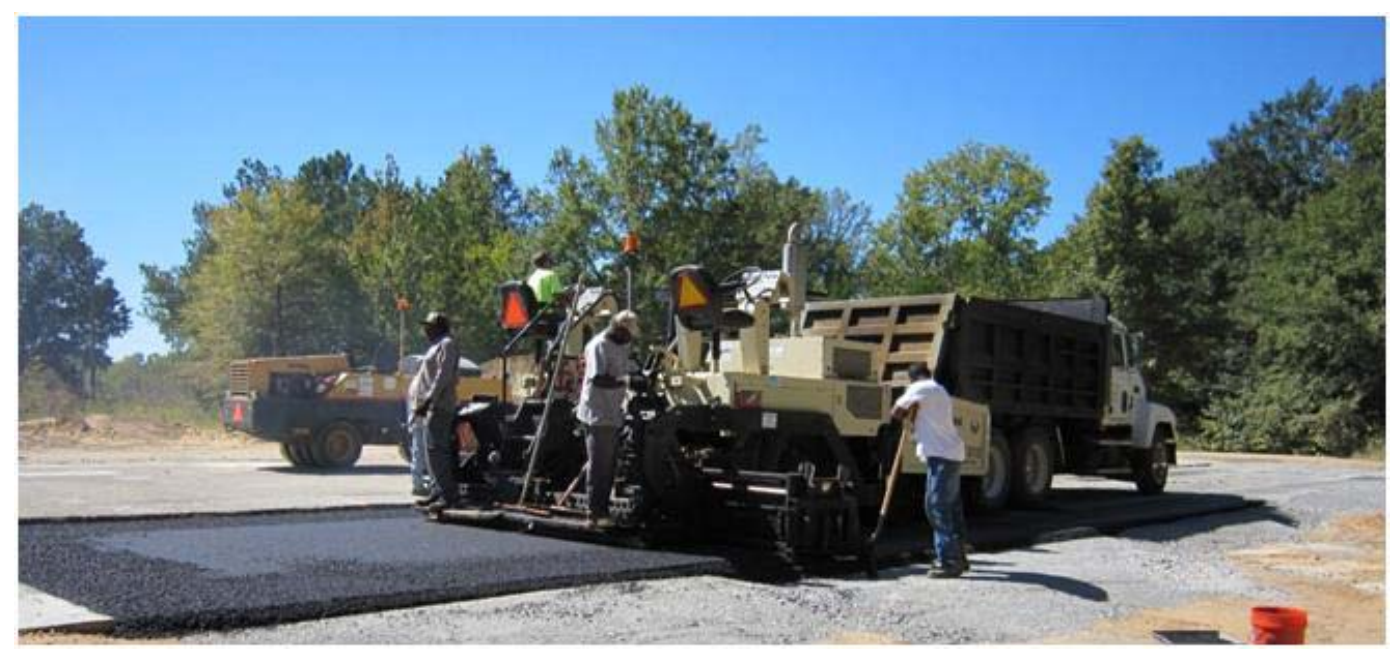

Figure 8. Asphalt placement. 


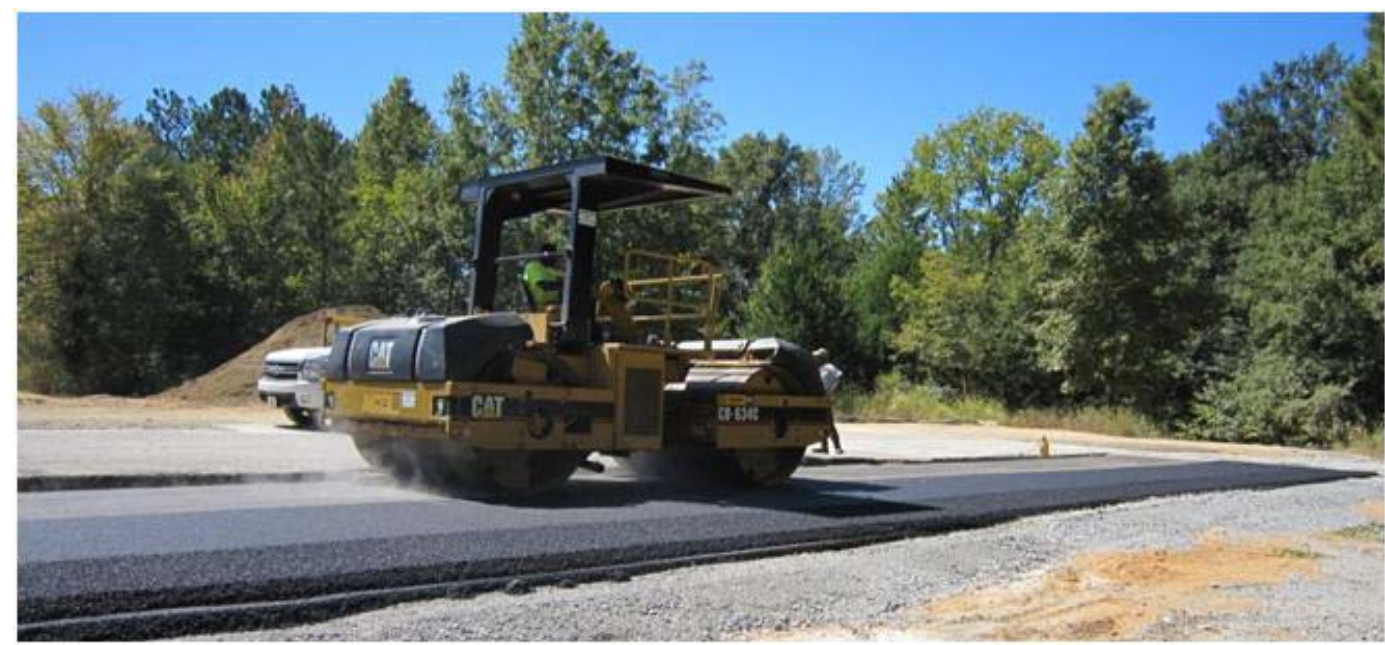

Figure 9. Compaction with a double drum vibratory compactor.

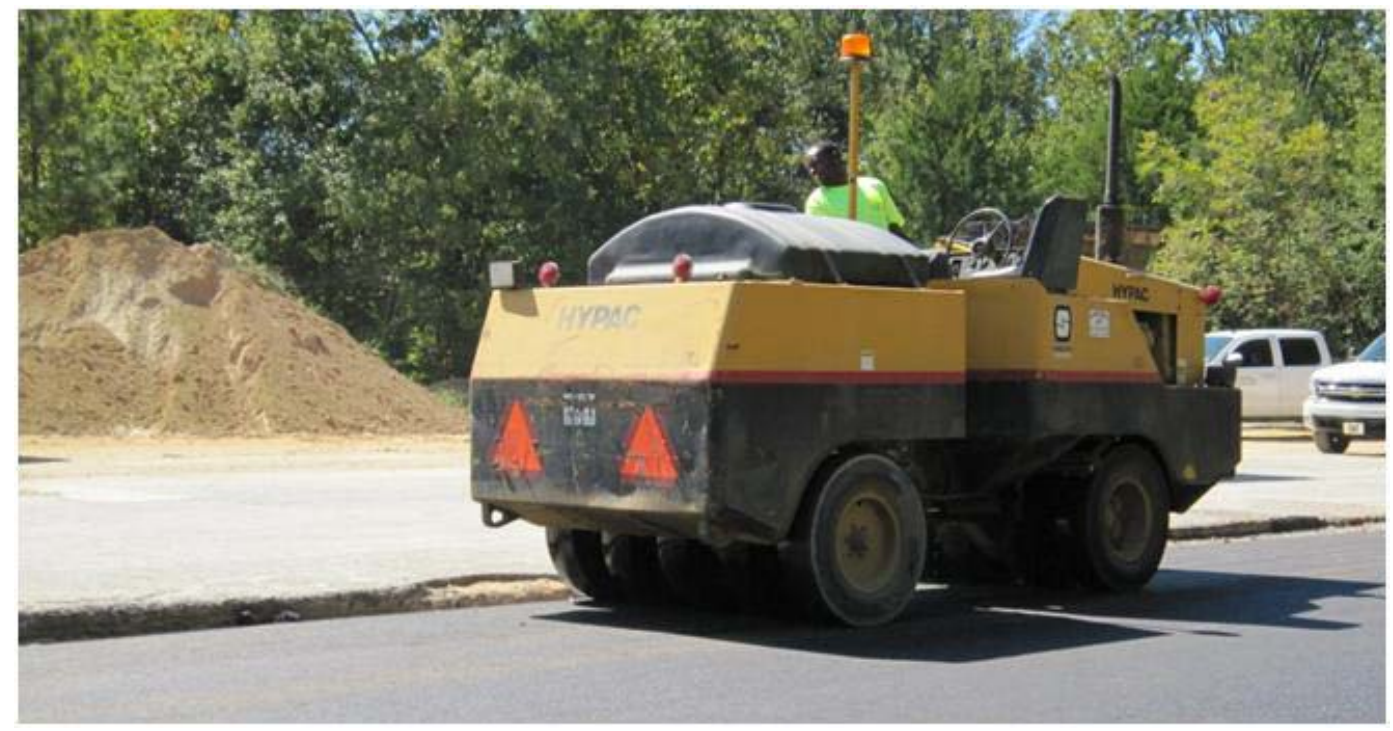

Figure 10. Compaction with a rubber tire roller.

For the PCC test section, as shown in Figure 3, the first section was constructed with 24-in. PCC and 6-in. limestone base. The second section was constructed with 15-in. PCC and 6-in. limestone base. The third section was constructed with 8-in. PCC and 6-in. limestone base.

The PCC mixture was produced using a local Federal Aviation Administration (FAA) mix designed for airfield pavement. The mix was a 650-psi flexural strength mixture using limestone as the coarse aggregate. During placement, test specimens were prepared in accordance to ASTM C39 (compressive cylinders) and ASTM C78 (flexural beams) (ASTM 2010a and 2010b, respectively). Actual laboratory data for this mixture are 
included in Table 7. The PCC was placed using the ready mix concrete delivery truck chute, consolidated with 2-in. spud vibrators, and screeded with a vibratory screed. The PCC section was finished with a light broom finish, and the joints were saw-cut approximately $4 \mathrm{hr}$ after the concrete placement. Figures 11- 13 show the stages of the construction of the test section.

Table 7. Laboratory data on concrete placement.

\begin{tabular}{|l|l|l|}
\hline Test Method and Sample Size & $\mathbf{7}$ day & $\mathbf{2 8}$ day \\
\hline Compressive Strength (average of two cylinders, 4 in. x 8 in.) & 5190 psi & 6444 psi \\
\hline Flexural Strength (average of two beams, 6 in. x 6 in. x 18 in.) & 623 psi & 728 psi \\
\hline
\end{tabular}

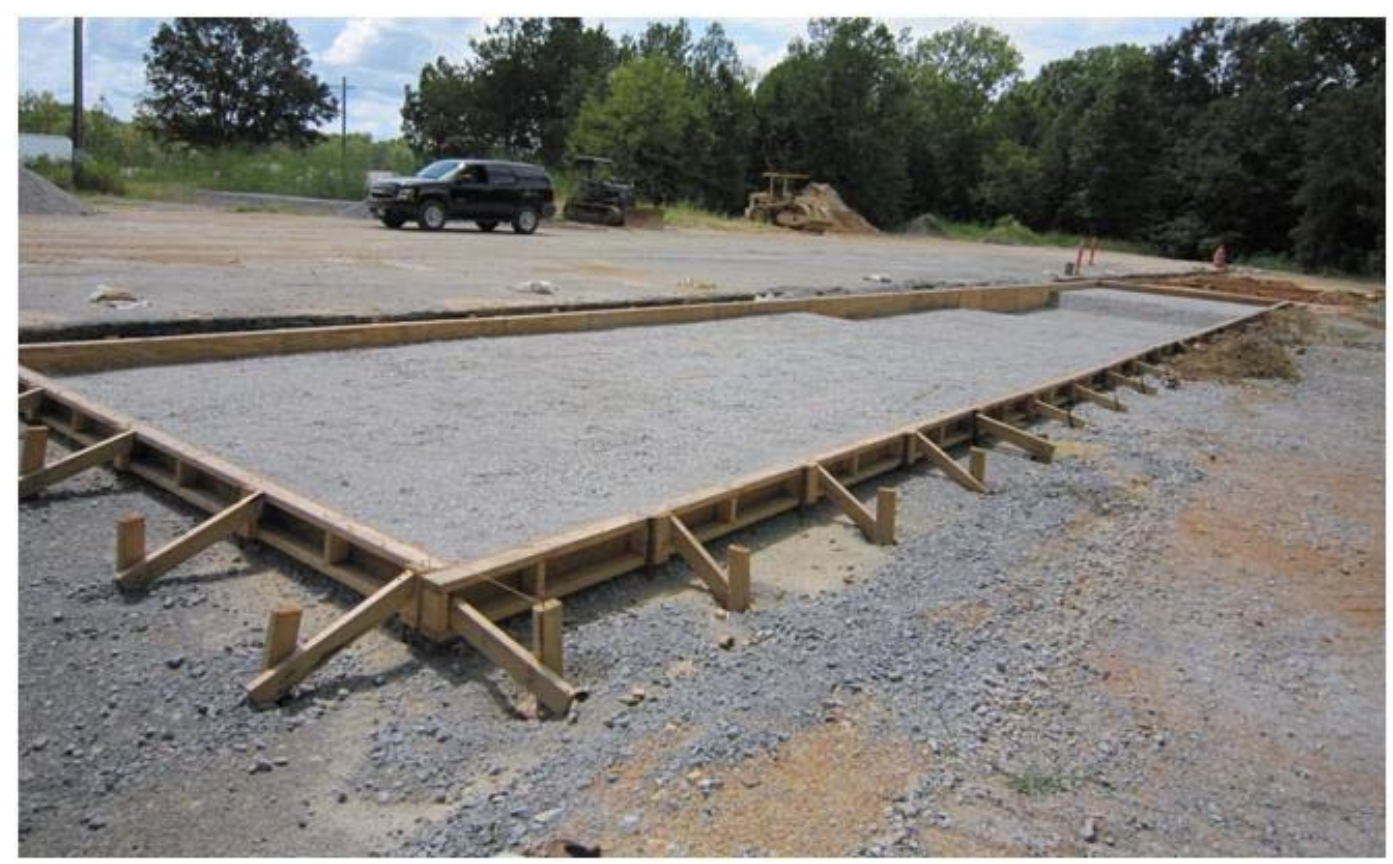

Figure 11. Forms for the PCC placement. 


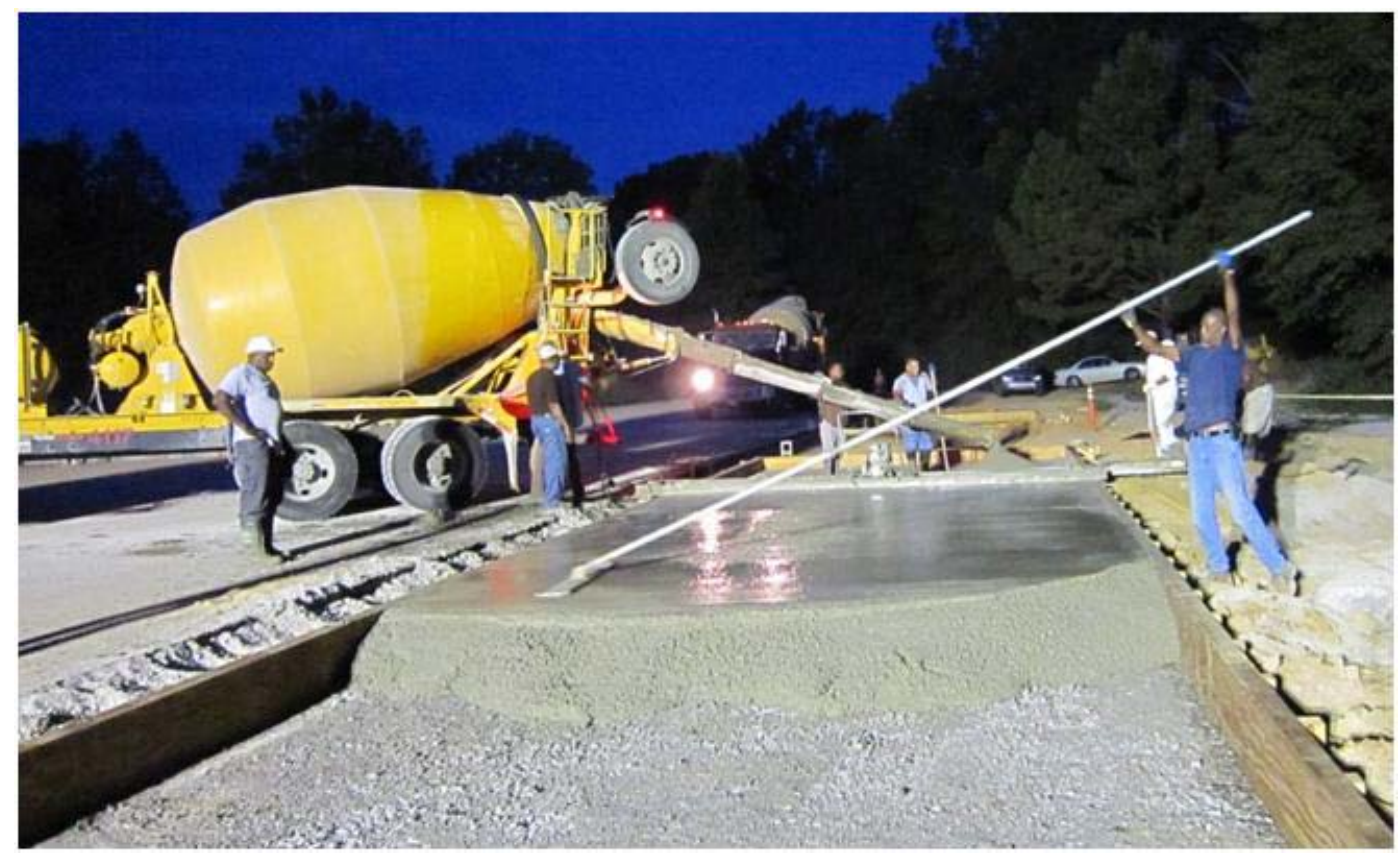

Figure 12. PCC placement.

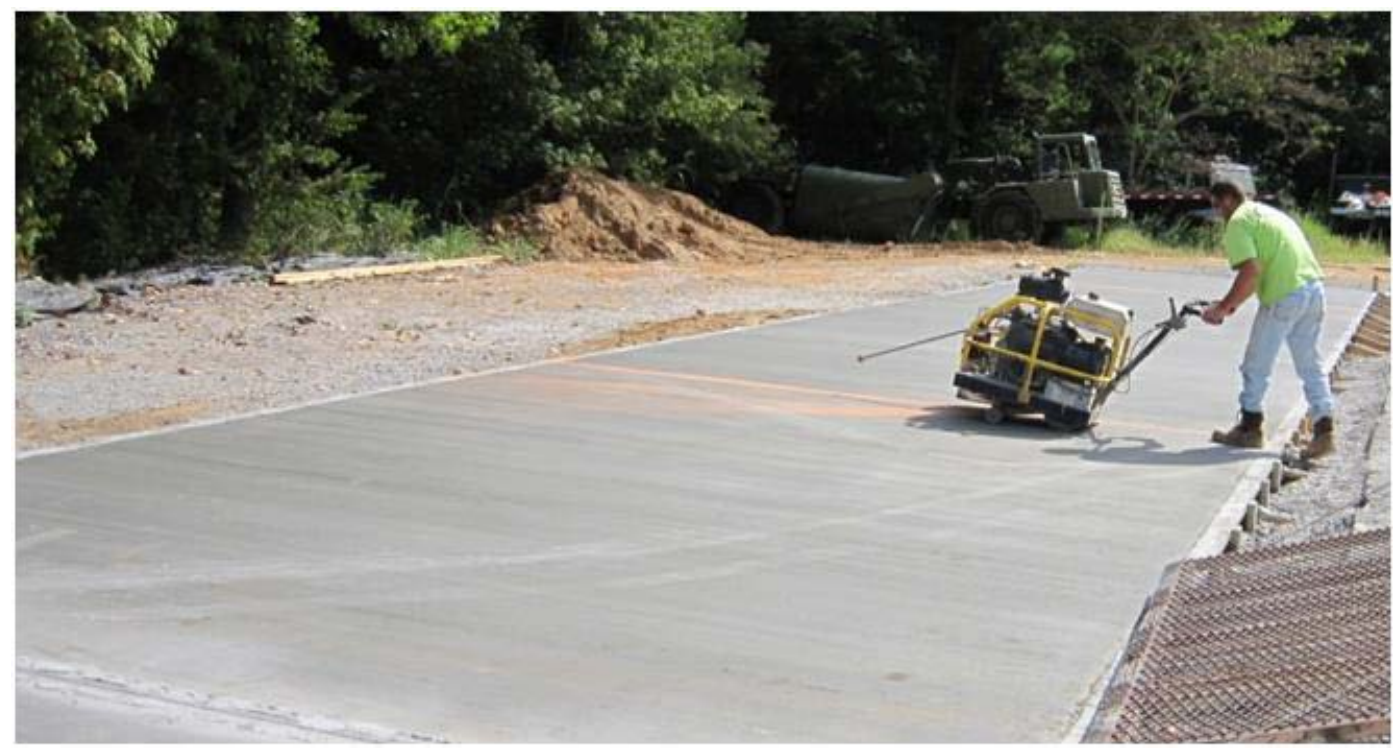

Figure 13. Saw cutting.

\section{Forest Service Road test section}

The Forest Service Road test section (shown in Figure 14) is an asphalt road with varying thicknesses constructed during the period of 1986 to 1988 for a project to evaluate the effects of variable tire pressures in logging trucks (Grau 1993). Due to severe rutting during the initial trafficking, rehabilitation of a section of the road was completed approximately one month after the completion of the road. Three test points were chosen 
for six sections, and a calibration point was chosen out of these sections for the original construction and for the rehabilitated sections.

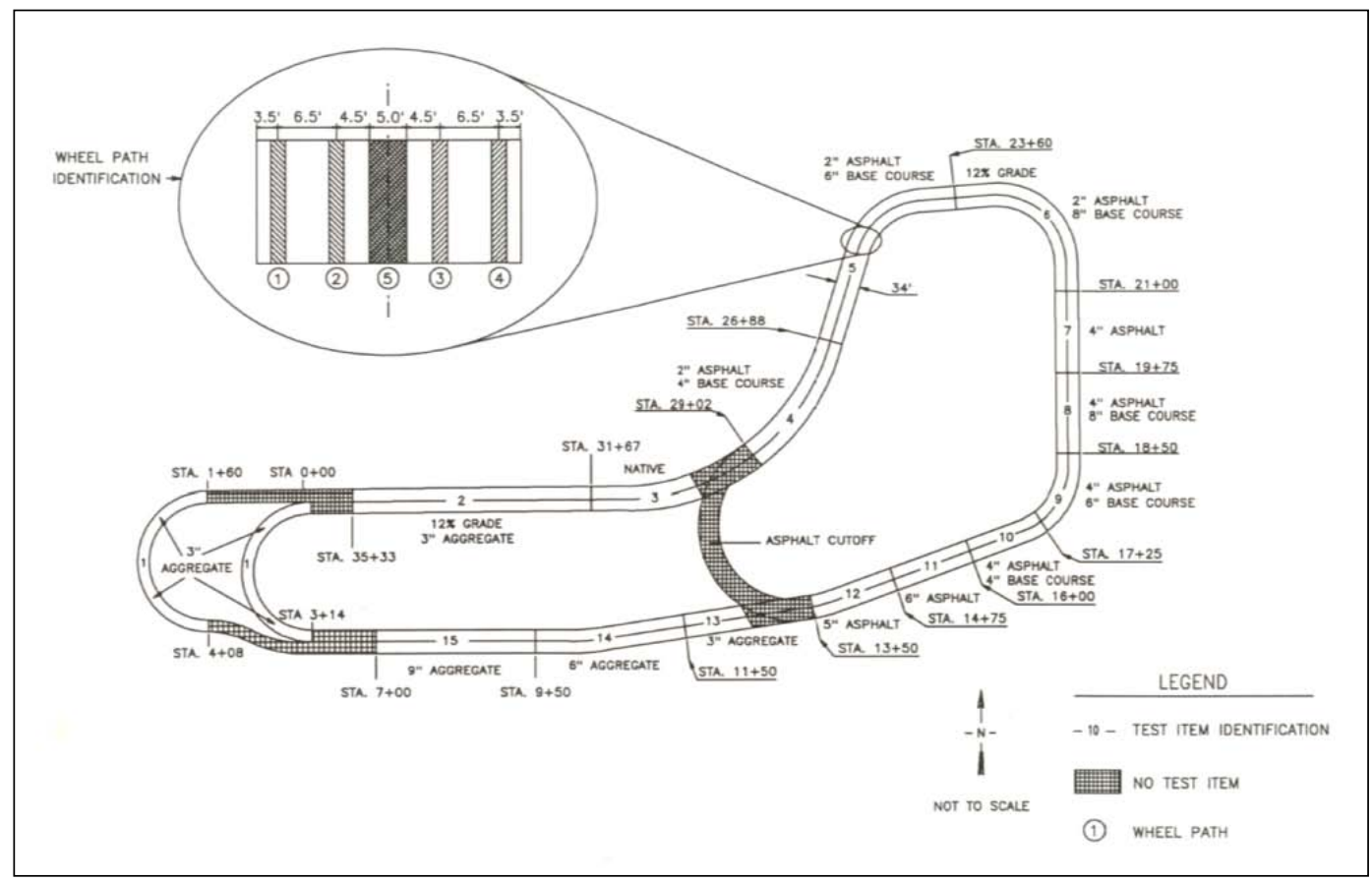

Figure 14. Construction map of the Forest Service Road.

In 2010, a section of the Forest Service Road was utilized for a research project on flowable fill (Figure 15). During this project, the existing AC pavement and base course were removed, and either flowable fill or wellgraded gravel was placed on the existing subgrade with a 6- to 8-in. PCC layer on top. Four test points and one calibration point were selected from this section to use for testing. 


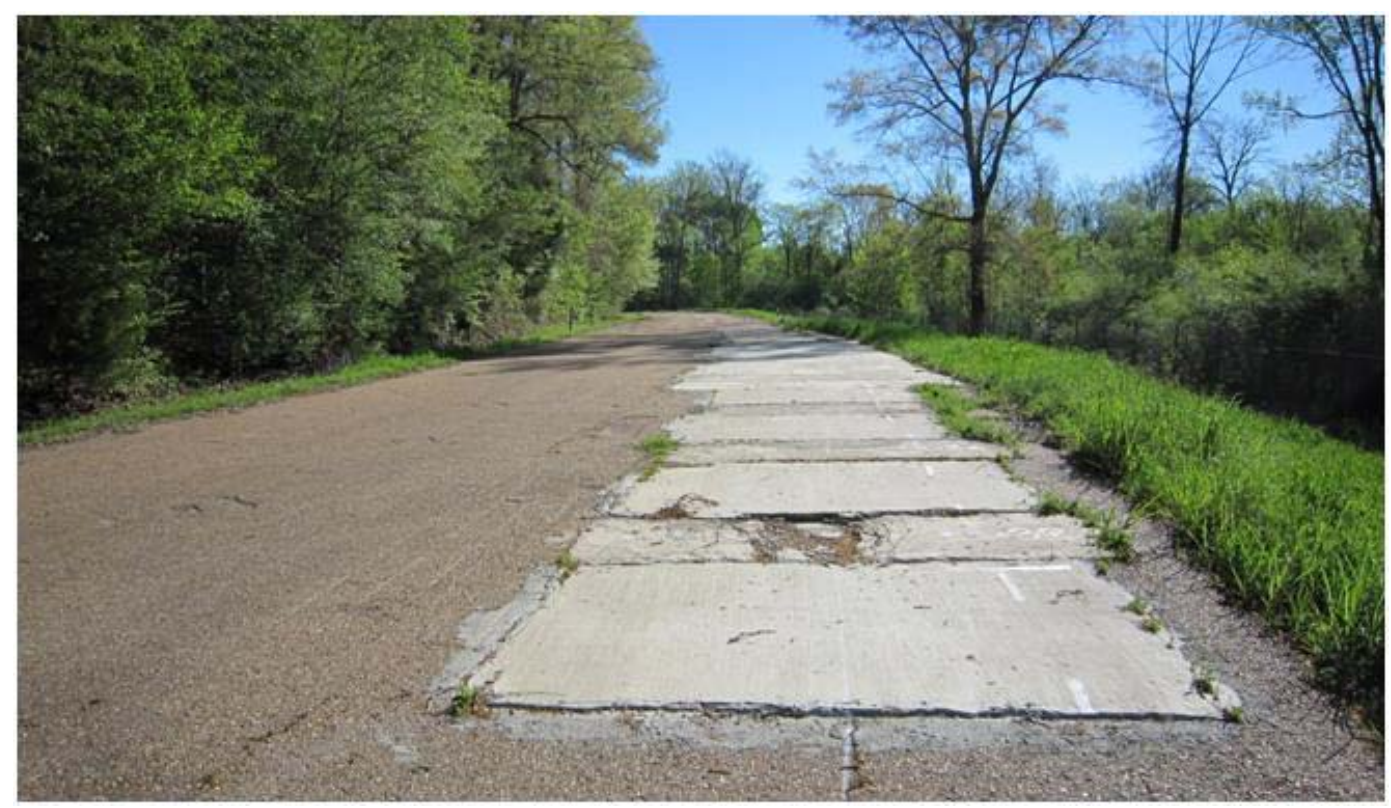

Figure 15. The flowable fill section is shown here on the right and was located within the Forest Service Road.

\section{Minimum PCC thickness test section at Hangar 4}

The remaining test points were taken from an existing test section located in ERDC's pavement test facility, known as Hangar 4. The test section was constructed to evaluate the minimum PCC thickness of airfield pavements and to verify the criteria for the design of rigid airfield pavements. This test section was constructed in February 2010.

The testing points at the site were taken from two of the slabs in the test section. One slab was constructed to be $11 \mathrm{in}$. of PCC on top of $13 \mathrm{in}$. of limestone base, and the other slab was constructed to be 8 in. of PCC on top of $18 \mathrm{in.}$ of limestone base. The PCC was a high strength (650-psi flexural strength) mixture of the same mix design as used to construct the section at the Poor House Test Area. Three test points and one calibration point were taken from this test section. 


\section{Field Evaluation of Nondestructive Testing Equipment}

Each technology was tested at the forty test locations listed in Table 1. For most of the devices, it took less than one day to collect the data. Most of the techniques required post-processing of data, prior to estimating the thicknesses of the tested pavement test points.

Eight vendors/ researchers from private companies or universities participated in this study. There were two types of seismic technologies, one ultrasonic technology, 12 different ground penetrating radar antennas, and one borescope. The University of Minnesota has been extensively working with the MIRA ultrasonic tomography technology and demonstrated this technology for this study. Olson Engineering tested three types of technologies that included an impact echo device, multiple impact surface wave (MISW) technology, and a 2-GHz ground-coupled GPR system. Infrasense, Inc. tested three GPR methodologies: a 1-GHz horn antenna, a single 1.5-GHz ground-coupled antenna, and a common midpoint method using two 1.5-GHz ground-coupled antennas. All of Infrasense's GPR systems were provided by Geophysical Survey Systems, Inc. (GSSI). Resource International tested with two ground-coupled GSSI GPR antennas with frequencies of $900 \mathrm{MHz}$ and $1.5 \mathrm{GHz}$. MAL $\AA$ evaluated 4 different GPR antennas with frequencies of $800 \mathrm{MHz}, 1.2 \mathrm{GHz}, 1.6 \mathrm{GHz}$, and $2.3 \mathrm{GHZ}$. 3D-Radar used a step frequency GPR system that provides threedimensional data. The ERDC has a GPR system that was evaluated as well. This system was originally manufactured by Pulse Radar, and the software has been recently updated by the Texas Transportation Institute of Texas A\&M University. A borescope was also tested by the ERDC for feasibility in determining pavement thickness.

\section{Testing protocol}

Data were collected for each technology at each of the test locations. Test locations were marked with a 4-in. circle to indicate where a 4-in. core would be extracted after the conclusion of testing (Figure 16). For GPR testing, metallic tape was put on the asphalt $2 \mathrm{ft}$, prior to the center of the 
circle. This metallic tape can be seen in the GPR signal and enables the user to locate test points.

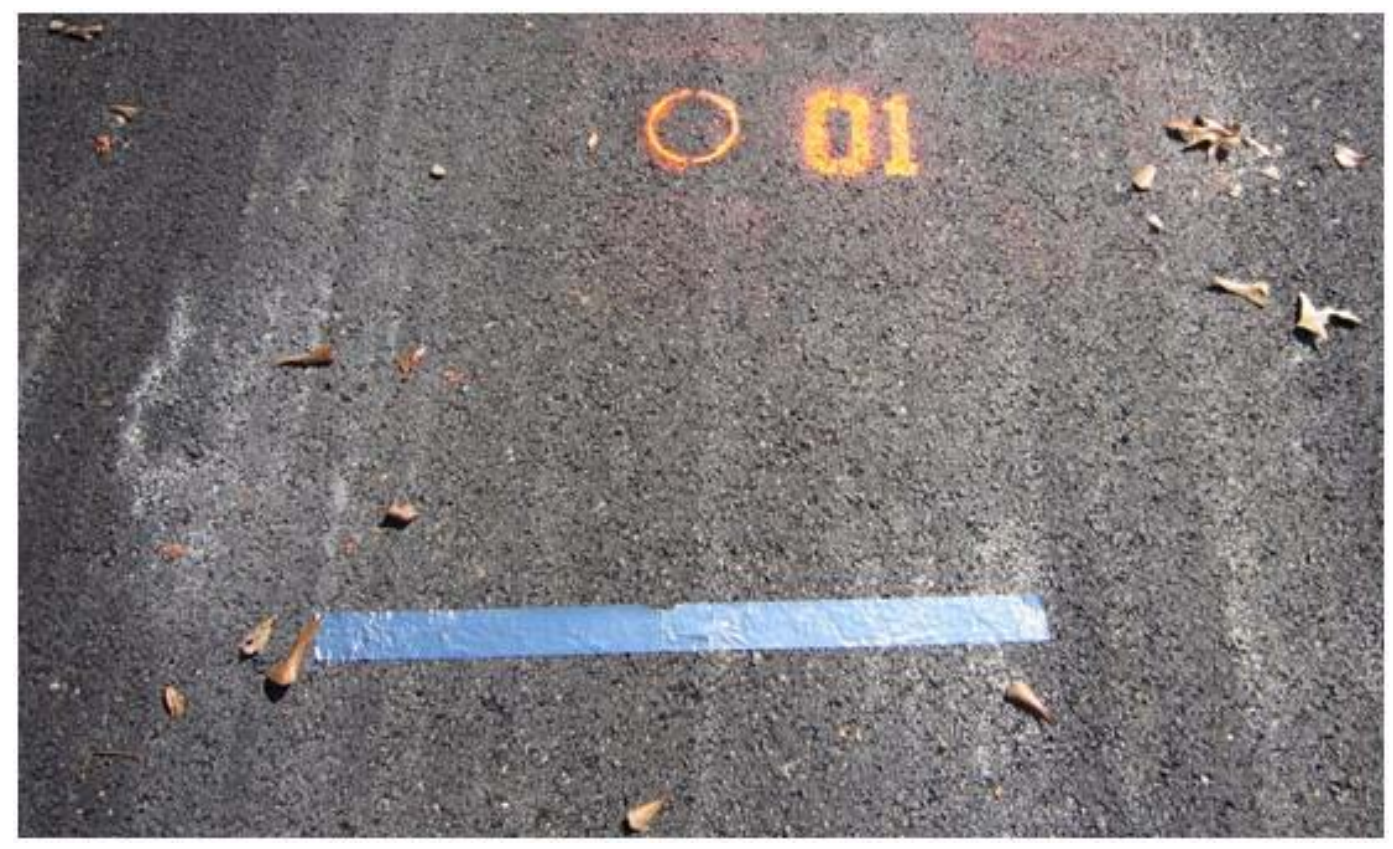

Figure 16. Test location marked with a circle to indicate location of the core hole and metallic tape spaced $2 \mathrm{ft}$ away from the center of the core hole.

Vendors were provided with the following information, prior to testing:

- PCC slabs can be up to 25 in. thick.

- AC pavement can be up to 10 in. thick.

- AC overlays on PCC have a combined thickness up to 20 in.

- Base layers can be up to 18 in.

- Total thickness can be up to 36 in.

- Thicknesses of similar pavements will be provided for calibration purposes (after initial results are provided). These cores are part of the 40 locations and are listed in Table 8.

Table 8. Calibration cores.

\begin{tabular}{|l|l|l|}
\hline Test Number & Measured Thickness, in. & Cores with Similar Material \\
\hline 10 & 2.58 & $1,2,3,4,5,6,7,8,9$ \\
\hline 11 & 8.42 & $12,13,14,15,16,17,18,19,20$ \\
\hline 21 & 4.5 & $22,23,24,25,31$ \\
\hline 26 & 9.25 & $27,28,29,30$ \\
\hline 34 & 8.79 & $32,33,35,36$ \\
\hline 40 & 8.92 & $37,38,39$ \\
\hline
\end{tabular}




\section{MIRA}

An ultrasonic tomography technology, MIRA, was tested by Dr. Lev Khazanovich and Kyle Hoegh from the University of Minnesota on 27 October 2010. MIRA was developed by Acoustic Control Systems, Ltd, which is a company based in Moscow, Russia. ${ }^{1}$ The name of the device, MIRA, is derived from the Spanish word "mirar," which means "to look," and the English word "mirror." It is also called the A1040 POLYGON, according to the website. Germann Instruments, based in Chicago, IL, is the sole vendor for MIRA in the U.S. The University of Minnesota has been further developing the post-processing of data from the MIRA and developing applications for this device.

The MIRA is an ultrasonic pulse-echo device that is able to penetrate concrete and reveal structures or layers in the concrete in real-time. It has been primarily used for concrete imaging applications to nondestructively view objects such as holes, cracks, and reinforcement bars within the concrete. It operates in a frequency range of $20-100 \mathrm{kHz}$, and at an average frequency of $50 \mathrm{kHz}$. The MIRA can reportedly measure a range of thicknesses from $50 \mathrm{~mm}$ to $1 \mathrm{~m}$ ( $1.97 \mathrm{in}$. to $3.28 \mathrm{ft}$ ). Near real-time thickness measurements can be obtained with this device. This device consists of 40 transmitting and receiving dry point contact (DPC) transducers on the bottom of the device, as shown in Figure 17. There are 45 transmitting and receiving transducer pair measurements that allow for redundancy to confirm measurements when measuring heterogeneous materials such as PCC and asphalt. The device is adaptable to rough surfaces because each transducer has a wear-resistant ceramic pin and independent spring load. A single measurement takes $3 \mathrm{sec}$, and the DPC transducers can measure up to 1-m deep (3.28-ft). The weight of the antenna array is $6.5 \mathrm{~kg}$ (14.3 lb), and the weight of the entire system (antenna array, laptop, and power source) is $15 \mathrm{~kg}(33 \mathrm{lb})$.

Testing at each location took approximately $1 \mathrm{~min}$ because calibration scans were done at every location in addition to five readings for comparison purposes (Figure 18). Calibration was accomplished by a method of measuring the average ultrasound velocity in the pavement and adjusting the gain accordingly. Calibration is not required if testing on similar pavements, but will increase the accuracy of the device because it measures the velocity of the ultrasonic waves in the material.

${ }^{1}$ http://acsys.ru/eng/production/?type_id=16\&subtype_id=7\&product_id=23. 


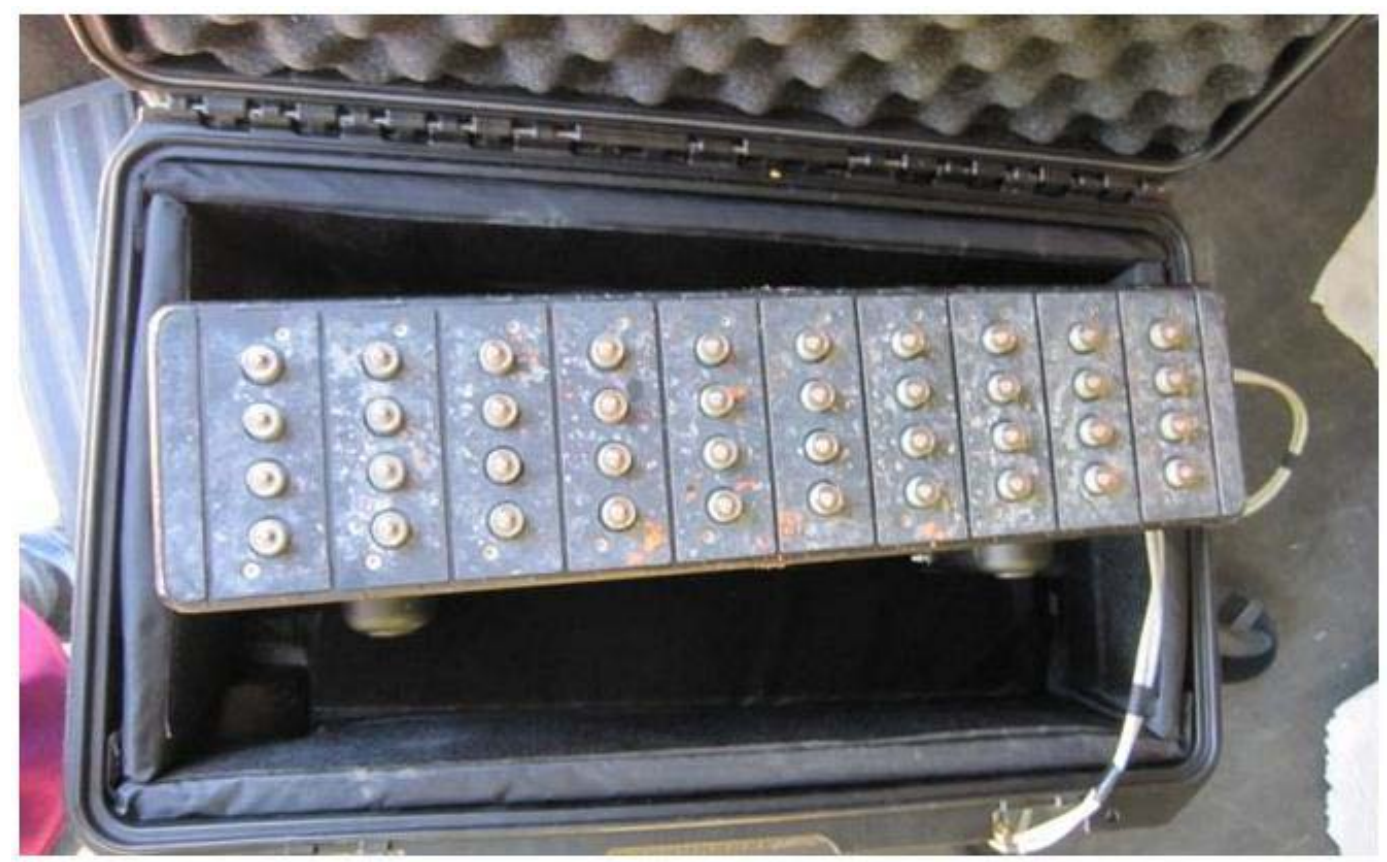

Figure 17. Bottom of the MIRA device, where the 40 transducers are located.

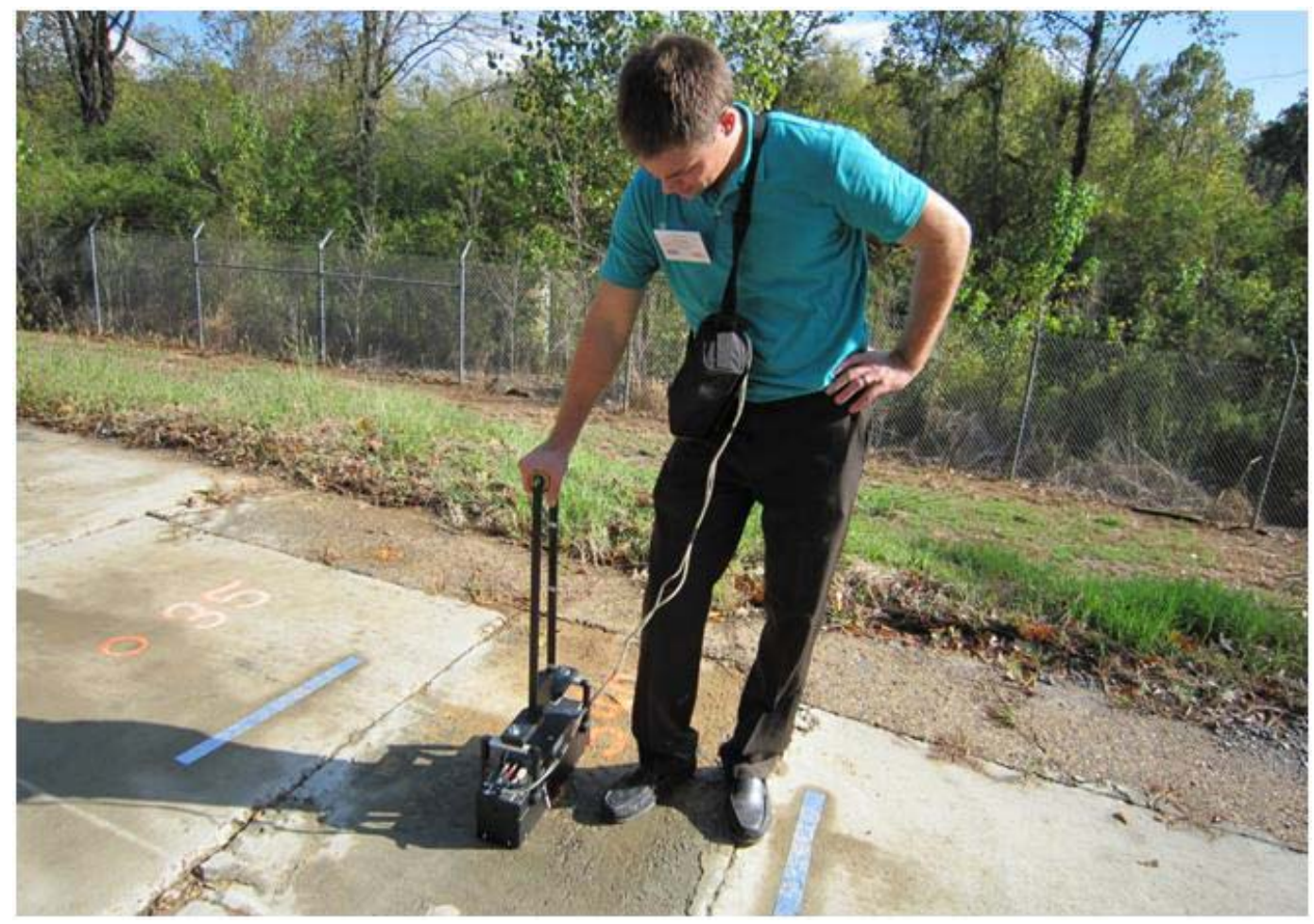

Figure 18. Testing a PCC slab with the MIRA. 
During the testing, near real-time thickness measurements were provided for the PCC locations. The layer interface generates a change in the signal, which can be seen in the B-scan representation of the data (Figure 19). The $\mathrm{B}$-scan is a representation of the pavement, with the horizontal axis representing the surface of the pavement, and the vertical axis representing depth of the pavement. Thickness measurements were extracted by using the software provided by Acoustic Control Systems, Ltd. Thickness measurements were determined by using the measurement tool in the software and measuring distance from the surface to the centroid of the bright spot.

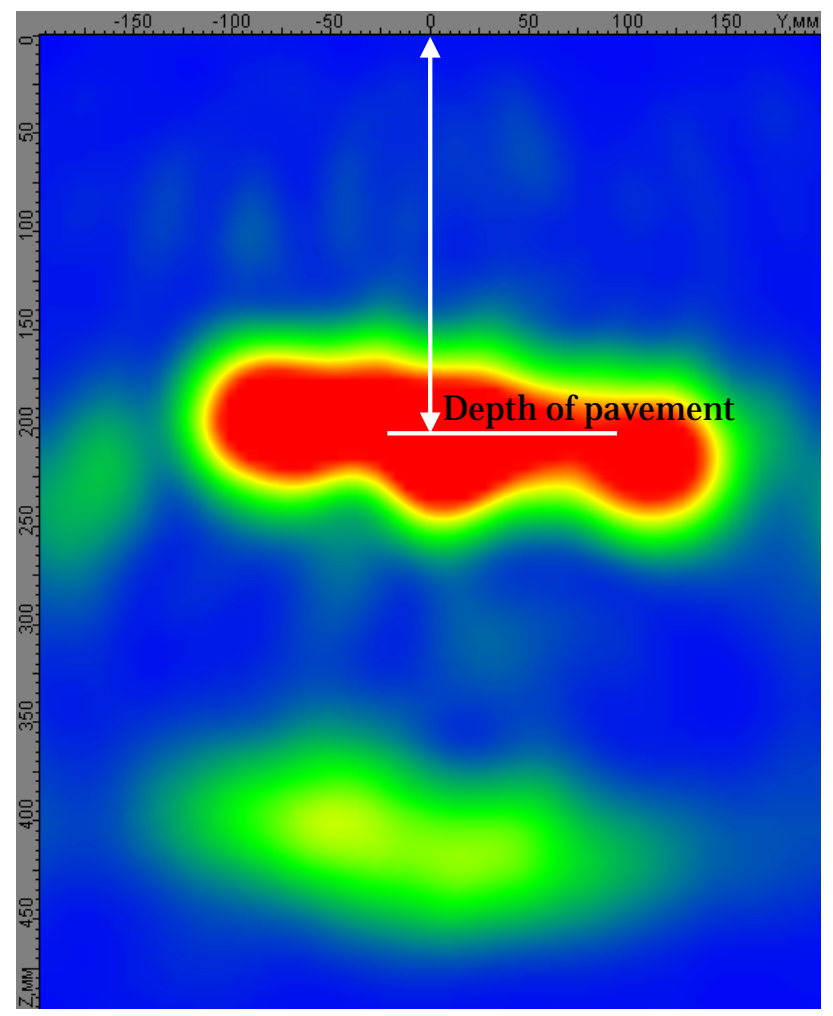

Figure 19. B scan from the MIRA scanner for location 20.

The system did not yield consistent results for AC locations. If there was any temperature gradient in the asphalt pavement, the signal became attenuated, and an accurate thickness measurement could not be taken. This is due to the changes in elastic modulus due to temperature differences. Thickness readings were successful from the AC constructed test sections but not at the AC locations at the Forest Service Road. A possible explanation could be the readings at the constructed test section were taken at approximately 11 a.m., while the Forest Service Road was not tested until 3 p.m., when it was much hotter. Additionally, the AC pavement's low stiffness results in a strong wave attenuation, making it 
difficult to obtain thickness values. Advanced methods for AC pavement thickness measurement are currently under development but were not available at the time of testing.

Limitations of the MIRA include the inability to detect more than one layer at a time and the lack of consistency in AC measurements. The MIRA detects changes within the pavement. If there is a change in the pavement, i.e., a void, then the shear wave would be reflected back to the surface, and other changes deeper within the pavement, such as the pavement layer interface, would not be measured. Additionally, only the top pavement layer could be measured with the MIRA, so composite pavements would not be detected, and base and subbase layer thicknesses could not be determined either.

It should also be noted that there was intermittent rain throughout the day during testing. However, rain does not affect the data as long as there is no standing water on the pavement to be tested.

The University of Minnesota is currently developing an advanced method of analyzing the raw data, but this method was not ready to be utilized at the time of publication of this report. This advanced method would include processing AC pavement data to provide more accurate results.

\section{Olson Engineering: multiple impact surface waves}

Olson Engineering performed a thickness estimation of the pavement test locations with the multiple impact surface waves (MISW) method on 2 December 2010 (Figure 20). The MISW method estimates the surface wave velocity of layered systems along the depth by using the dispersive characteristics of surface waves (Olson et al. 2010). MISW equipment consisted of a measuring tape, 3.2-oz instrumented hammer, seismic accelerometer, Olson Instruments Freedom Data PC computer, and lithium based grease. Each test, including the setup of the test, took approximately 10 to $15 \mathrm{~min}$. All of the equipment had to be moved from location to location, which increased the total testing time. 


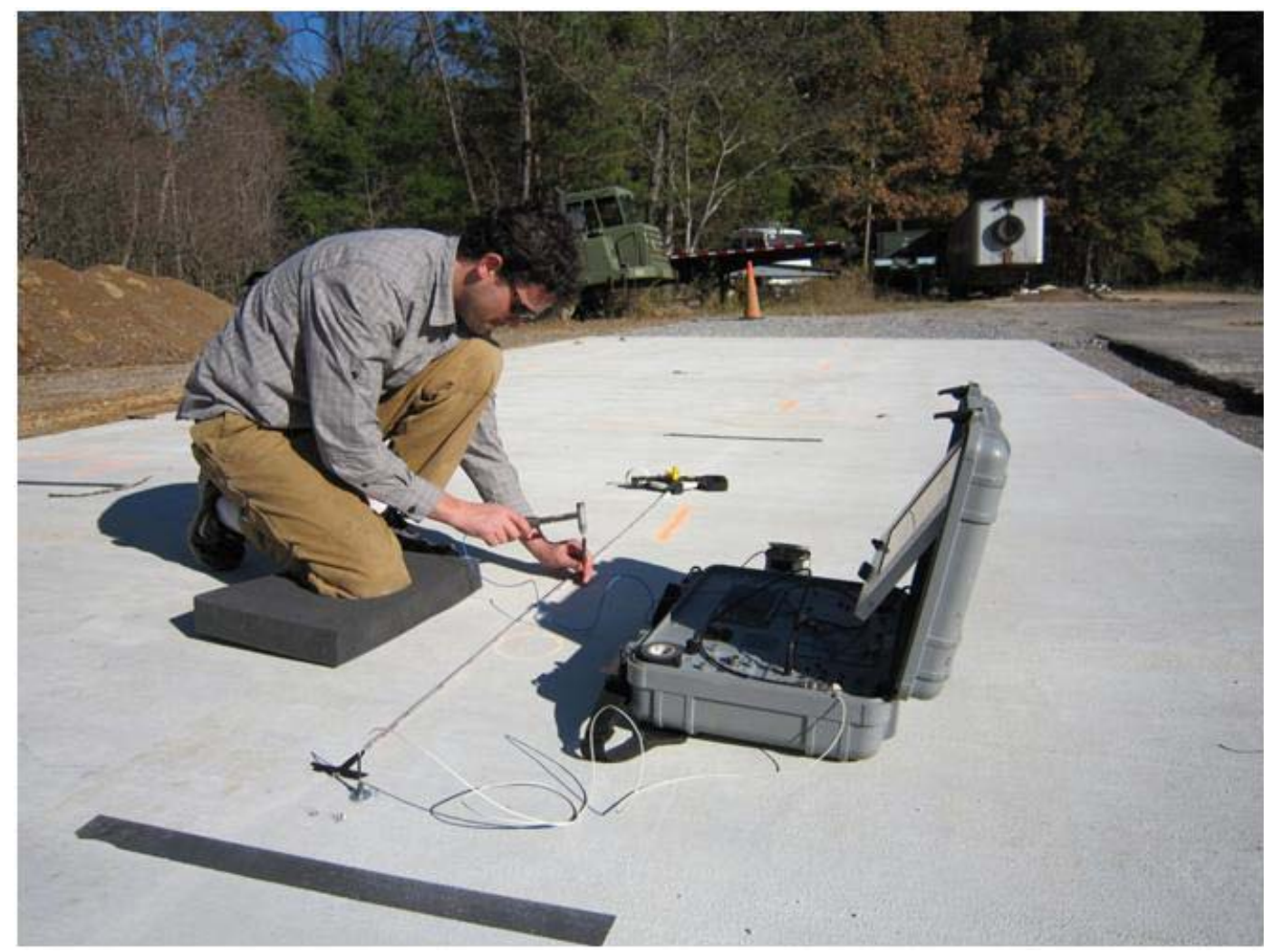

Figure 20. MISW testing.

The accelerometer was placed on the location of interest with the lithiumbased grease to hold it in place, and a measuring tape was stretched to $1.5 \mathrm{~m}$ ( $4.9 \mathrm{ft}$ ) away from the accelerometer. The hammer was used to tap the pavement four times every $5 \mathrm{~cm}$ ( 2 in.). The first tap was a seating tap, and the last three taps were averaged. The hammer was instrumented to trigger data acquisition. The accelerometer measured the Rayleigh waves (surface waves) propagating through the concrete. Data processing involved the determination of the variation of the surface wave velocity with depth by using the dispersive characteristics of surface waves (Olson Engineering 2001).

Since the MISW method can reportedly estimate the surface wave velocity of the material by using the surface wave measurement, it should require less correction via the calibration cores. A limitation of MISW is the presence of cracks in the pavement. Surface waves do not propagate through them, so care should be taken to place the entire setup on pavement without significant cracks.

Data were not collected for test locations 32 through 40 because the equipment would not work, possibly because of an electric short in the hammer. 


\section{Olson Engineering: impact echo}

Olson Engineering also performed impact echo testing on 2 December 2010. The equipment used was a custom-developed device by Olson Engineering, which comes with a computer and is housed in a ruggedized case. Setup required less than $5 \mathrm{~min}$ because all that was required was for the computer to be turned on and the cables to be connected. Data acquisition took approximately $1 \mathrm{~min}$ per test location. Thickness estimates are displayed immediately after data acquisition.

The Olson Engineering impact echo device consisted of a piezoelectric transducer with an impactor, or impulse hammer. The impactor, or impulse hammer ( $4 \mathrm{oz}$ ), induces vibration in the pavement, which is reflected back to the receiver of the device. The built-in impactor was used for pavements with thicknesses 4 to $24 \mathrm{in}$. The small hammer was used for pavements 12- to 36-in. thick. The reflected wave test data are collected in the time domain and undergoes a Fast Fourier Transform to extract the frequency peaks. The following equation is used to determine the thickness of the pavement:

$$
\mathrm{V}_{\mathrm{P}} \not \beta 2 * \mathrm{~d} * \mathrm{f} /
$$

where:

$$
\begin{aligned}
\mathrm{V}_{\mathrm{P}} & =\text { compression wave velocity } \\
\mathrm{d} & =\text { slab thickness } \\
\mathrm{f} & =\text { resonant frequency peak } \\
\beta & =\text { constant }(0.96 \text { for walls and slabs) }
\end{aligned}
$$

If the thickness of the pavement is unknown, the compression wave velocity $\left(\mathrm{V}_{\mathrm{P}}\right)$ is given an estimate that is typical of pavement material being tested. Once calibration cores were provided, the compression wave velocity could be determined for each pavement type. Additionally, the MISW (Olson Engineering), described later in this report, is another alternative that could be used to provide compression wave velocity.

The impact echo method (Figure 21) can be limited for pavements less than 3-in. thick because high frequencies generated by the impact are required. 


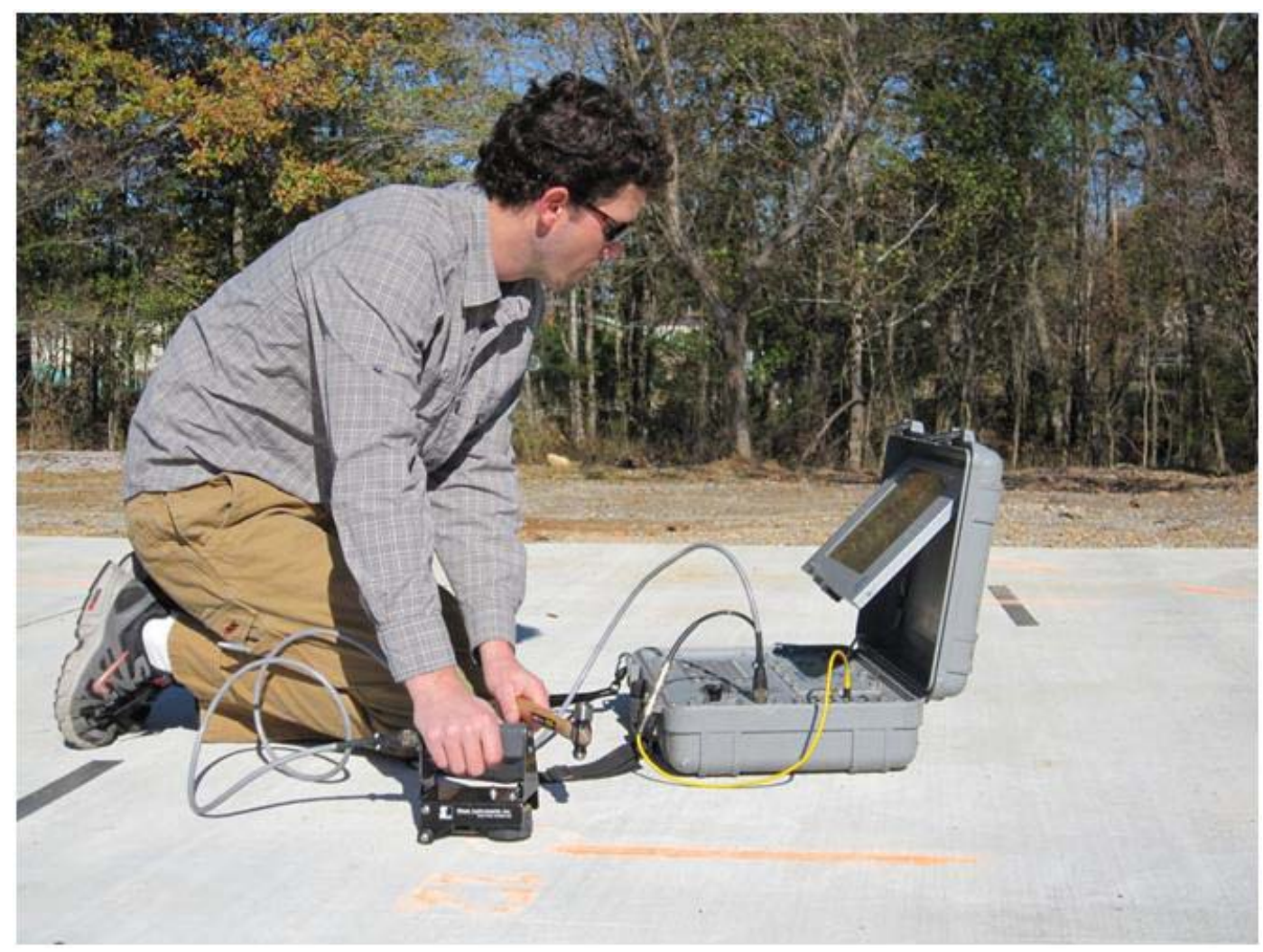

Figure 21. Impact echo testing.

\section{Olson Engineering: GPR}

Olson Engineering also tested a ground-coupled IDS Aladdin GPR system on the test locations (Figure 22). This system had a 2-GHz GPR antenna with a built-in distance measuring instrument to account for the travel distance of the antenna. The data acquisition system had a wireless connection to a laptop to make data collection easier. Setup of the system was completed in less than $5 \mathrm{~min}$ and required only that the cables be connected and the laptop turned on. Data acquisition consisted of moving the GPR antenna by hand across the test location. The acquisition time for each test location was approximately $30 \mathrm{sec}$.

As with other GPR systems, the thickness of the pavement is found by sending electromagnetic wave pulses into the pavement and measuring the time the pulse takes to reflect back. If the pavement material has a change in its dielectric constant, a portion of electromagnetic wave will reflect back to the antenna, and the remaining wave will travel further down. The IDS GPR system sends out approximately 60 pulses per $\mathrm{ft}$. 


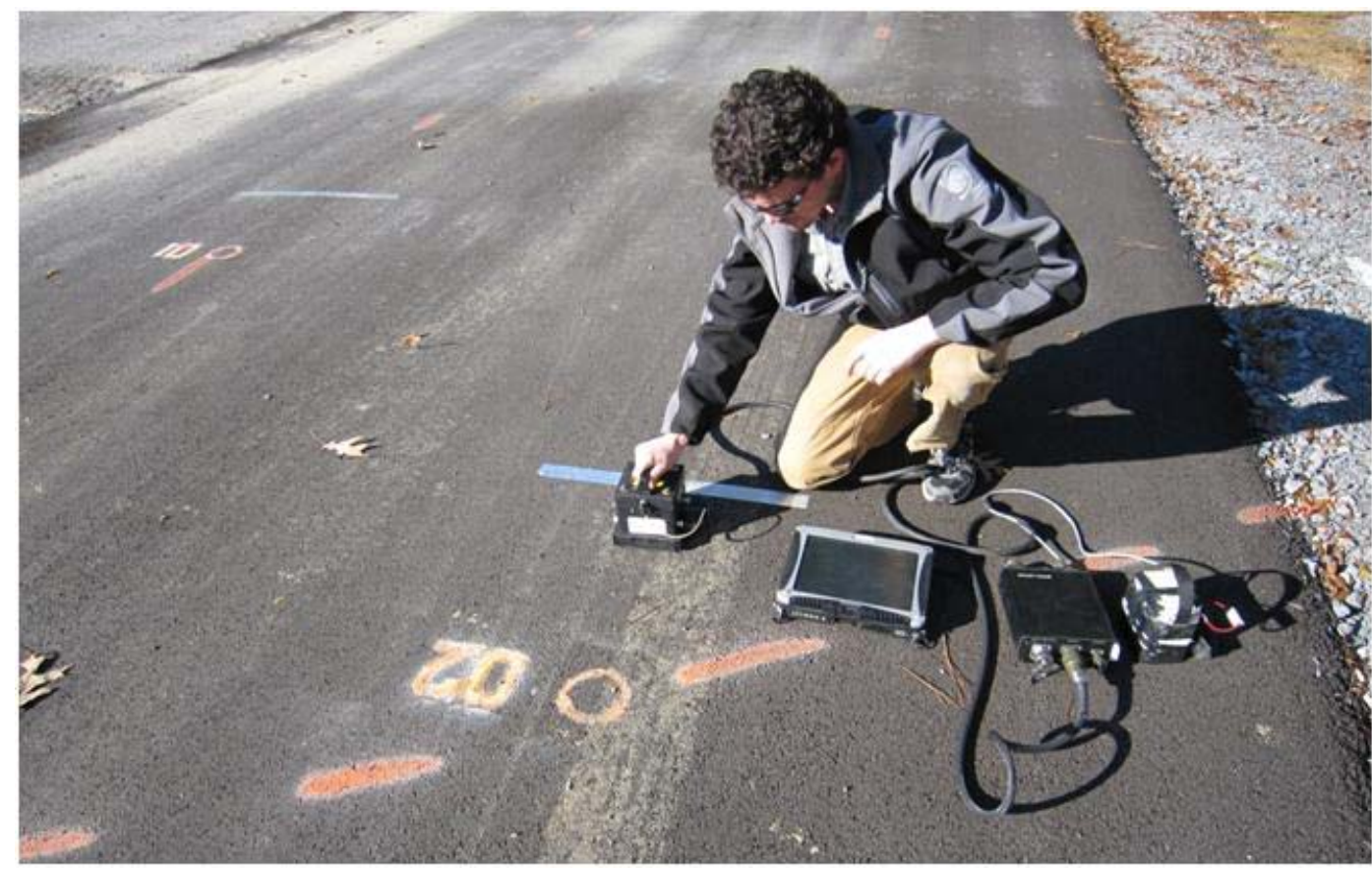

Figure 22. 2-GHz Ground-Coupled IDS Aladdin GPR (Olson Engineering) testing.

\section{Infrasense, Inc.: single 1.5-GHz ground-coupled GSSI antenna}

Infrasense evaluated the pavement on 21 October 2010 using a single ground-coupled antenna with an addition that is not normally seen with the ground-coupled antenna, side-by-side metal plate calibrations. The 1.5-GHz ground-coupled antenna and a SIR-20 controller from Geophysical Survey Systems, Inc. (GSSI) of Salem, NH were used. This antenna can reportedly penetrate up to 20 in. in AC, but penetration will vary in PCC as this material attenuates GPR signal. The antenna was attached to a cart equipped with a Distance Measuring Instrument (DMI), also provided by GSSI, to assist in the ease of data collection (Figure 23). The SIR-20 controller remained in the survey vehicle. Data were collected at a rate of 40 scans per $\mathrm{ft}$, and an electronic trigger was activated as the antenna traveled over the test location. As an experiment, side-by-side metal plate calibrations were run every time there was a change in pavement type or thickness to estimate the dielectric constant of the pavement; however, these data were not used in the post-processing for this study. Testing took approximately 2 min if running a side-by-side plate calibration, and less than 1 min if running a test only. 


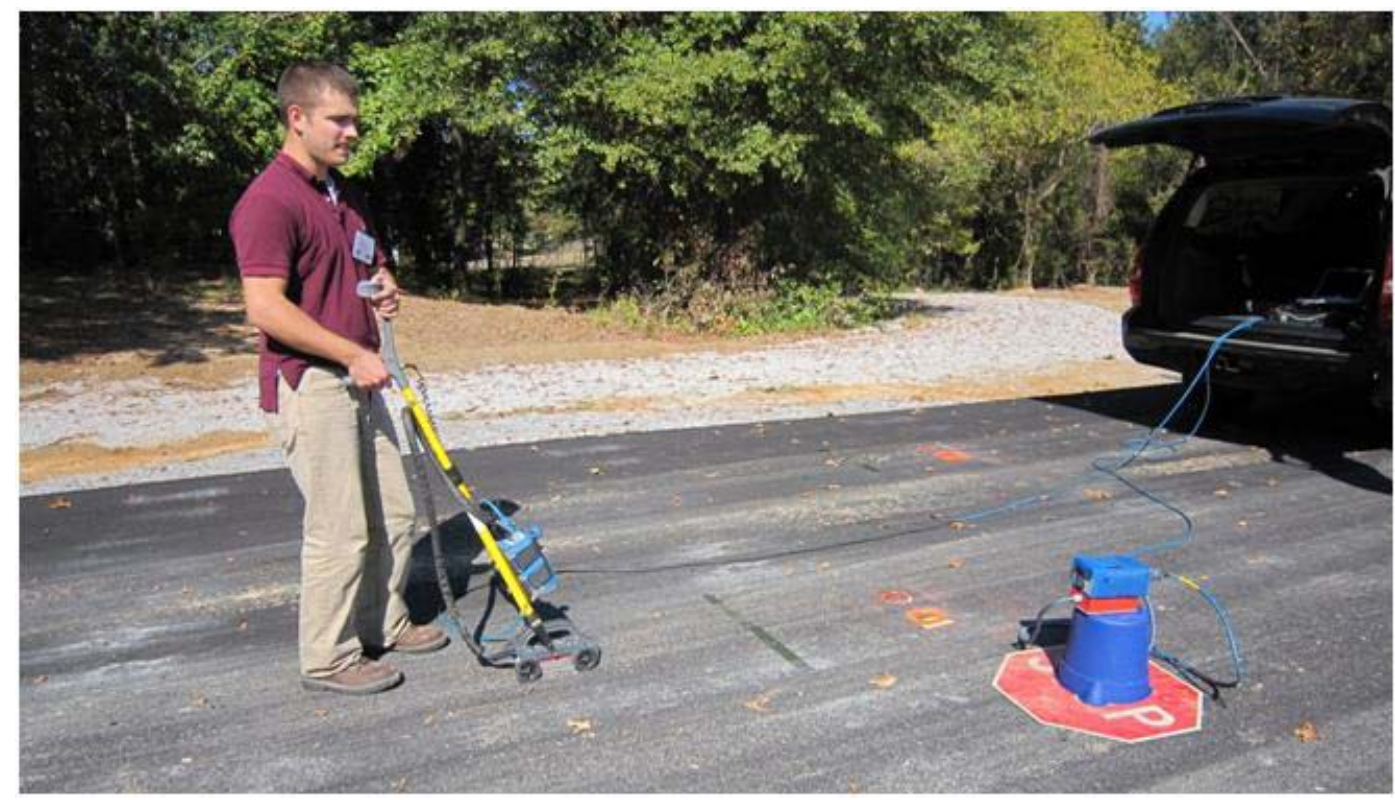

Figure 23. Single 1.5-GHz ground-coupled GPR testing.

A limitation of the single ground-couple antenna method is that dielectric constants cannot be estimated from the collected data. However, by using this method, the amplitude of the signal that the antenna transmits into itself, called direct coupling, is correlated to the dielectric constant and velocity of each pavement material. The dielectric constants collected, using the horn antenna method (described later in this chapter), were used to correlate the direct coupling and dielectric constants, so that the thickness could be estimated (Infrasense, Inc. 2010). Figure 24 shows an example of the data acquired with the single ground-couple method. Custom written software by Infrasense, winDECAR ${ }^{\circledR}$, was used to process the data.

Calibration of the data was calculated based on the calibration core data provided in Table 8. A calibration factor for AC and one for PCC were developed and applied to all of the test location measurements. Table 9 shows the comparison of the estimated thicknesses to the actual core data before and after calibration. If the discrepancy between the estimated and actual measurements after calibration was too large, the estimated measurement was not used for that test location. 


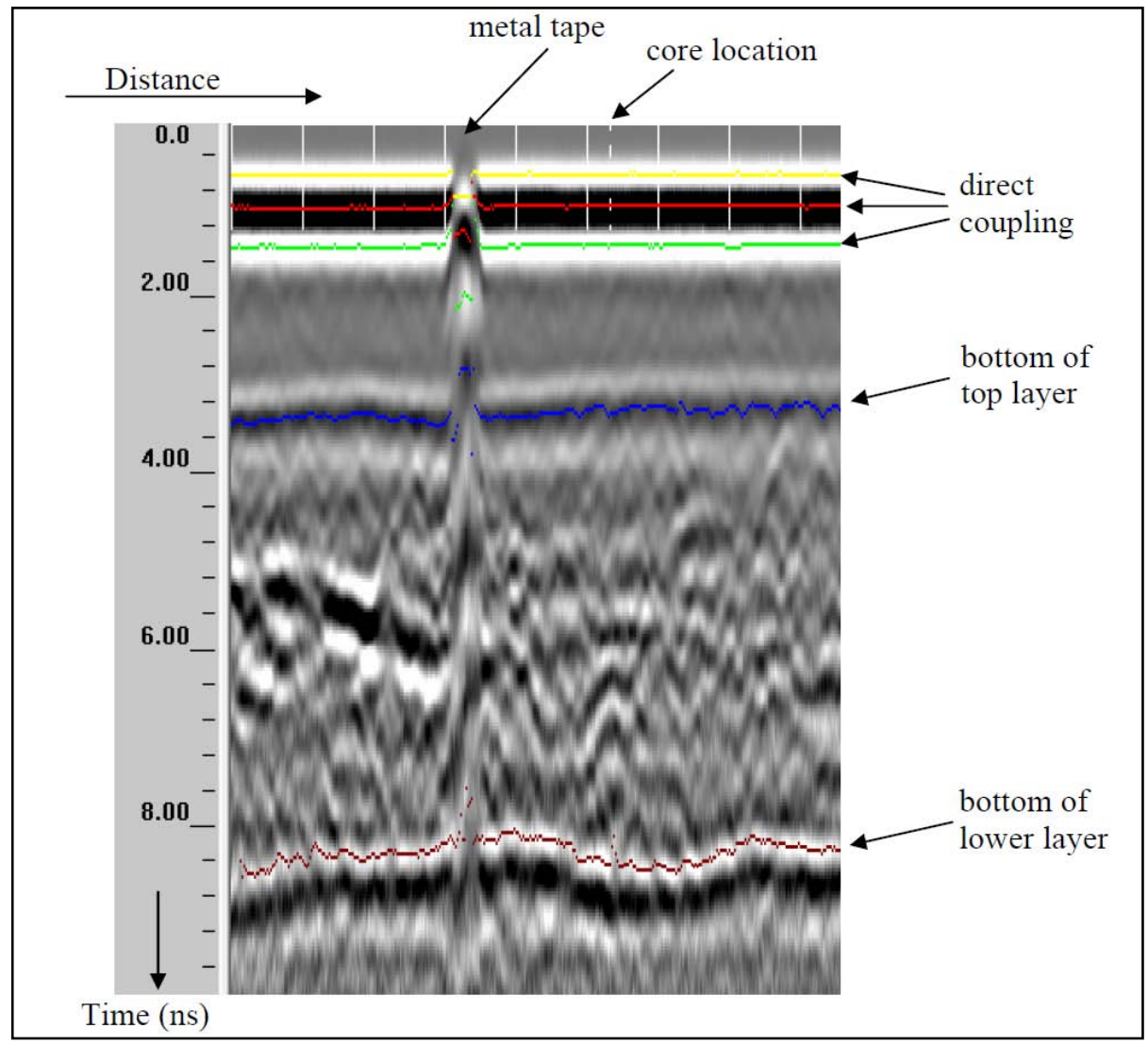

Figure 24. Example of the single ground-coupled GPR data from test location 8 (figure taken from Infrasense, Inc. 2010).

Table 9. Comparison of measured core data to GPR data at the calibration locations for the single 1.5-GHz ground-coupled GPR antenna (table taken from Infrasense, Inc. 2010).

\begin{tabular}{|l|l|l|l|l|l|}
\hline Core No. & $\begin{array}{l}\text { Infrasense } \\
\text { Layer 1 } \\
\text { Thickness } \\
\text { in. }\end{array}$ & $\begin{array}{l}\text { ERDC Core } \\
\text { Layer 1 } \\
\text { Thickness } \\
\text { in. }\end{array}$ & $\begin{array}{l}\text { Infrasense } \\
\text { Calibrated } \\
\text { Layer 1 } \\
\text { Thickness } \\
\text { in. }\end{array}$ & $\begin{array}{l}\text { Absolute } \\
\text { Difference } \\
\text { Original } \\
\text { in. }\end{array}$ & $\begin{array}{l}\text { Absolute } \\
\text { Difference } \\
\text { After } \\
\text { Calibration } \\
\text { in. }\end{array}$ \\
\hline 10 AC & 3.04 & 2.58 & 3.04 & 0.46 & 0.46 \\
\hline 11 PCC & 7.04 & 8.42 & 8.03 & 1.38 & 0.39 \\
\hline 21 AC & 4.00 & 4.50 & 4.00 & 0.50 & 0.50 \\
\hline 26 AC & 11.30 & 9.25 & n.a. ${ }^{1}$ & 2.05 & n.a. ${ }^{1}$ \\
\hline 34 PCC & 7.49 & 8.79 & 8.54 & 1.30 & 0.25 \\
\hline 40 PCC & 7.78 & 8.92 & 8.87 & 1.14 & 0.05 \\
\hline
\end{tabular}

1 This location was not included in the analysis because there was a large discrepancy that could not be corrected with calibration. 


\section{Infrasense, Inc.: CMP method with two 1.5-GHz ground-coupled GSSI antennas}

Infrasense also tested with the common midpoint (CMP) method using two 1.5-MHz ground-coupled antennas and a SIR-20 controller from GSSI. This method consisted of the two antennas, a controller, a wooden frame to hold the antennas, a plastic sheet to aid in the movement of the antennas, and a DMI (Figure 25). It took about 2 to 5 min to acquire data for a single location using this method. Extensive post-processing was required after the data collection.

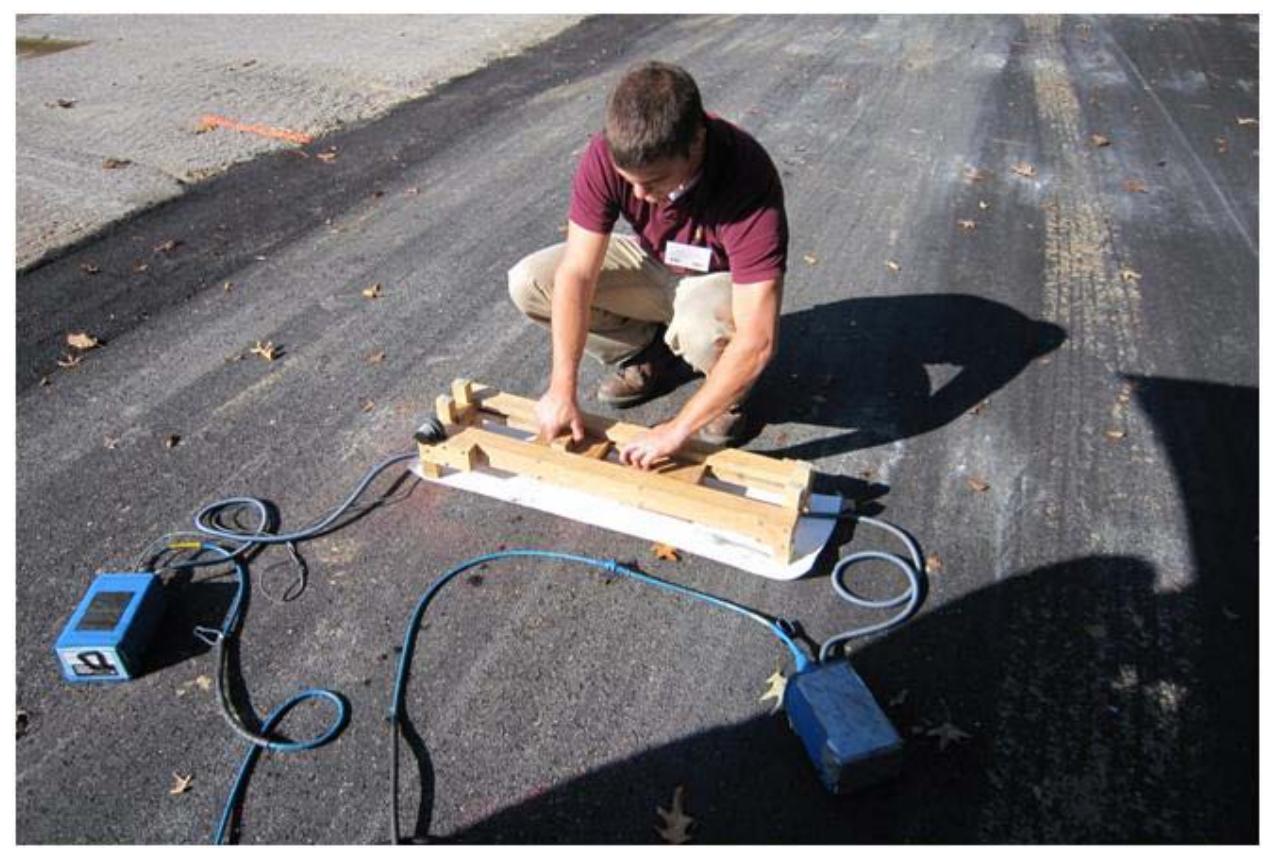

Figure 25. Common midpoint testing using two 1.5-GHz GSSI antennas.

The two antennas were attached to a wooden form, which was developed by GSSI and consists of a pulley system that controls the movement of the two antennas, so that they are moved equally and opposite from a common initial starting position. One antenna serves as the transmitter antenna, and the other serves as the receiver antenna. GPR data and distance data are recorded as the antennas move; GPR data were collected every $1 \mathrm{~mm}$. CMP data were processed using RADAN, the GSSI GPR software. The reflected GPR data result in a hyperbolic pattern, as described in Equation 4 (repeated below), and shown in Figure 26:

$$
\mathrm{t}_{\text {tot }}(\mathrm{i})=\frac{2}{\mathrm{~V}_{2}} \sqrt{\mathrm{x}(\mathrm{i})^{2}+\mathrm{d}^{2}}
$$




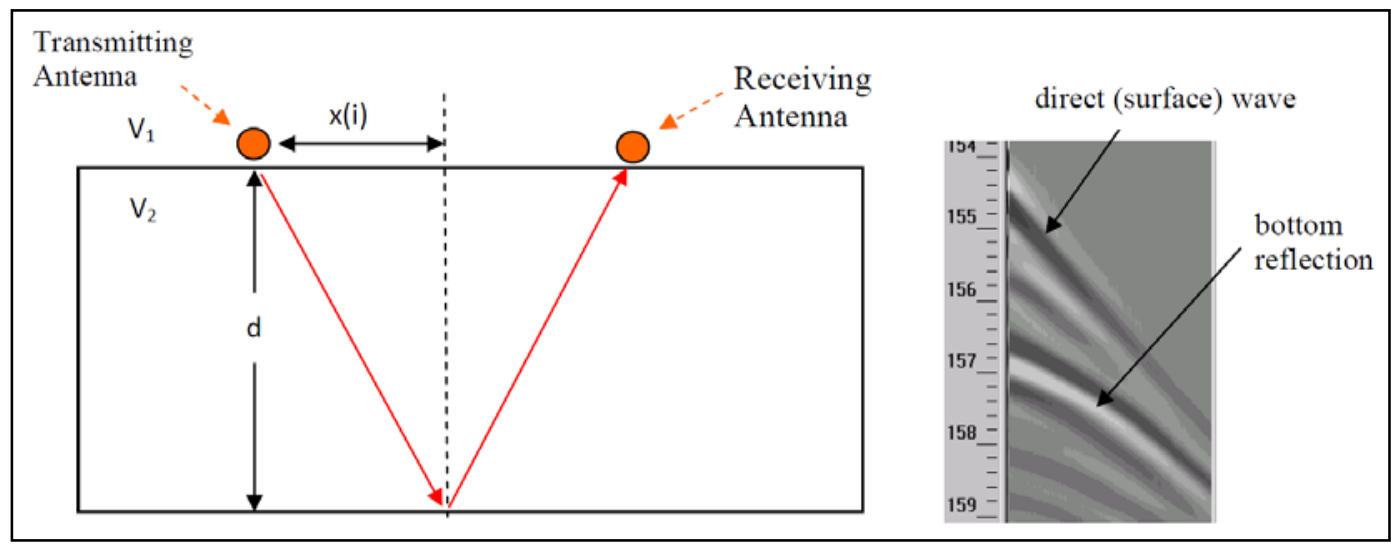

Figure 26. Description of the variables in the CMP method and the hyperbolic pattern generated by the GPR signal (figure taken from Infrasense, Inc. 2010).

By using the data in Equation 4, both the pavement layer velocity and layer thickness can be estimated (Maser et al. 2006). This method is still experimental and is not sold commercially. In the past, it has been used for AC pavements, but there has only been limited use on PCC pavements.

The data were calibrated using the core data provided in Table 8. A calibration factor for $\mathrm{AC}$ and one for PCC were developed and applied to all of the test location measurements. Table 10 shows the comparison of the estimated thicknesses to the actual core data before and after calibration. If the discrepancy between the estimated and actual measurements after calibration was too large, the estimated measurement was not used for that test location.

Table 10. Comparison of measured core data to GPR data at the calibration locations for the CMP method using dual 1.5-GHz ground-coupled GPR antennas

(table taken from Infrasense, Inc. 2010).

\begin{tabular}{|l|l|l|l|l|l|}
\hline & $\begin{array}{l}\text { Infrasense } \\
\text { Layer 1 } \\
\text { Thickness } \\
\text { in. }\end{array}$ & $\begin{array}{l}\text { ERDC Core } \\
\text { Layer 1 } \\
\text { Thickness } \\
\text { in. }\end{array}$ & $\begin{array}{l}\text { Infrasense } \\
\text { Calibrated } \\
\text { Layer 1 } \\
\text { Thickness } \\
\text { in. }\end{array}$ & $\begin{array}{l}\text { Absolute } \\
\text { Difference } \\
\text { Original } \\
\text { in. }\end{array}$ & $\begin{array}{l}\text { Absolute } \\
\text { Difference } \\
\text { After } \\
\text { Calibration } \\
\text { in. }\end{array}$ \\
\hline 10 AC & 4.23 & 2.58 & 3.72 & 1.65 & 1.14 \\
\hline 11 PCC & 13.06 & 8.42 & n.a. ${ }^{1}$ & 4.64 & n.a. ${ }^{1}$ \\
\hline 21 AC & 4.90 & 4.50 & 4.31 & 0.40 & 0.19 \\
\hline 26 AC & 10.30 & 9.25 & 9.07 & 1.05 & 0.18 \\
\hline 34 PCC & 9.66 & 8.79 & 9.66 & 0.87 & 0.87 \\
\hline 40 PCC & 9.10 & 8.92 & 9.10 & 0.18 & 0.18 \\
\hline
\end{tabular}

1 This location was not included in the analysis because there was a large discrepancy that could not be corrected with calibration. 


\section{Infrasense, Inc.: 1-GHz GSSI horn antenna}

The final method Infrasense used for the pavement evaluation on 21 October 2010 was a 1-GHz GSSI air-coupled horn antenna (Figure 27). Setup of the horn antenna required attaching the antenna to the rear of the vehicle and connecting the cables. Setup required approximately $30 \mathrm{~min}$, but the actual testing of each test point was very quick to execute ( $<10 \mathrm{sec})$ because all that was required was that the horn antenna be driven over the test locations. Test points within an area could be collected during one pass with this system as long as the points were in a straight line. To determine the dielectric constants, a metal plate calibration was completed, prior to testing. Additionally, a bounce test to account for the changes in antenna height was completed, prior to testing, to enhance the data processing later. The bounce test consisted of standing on the back of the vehicle and making the antenna bounce. The metal plate calibration and bounce test took approximately $15 \mathrm{~min}$.

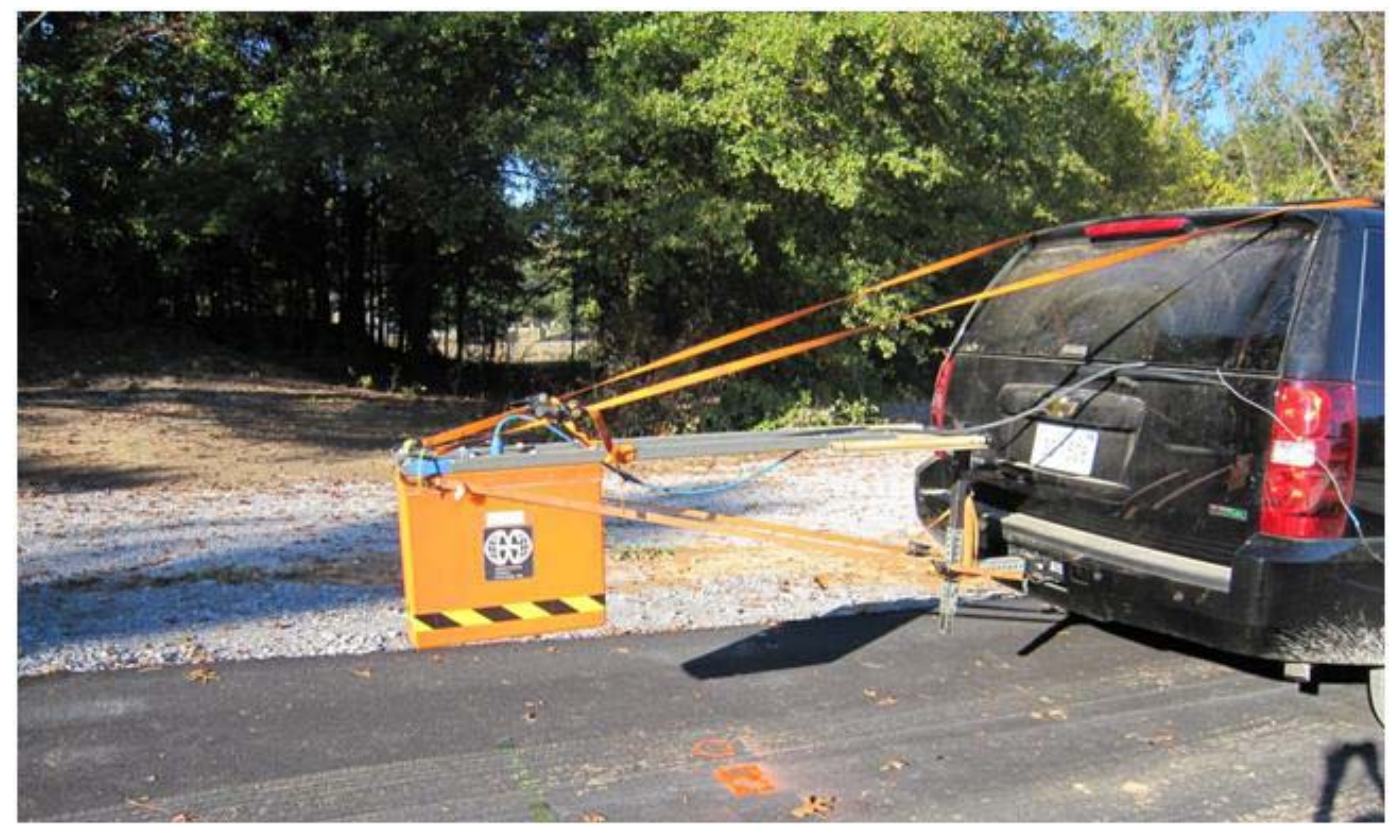

Figure 27. Infrasense testing of GSSI 1-GHz horn antenna.

The horn antenna method is the air-coupled pulse radar method, described in Chapter 2 . The horn antenna has both the transmitting and receiving antennas in the same encasement. An electromagnetic pulse is transmitted into the pavement, and when the pulse encounters a layer interface, which is a change in its dielectric constant, the GPR signal is reflected back to the receiving antenna. Data are collected as the vehicle is traveling, but data processing is required afterwards. Data were collected 
at 10 scans per $\mathrm{ft}$ of travel with GSSI's SIR-20 GPR system. An electronic distance measuring instrument (DMI) was mounted to the vehicle at the rear wheel to monitor distance as data were collected.

Data were processed using winDECAR ${ }^{\circledR}$, the custom software developed by Infrasense. Sample data, from test location 30, are shown in Figure 28. These data have been processed by the software and a GPR analyst to show only two layer interfaces, the bottom of the AC layer and the bottom of the base, as white bands. The dielectric constant and thicknesses of the pavement layers are calculated by the software for the picked layers (Infrasense, Inc. 2010).

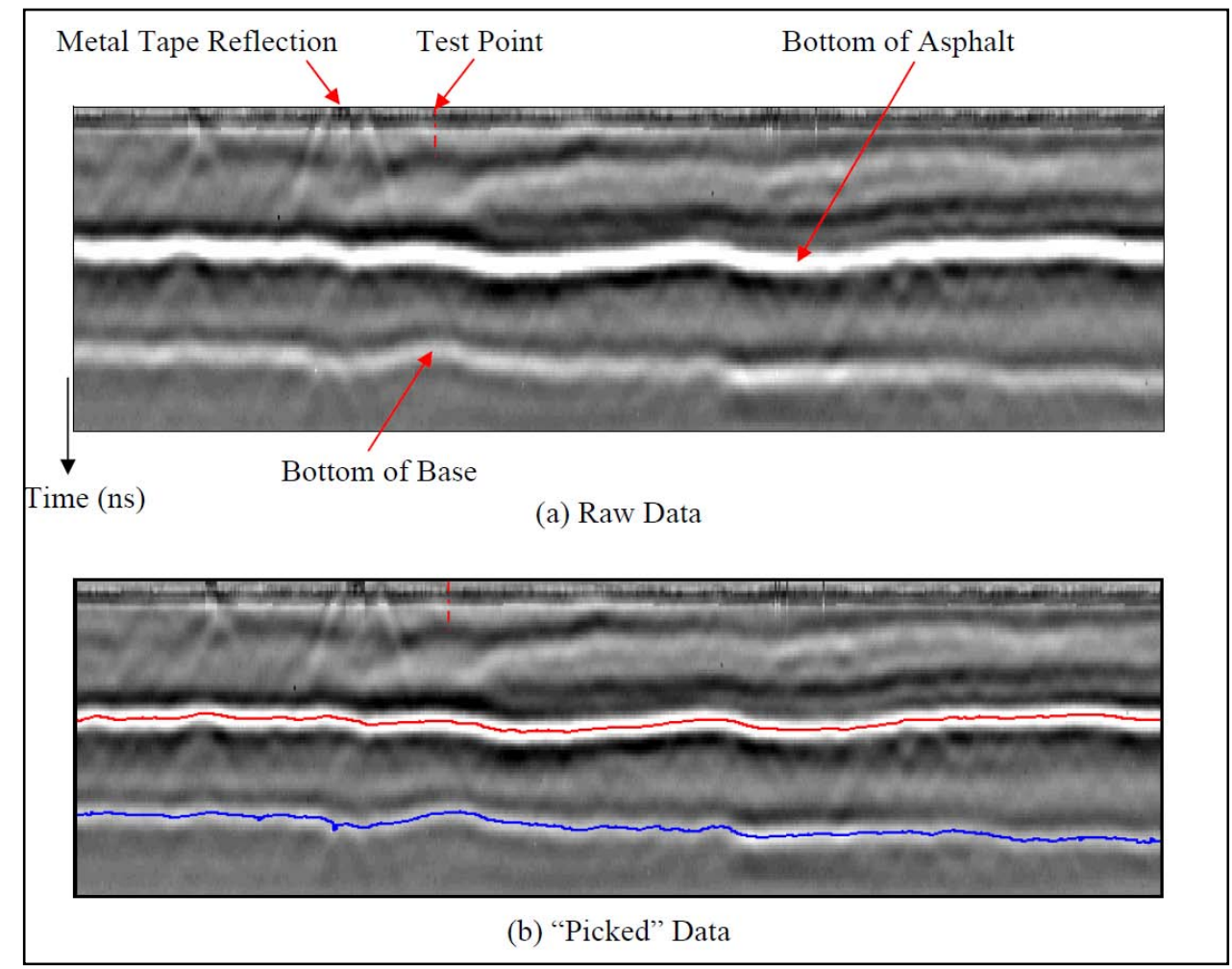

Figure 28. Data from the 1-GHz horn antenna at test location 30 (figure taken from Infrasense, Inc. 2010).

Since the horn antenna is not placed directly on the ground, the metal plate calibration and the air gap allows for the estimation of dielectric constants of the pavement layers because the dielectric constant of air is known. This allows for more accurate estimates of thicknesses than a ground-coupled radar system. However, the horn antenna is quite bulky and requires at least $30 \mathrm{~min}$ of setup, and $15 \mathrm{~min}$ to execute the metal plate calibration and bounce test. 
Calibration of the data was calculated based on the calibration core data provided in Table 8. Calibration factors for AC and for PCC were developed and applied to all of the test location measurements. Table 11 shows the comparison of the estimated thicknesses to the actual core data before and after calibration. If the discrepancy between the estimated and actual measurements after calibration was too large, the estimated measurement was not used for that test location.

Table 11. Comparison of measured core data to GPR data at the calibration locations for the 1-GHz horn GPR antenna (table taken from Infrasense, Inc. 2010).

\begin{tabular}{|l|l|l|l|l|l|}
\hline & $\begin{array}{l}\text { Infrasense } \\
\text { Layer 1 } \\
\text { Thickness } \\
\text { in. }\end{array}$ & $\begin{array}{l}\text { ERDC Core } \\
\text { Layer 1 } \\
\text { Thickness } \\
\text { in. }\end{array}$ & $\begin{array}{l}\text { Infrasense } \\
\text { Calibrated } \\
\text { Layer 1 } \\
\text { Thickness } \\
\text { in. }\end{array}$ & $\begin{array}{l}\text { Absolute } \\
\text { Difference } \\
\text { Original } \\
\text { in. }\end{array}$ & $\begin{array}{l}\text { Absolute } \\
\text { Difference } \\
\text { After } \\
\text { Calibration } \\
\text { in. }\end{array}$ \\
\hline $10 \mathrm{AC}$ & 3.18 & 2.58 & 3.06 & 0.60 & 0.48 \\
\hline $11 \mathrm{PCC}$ & 8.83 & 8.42 & 8.83 & 0.41 & 0.41 \\
\hline $21 \mathrm{AC}$ & 4.60 & 4.50 & 4.39 & 0.10 & 0.11 \\
\hline $26 \mathrm{AC}$ & 9.87 & 9.25 & 9.48 & 0.62 & 0.23 \\
\hline $34 \mathrm{PCC}$ & n.a. 1 & 8.79 & n.a. 1 & n.a. 1 & n.a. ${ }^{1}$ \\
\hline $40 \mathrm{PCC}$ & 8.01 & 8.92 & 8.81 & 0.91 & 0.11 \\
\hline
\end{tabular}

1 This location was not included in the analysis because there was a large discrepancy that could not be corrected with calibration.

\section{Resource International: 900-MHz and 1.5-GHz ground-coupled GSSI antennas}

Resource International tested on 26 October 2010 with two different GSSI GPR antennas. Two small, portable ground-coupled GPR antennas were tested - a 900-MHz antenna and a 1.5-GHz antenna. The 900-MHz antenna came with a pole attachment that allows the user to push the system along the pavement test site, as seen in Figure 29.

The 1.5-GHz GSSI ground-coupled antenna had wheels to assist with moving the antenna along the pavement, as shown in Figure 30. This antenna operates at a higher frequency than the previous one and will yield higher resolution but will not penetrate as deep. Testing took less than $30 \mathrm{sec}$ per location for both antenna systems. 


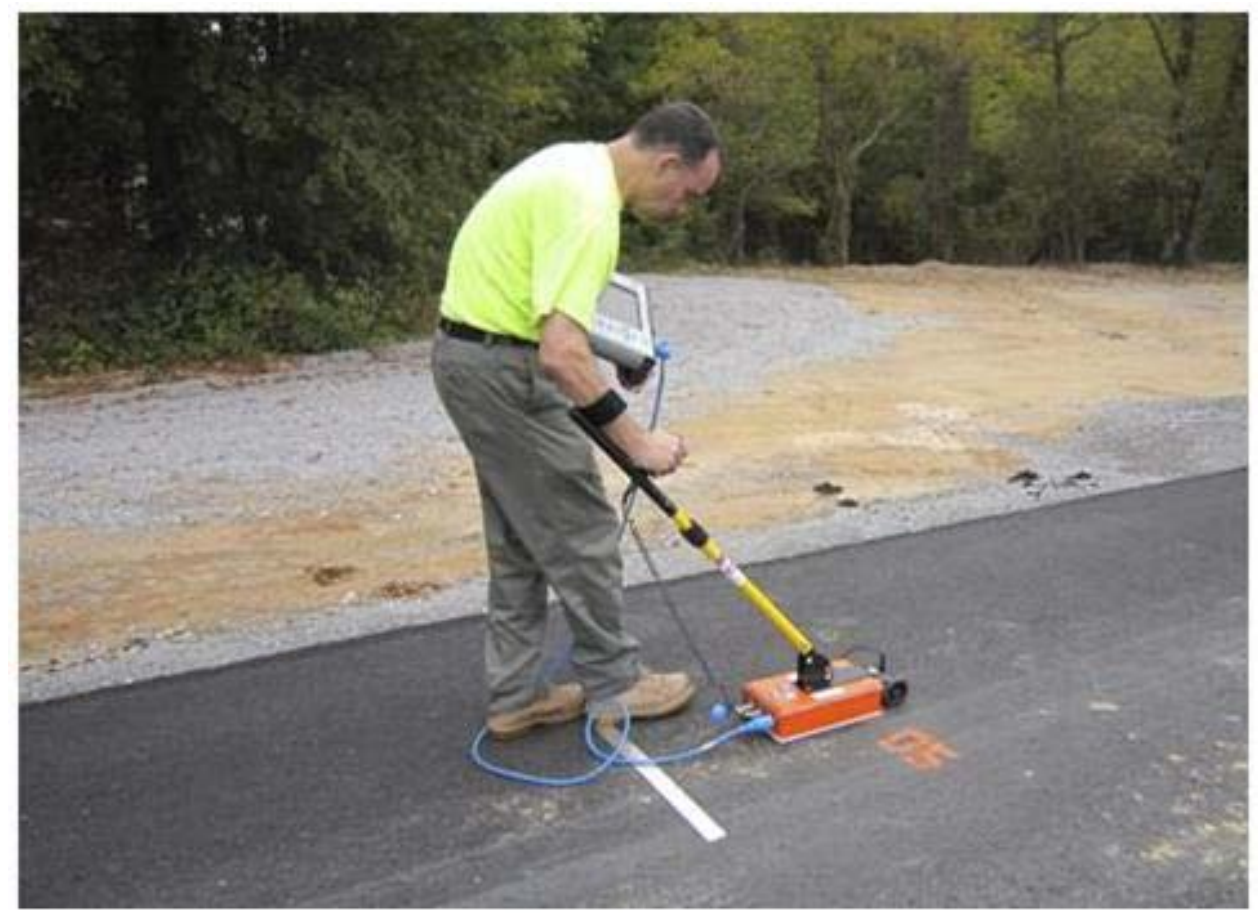

Figure 29. 900-MHz GSSI GPR system.

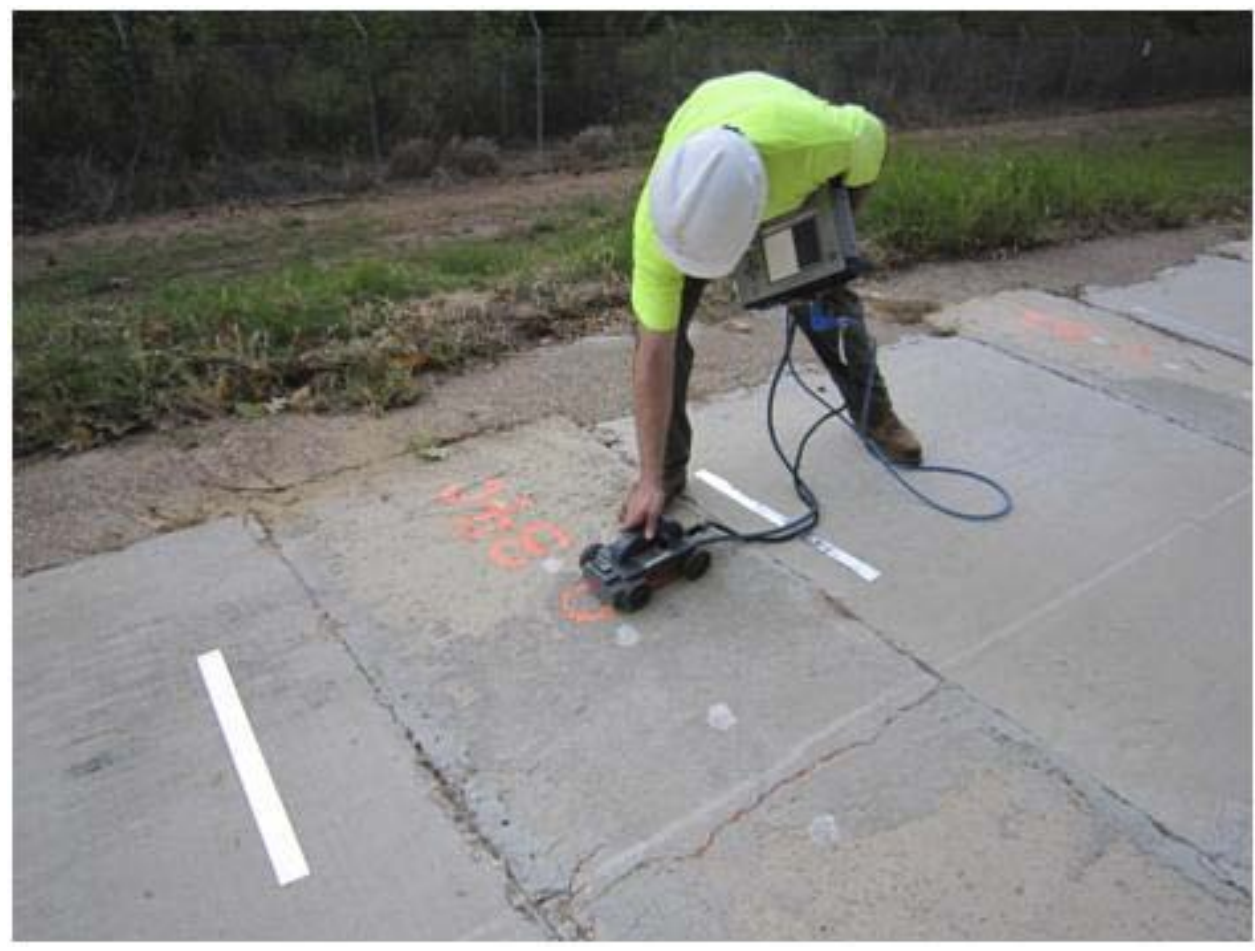

Figure 30. Testing with the 1.5-GHz GSSI antenna. 
Post-processing was completed with the GSSI RADAN software. RADAN automatically determines the thickness of the layers, but the interpretation of the data should be completed by an experienced GPR analyst. Figures 31 and 32 show screenshots of the data from the RADAN software for the 900-MHz and 1.5-GHz antennas, respectively. Resource International used both sets of data to determine the thicknesses. As a general rule, for pavements less than 18 in., the 1.5-GHz antenna was used. If the pavement was thicker than 18 in., the $900-\mathrm{MHz}$ antenna was used. The $1.5-\mathrm{GHz}$ antenna data were used for the top pavement layer thicknesses. For test locations 15, 16, 17, 32, 33, and 36, the 900-MHz antenna was used to determine the top pavement layer thicknesses.

Because both systems used were ground-coupled systems, dielectric constants were assumed for the initial thickness estimates. Resource International assumed a dielectric constant of 5 for the AC sections, and a dielectric constant of 9 for the PCC sections. Upon receiving the core data for the calibration data points, dielectric constants were calculated and found to be 4.92, 4.97, and 4.73 for AC test locations 10, 21, and 26c; and dielectric constants were calculated and found to be $9.40,8.25$, and 9.50 for PCC test locations 11c, 34c, and 40c, respectively. These new dielectric constants were applied to those test locations of similar material to provide a more accurate estimate of thickness.

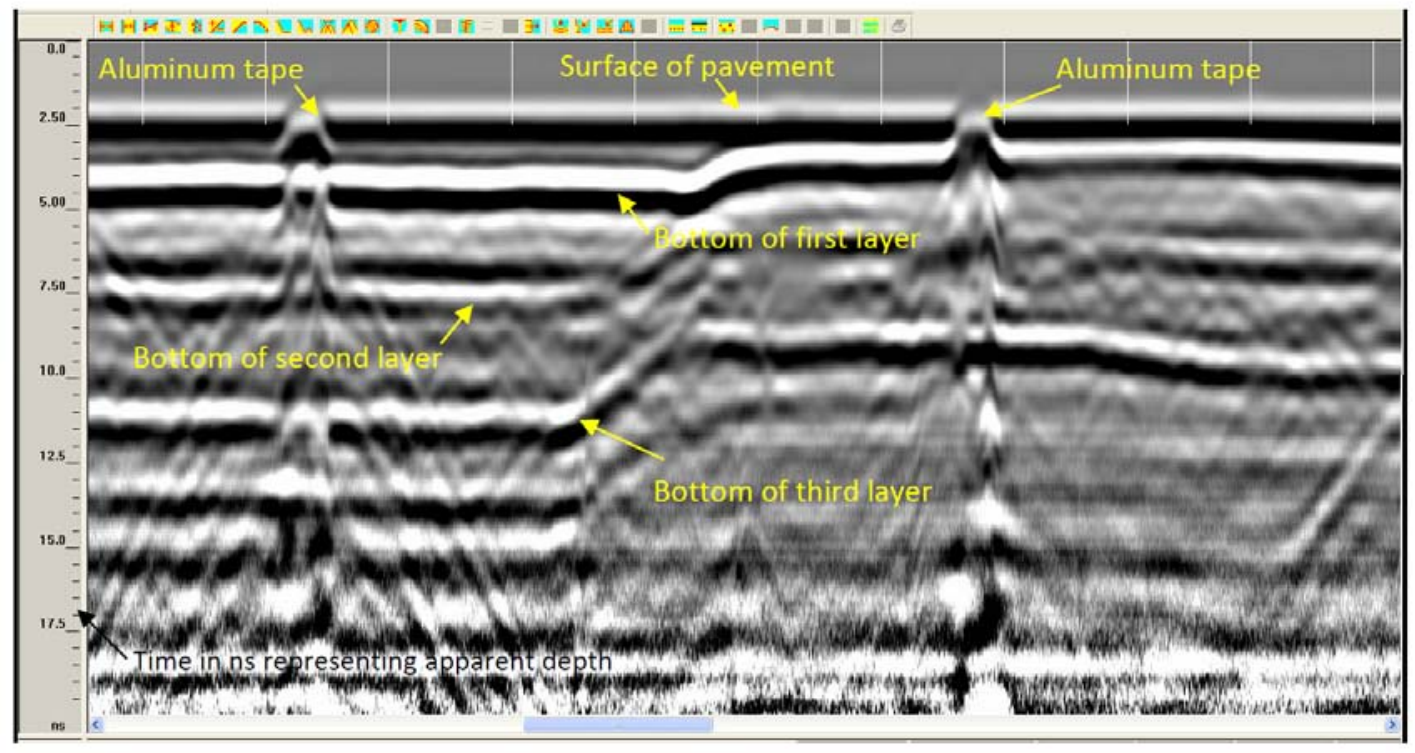

Figure 31. Example of data from the 900-MHz GSSI antenna. 


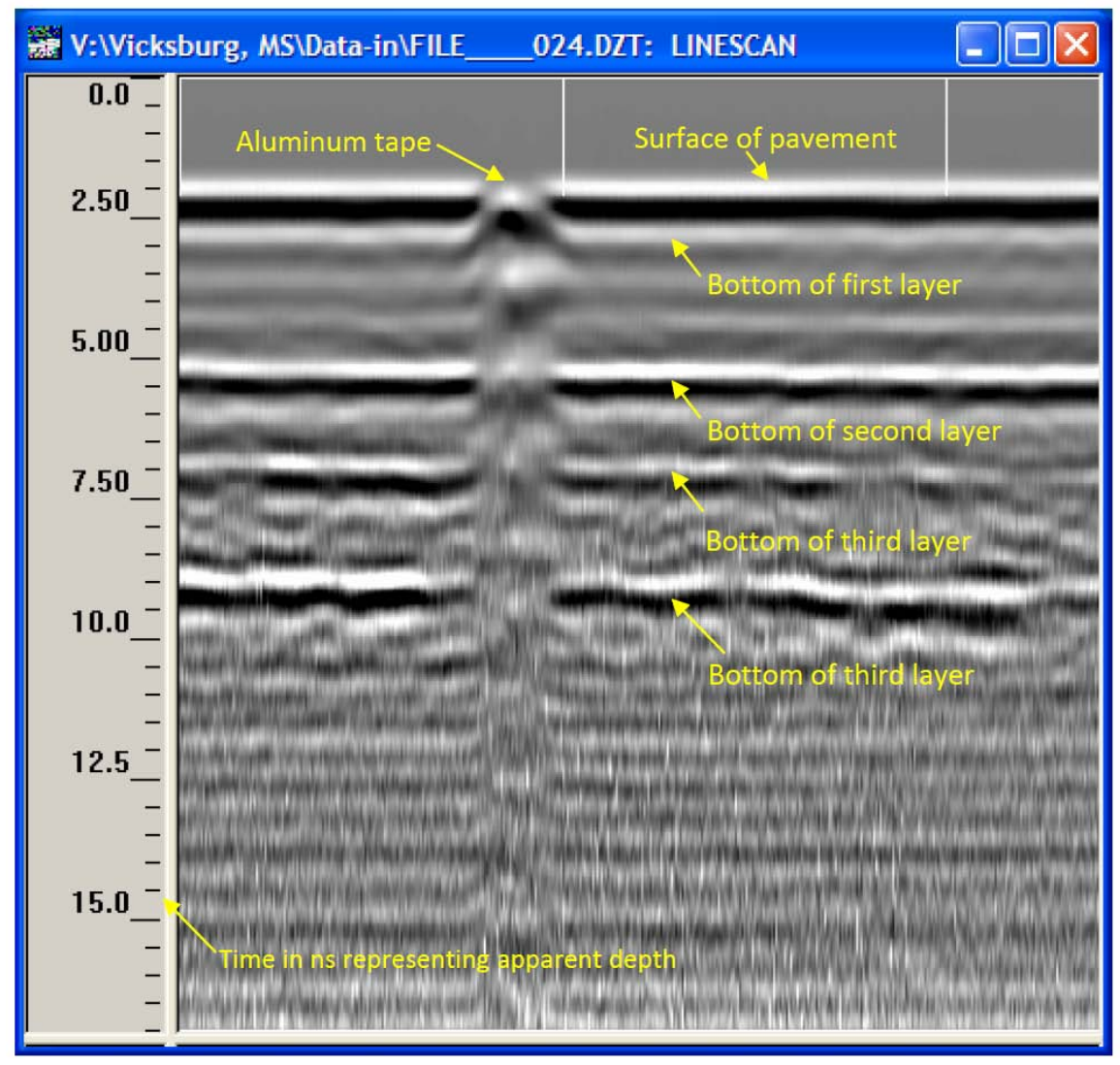

Figure 32. Example of data from the 1.5-GHz antenna.

\section{MALÅ: 800-MHz, 1.2-GHz, 1.6-GHz, and 2.3-GHz ground-coupled MALÅ antennas}

MALÅ Geoscience, a Swedish based company with a branch in Charleston, SC, tested their equipment on 22 November 2010. MAL $\AA$ tested for this study using MALÅ's ProEx system with four different ground-coupled GPR antennas with frequencies of $800 \mathrm{MHz}, 1.2 \mathrm{GHz}, 1.6 \mathrm{GHz}$, and $2.3 \mathrm{GHz}$.

Setup required approximately $30 \mathrm{~min}$ and consisted of assembling the cart and connecting the cables. The utility cart, shown in Figure 33, is a generic cart used to hold antennas of different sizes, the ProEx control system, and a laptop for data collection. This cart was easy to take apart and reassemble as needed. Initially, only one antenna was tested at a time, but after the initial setup, two antennas were tested at a time. The time to switch out the antennas was approximately $5 \mathrm{~min}$. Once the antennas were in the cart and plugged in, testing was rapid (less than $1 \mathrm{~min}$ ) as data were collected as soon as the cart was rolled over the testing location. 


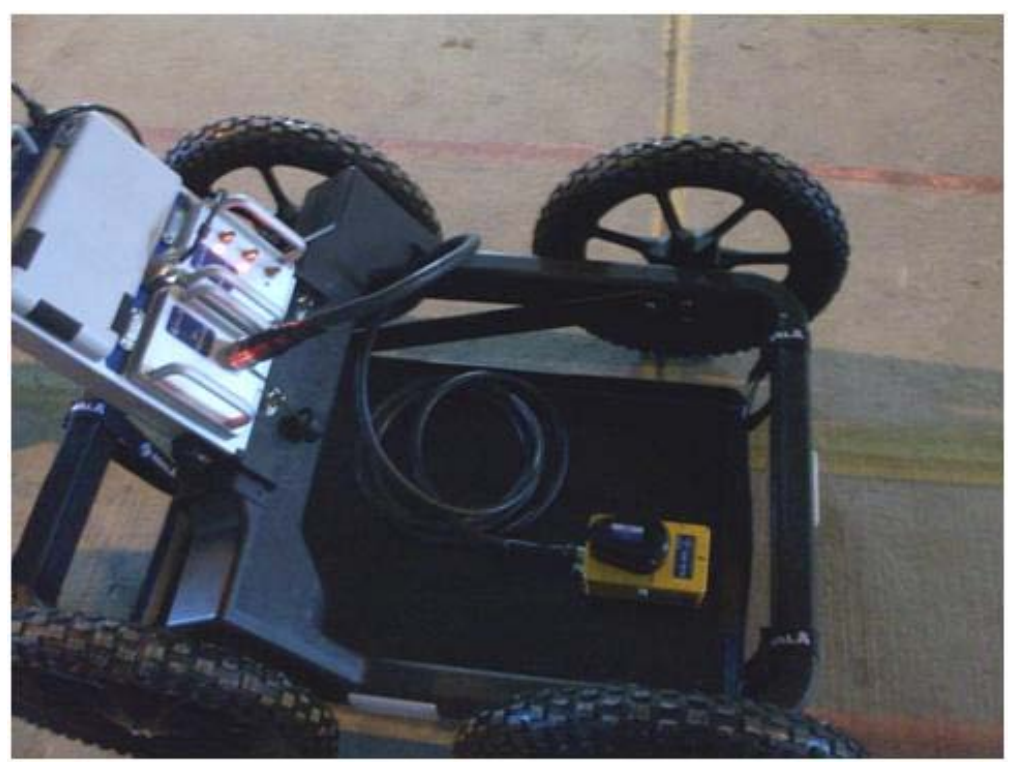

Figure 33. MALÅ equipment on a utility cart.

There was significant rain during the day of testing. Only light rain occurred during the actual data acquisition period. A tarp, as seen in Figure 34, was used to protect the equipment.

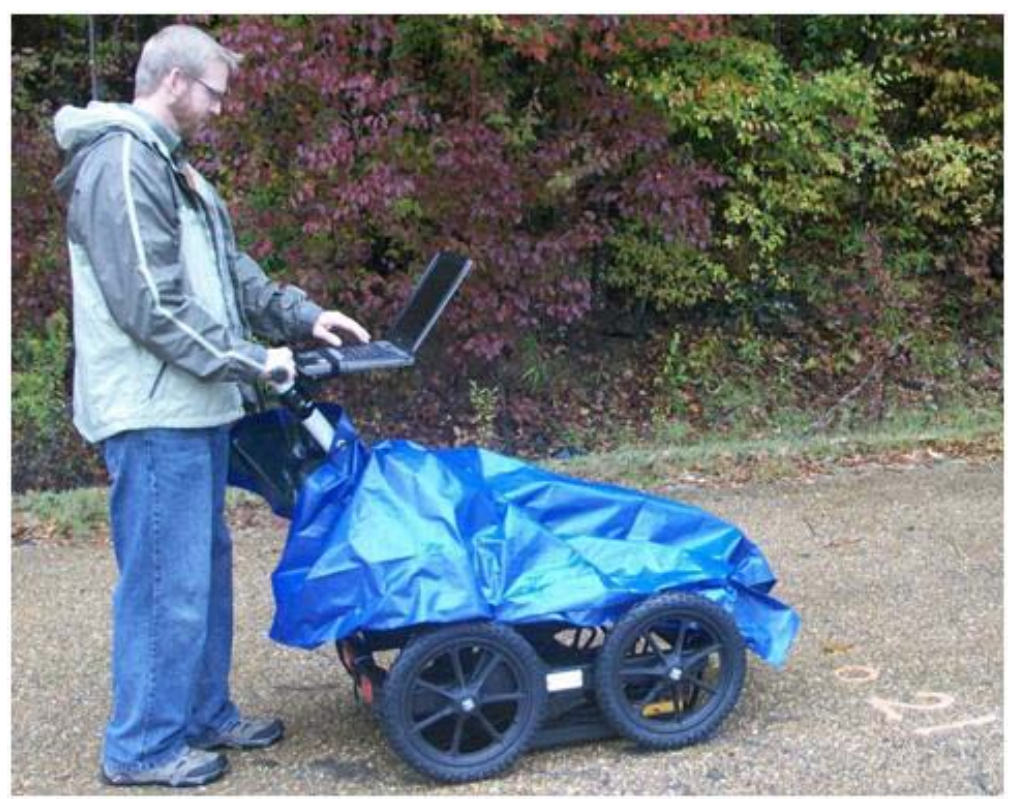

Figure 34. Testing during intermittent rain.

The utility cart used during testing was large in size because MAL $\AA$ wanted to test four different antennas. If this were used in practice, two antennas would probably be sufficient. A smaller cart could be used to accommodate the antennas. Some of their systems have built-in control panels. 
Because the MAL $\AA$ antennas tested for this study were ground-coupled antennas, pavement velocities had to be assumed for the initial thickness estimates. After the calibration core data were given, more accurate data could be provided because the pavement velocities could be calculated.

MAL $\AA$ noted that while all four antennas were tested for this study, the best antennas for this study were the 2.3-GHz antenna for shallow depths, and the $800-\mathrm{MHz}$ antennas for the deeper depths. The 800-MHz antenna was required for test locations 14-20, where potential layer interfaces were thought to be approximately 36 in. deep (MAL $\AA$ Geoscience USA, Inc. 2010).

\section{D-Radar}

3D-Radar tested on 10 and 17 November 2010. 3D-Radar is a company based in Norway, with a branch in Homer, NY. The 3D-Radar system used was the GeoScope-GS3F with the V1821 antenna. 3D-Radar GPR is different from other radar systems used in that it operates in the step frequency mode and provides three-dimensional data. The system covers a frequency range from $140 \mathrm{MHz}$ to $3 \mathrm{GHz}$, with a step frequency of $2 \mathrm{MHz}$. The V1821 antenna is $1.8-\mathrm{m}$ (4.9-ft) wide and has 21 channels spaced $7.5 \mathrm{~cm}$ (2.95 in.) apart.

Setup of the equipment, shown in Figure 35, required approximately $1 \mathrm{hr}$. Data were collected as the antenna traveled over the test location (Figure 36). High resolution data were collected during testing, and thus the vehicle had to travel at a slow speed averaging $2 \mathrm{mph}$. Because there are multiple channels, it was easier to align the antenna to the test location. One person walked behind the antenna and would notify the operator when the antenna reached the test location. The horizontal position of the test location was noted by the channel number labeled on the antenna. This ensured that the exact test location was measured.

Data collected are three dimensional and can be displayed in three different views in the 3dr-Examiner software package. Data are available in real-time during collection for thickness estimation, but further analysis and processing is required before thickness data can be more accurately determined. 


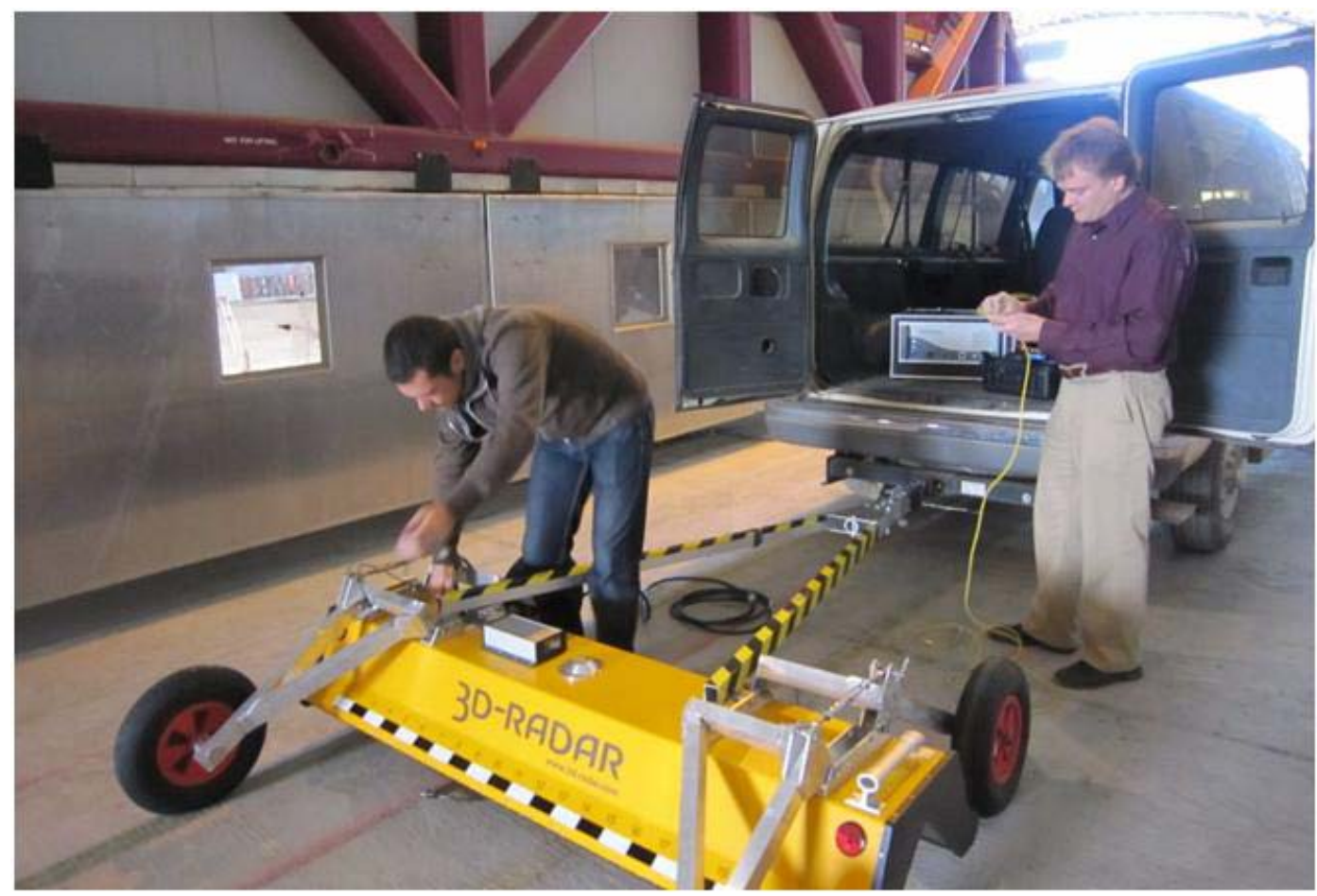

Figure 35. Setup of the 3D-Radar system.

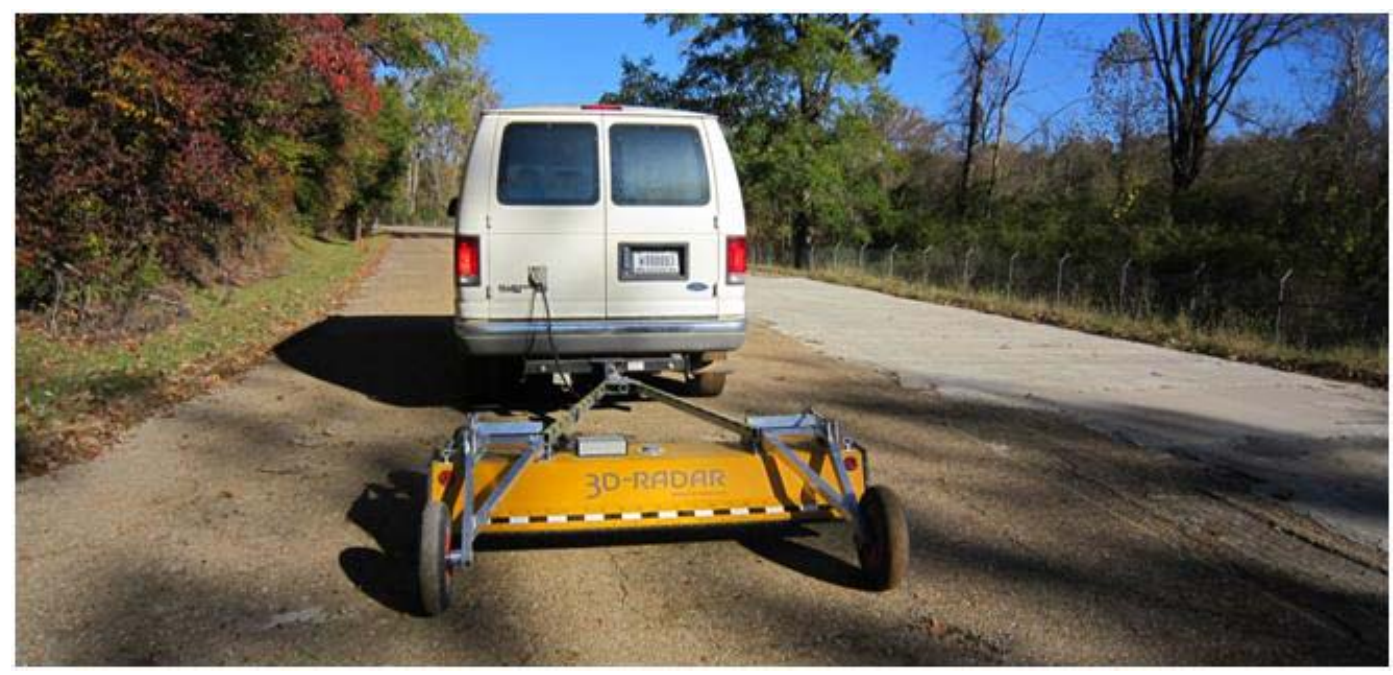

Figure 36. Testing with the 3D-Radar system.

During the initial day of testing, data from the Poor House Test Area and Hangar 4 had been collected when the antenna stopped working. 3DRadar took the antenna in for repairs and returned a week later to collect the remaining data from the Forest Service Road Test Area.

Similar to the ground-coupled GPR systems, this 3D-Radar system required an estimated dielectric constant because it could not be extracted from the data collected. Calibration for the system should assist in 
providing more accurate dielectric constants for thickness estimations. 3D-Radar is currently developing a common midpoint method, where the signal is transmitted from one side of the array in the antenna and is received from the other side. This development would assist in calculating the dielectric constant of the pavement material. However, it was not available at the time of testing.

\section{ERDC: 1-GHz Pulse Radar horn antenna}

The GPR system discussed in this report (Figure 37) was developed by Pulse Radar, Inc., under a Small Business Innovative Research (SBIR) project with the ERDC. This system consists of three air-coupled antennas: a 1-GHz antenna that penetrates up to $1 \mathrm{~m}$ ( $3.3 \mathrm{ft})$, a $500-\mathrm{MHz}$ antenna that penetrates up to $2 \mathrm{~m}$ ( $6.6 \mathrm{ft})$, and a $250-\mathrm{MHz}$ antenna that penetrates up to $3 \mathrm{~m}$ (9.8 ft). There is one ground-coupled antenna of $100 \mathrm{MHz}$ that can penetrate from 5 to $10 \mathrm{~m}$ ( 16.4 to $32.8 \mathrm{ft}$ ). The system is designed to be rugged, can collect data in the temperature range of -10 to $50{ }^{\circ} \mathrm{C}$ (14 to $122^{\circ} \mathrm{F}$ ), and can tolerate relatively high humidity, rain, dust, shock, and vibrations that are frequently encountered during field testing (Pulse Radar 1995). Only the 1-GHz antenna was used for this study. The original software was replaced in 2007 with ColorMap, Version 2.1, which was developed by the Texas Transportation Institute of Texas A\&M University. This software improved the pavement thickness determination, was more user-friendly, and could operate in the Windows XP operating system.

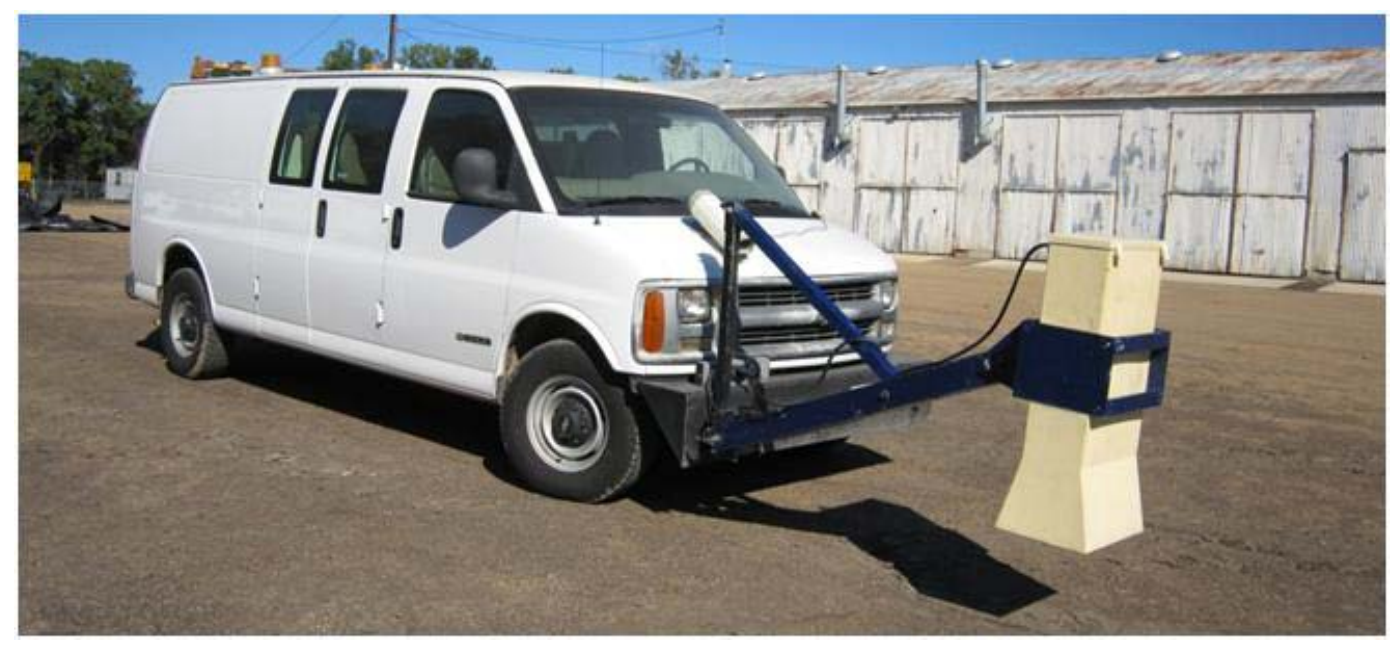

Figure 37. ERDC 1-GHz horn antenna. 
The 1-GHz Pulse Radar horn antenna (ERDC) system can operate at speeds up to 50 miles per hr. For the 1-GHz system, each signal, or trace, consists of a 1-nsec transmitting pulse, followed by $18 \mathrm{nsec}$ of receiving the reflected signals. This system can acquire data at a rate of 50 traces per $\mathrm{sec}$, but data acquisition is distance driven so the operator can specify the frequency of data collection. A metal plate calibration was completed, prior to data collection, so that the dielectric constants could be calculated.

Setup of the equipment took approximately $30 \mathrm{~min}$, mainly because the system had to warm up, prior to collecting data. The data acquisition was rapid (less than $30 \mathrm{sec}$ per test location) because all that was required was for the system to drive over the test location.

Data processing was performed within ColorMap, Version 2.1. At the test locations, the single trace display was used (Figure 38). The peaks of the waveform were selected to calculate the thickness and dielectric of that location.

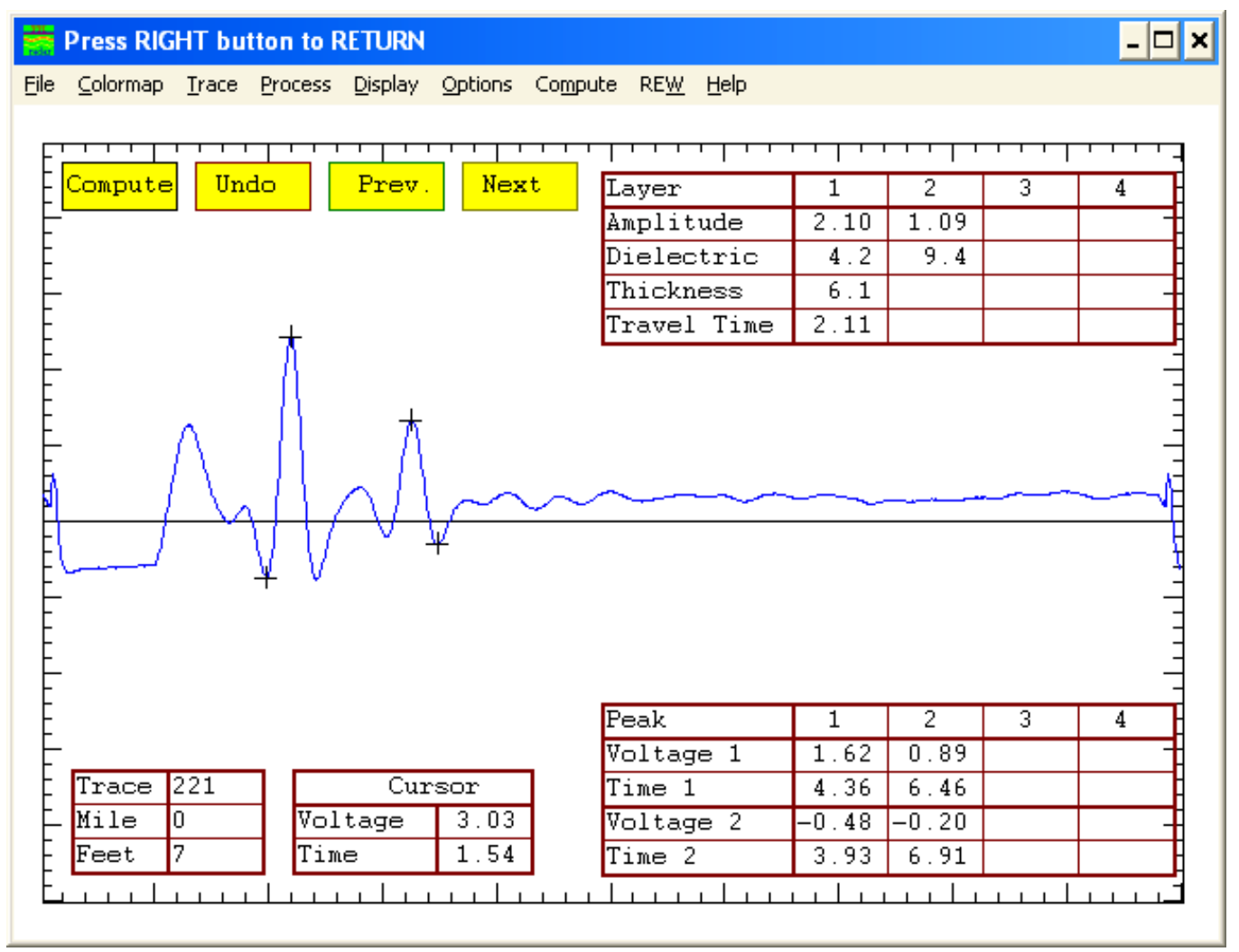

Figure 38. Data processing with the 1-GHz Pulse Radar horn antenna (ERDC) system. 


\section{Borescope}

A borescope consisting of a wireless inspection camera with a 3.5-in. LCD monitor was used to estimate the depth of the layer interface between the AC and limestone base. A 2-in. drill bit was used to drill a hole for the borescope (Figure 39). Because of the amount of fines generated during the drilling, a shop vacuum was used to extract the fines from the hole. A measuring tape was inserted into the hole, along with the camera of the borescope (Figure 40). It was extremely difficult to see any contrast at the layer interface because of the fines that were compacted along the side of the drilled hole. Water was sprayed along the sides to wash off the fines (Figure 41), but this did not improve the visibility of the layer interface. It was extremely difficult to focus the camera on the numbers of the measuring tape and the side of the drilled hole (Figure 42). Video was also taken for the entire depth of the drilled hole, but the layer contrast did not improve in the videos. The PCC test locations were not tested because the color contrast between PCC and limestone would be even less than the $\mathrm{AC} /$ limestone interface.
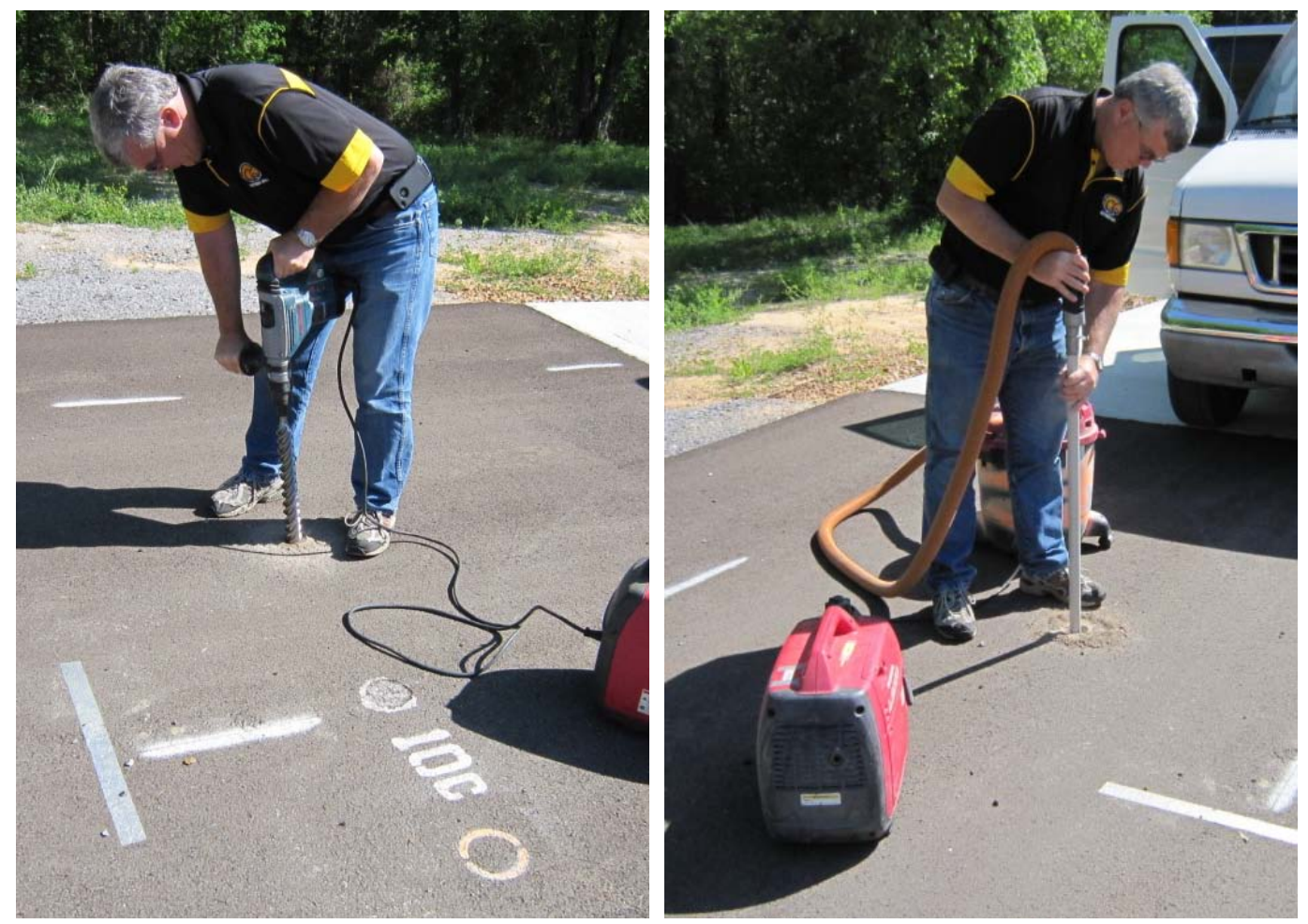

Figure 39. Drilling a 2-in. hole and vacuuming the fines out of the hole. 


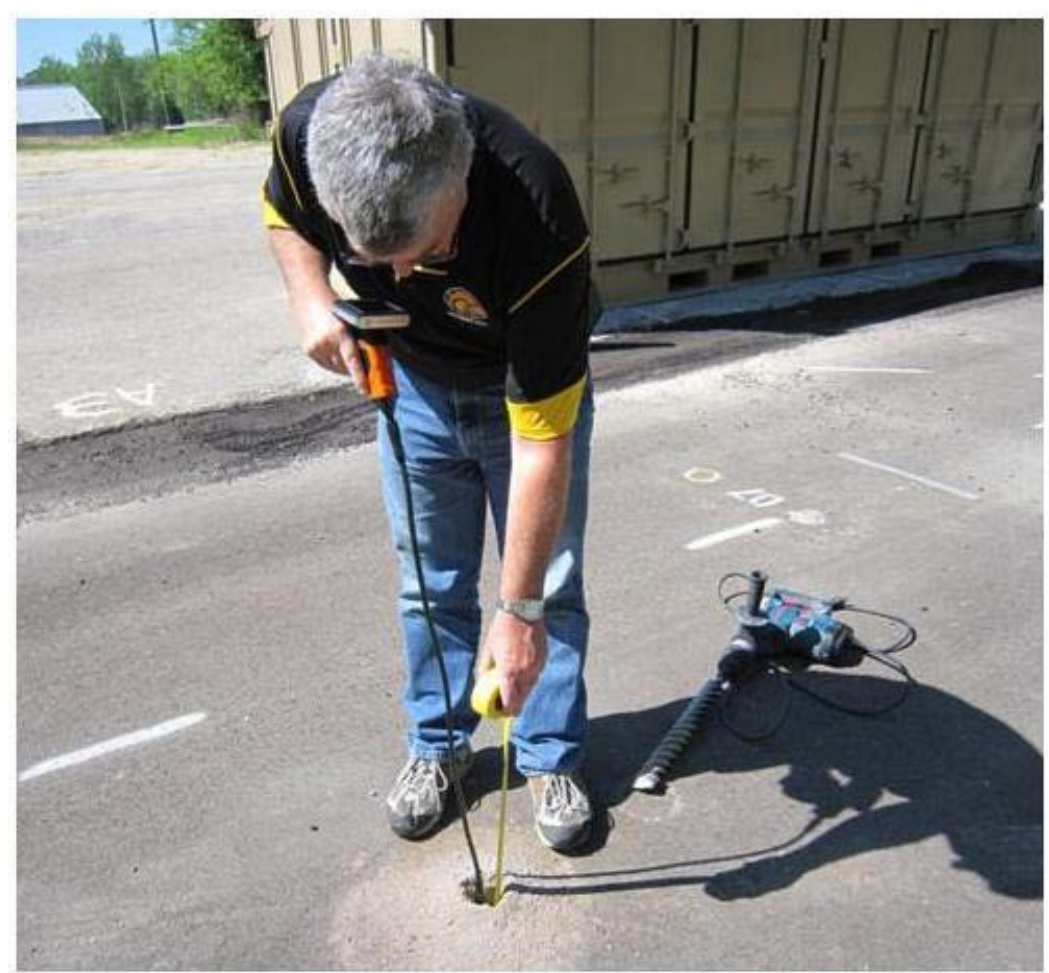

Figure 40. Using the borescope and measuring tape inside the drilled hole.

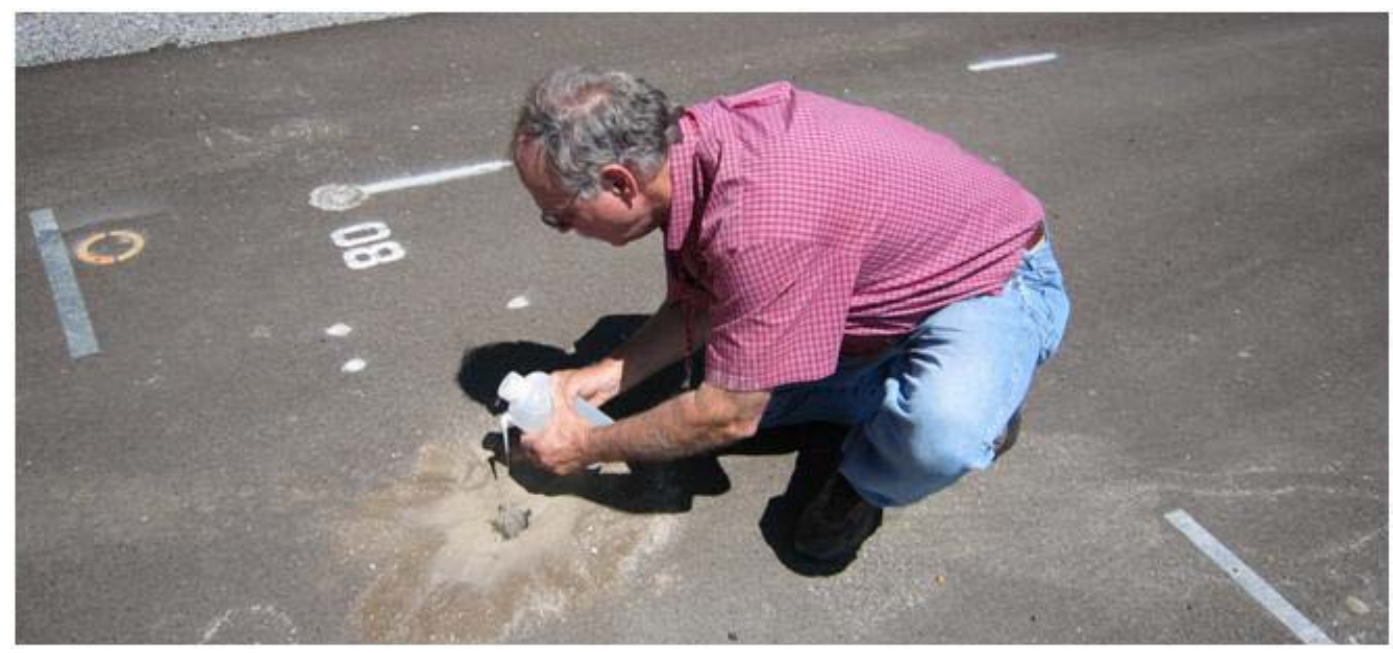

Figure 41. Washing the drilled hole. 


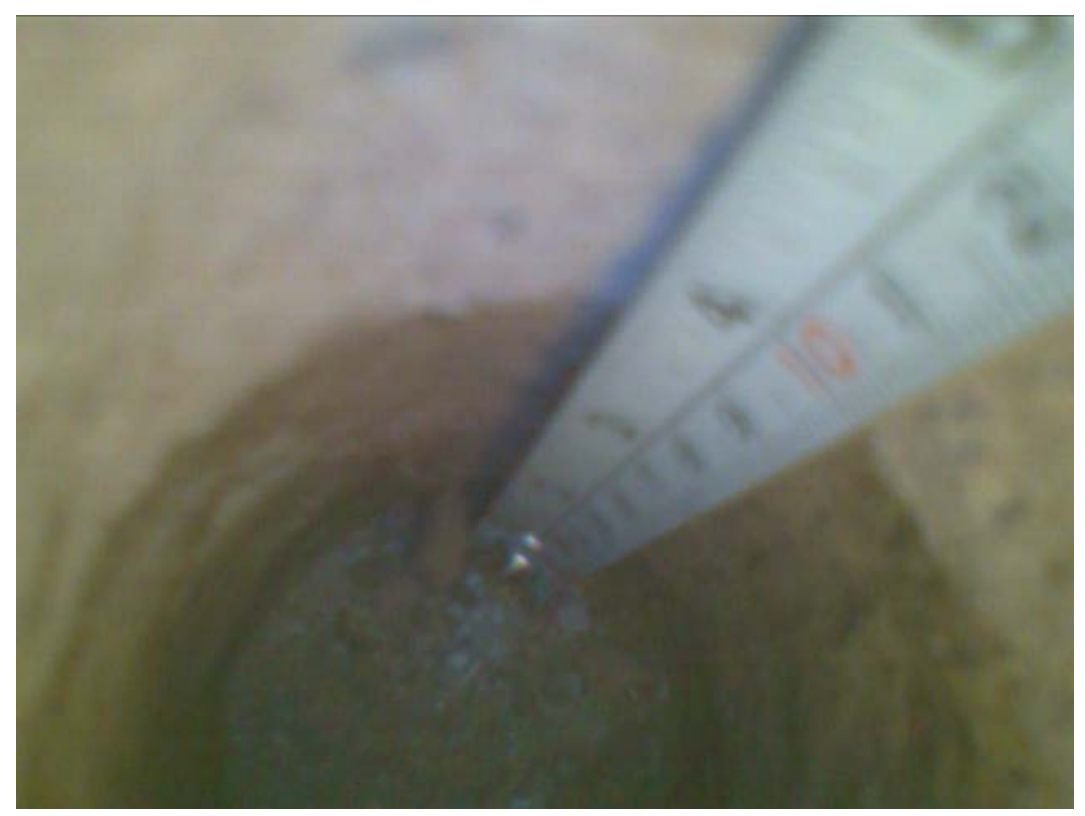

Figure 42. Snapshot from borescope camera.

Improvements to the borescope method would have to be made to be successful for determining pavement thickness. A fixed travel path for the camera, as it progresses down the drilled hole, would provide more consistency and make it easier to read the numbers on the ruler. The camera field of view would have to be rotated 90 deg to better view the side of the hole and the ruler.

The 2-in. hole provided a better view of the inside of the hole, but the drill generated fines that were compacted into the side of the hole, which made the color contrast between the AC and limestone layer difficult to see. A 1-in. hole would have been too small to be useful. 


\section{Results and Discussion}

The results of this study comparing different devices for nondestructive thickness measurements are shown and discussed in this section. For each of the test locations, 4-in. diameter cores were extracted at the marked location. Each of the cores were measured three times around the perimeter of the core and averaged for the actual core thickness measurement for the pavement layers (Figure 43).

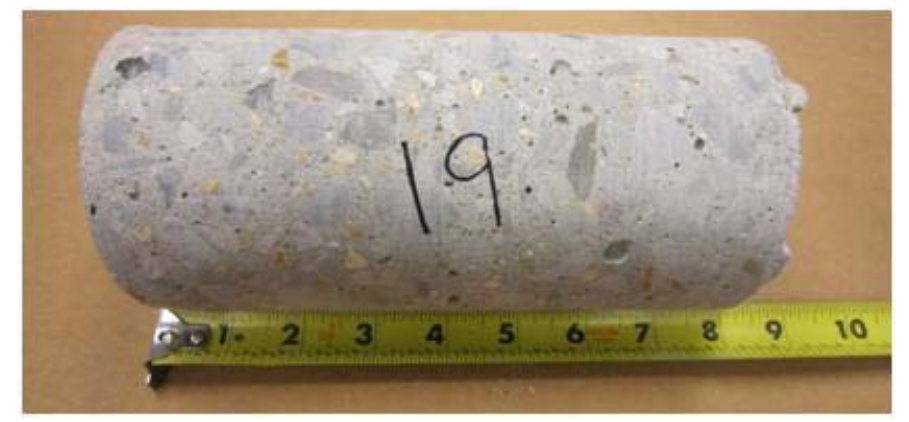

Figure 43. Measurement of PCC pavement layer for test location 19.

For this evaluation, the comparisons were focused only on the ability to estimate the thickness of the surface pavement layer, except for test locations 4, 5, and 6. These test locations had an AC top layer and a PCC layer below the AC layer. Most devices were only able to see the bottom of the top AC layer, but two of the devices, impact echo (Olson Engineering) and MISW (Olson Engineering), did not distinguish the AC/ PCC interface and measured the PCC/limestone interface as the bottom of the first layer. None of the devices accurately measured both the AC/ PCC and PCC/ limestone base layer interfaces (the smallest error for the PCC layer thickness was 1.79 in.). For test location 31, the core revealed a pavement structure of an AC top layer, and two stabilized base layers below the top AC layer (Figure 44). However, none of the devices were able to accurately detect the two stabilized based layers, and only the top AClayer was measured.

It should be noted that for the remainder of this report, all of the devices will be listed by the manufacturer; and in parentheses, the vendor/ researcher that performed the actual testing will be listed. 


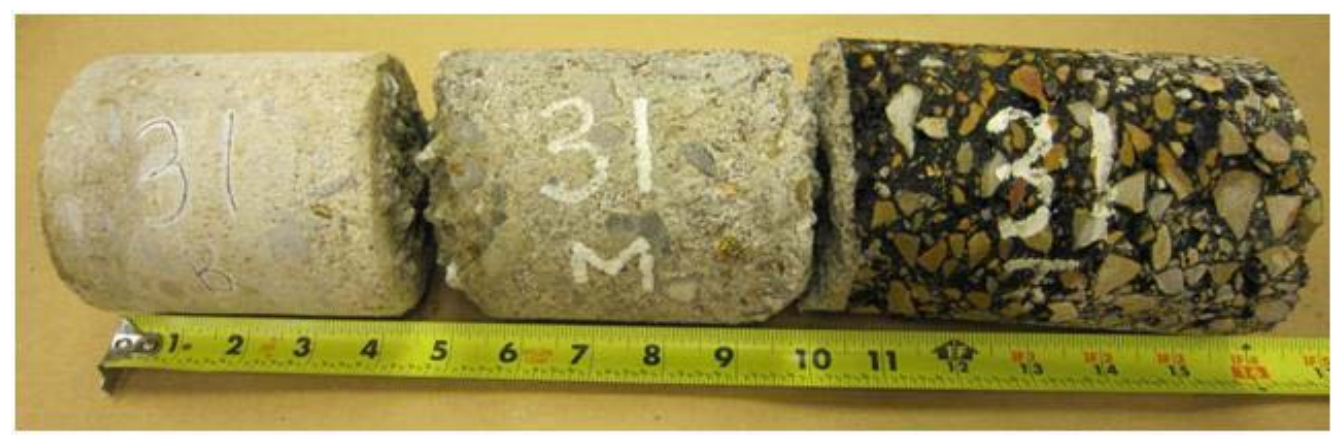

Figure 44. Measurement of pavement layers for test location 31.

\section{Evaluation methods}

For each of the devices, the estimated measurements were correlated to the actual core measurements. The coefficient of determination, $\mathrm{R}^{2}$, for each device for all the test locations was reported as a measure of how well the measured data correlated to the actual core thicknesses. The error was calculated as the absolute difference between the estimated measurement from the device and the actual core measurement. The average of the errors was calculated for all of the test locations, and also separately for the AC test locations and PCC test locations. The average error represents the accuracy of the results. The percentage of test locations measured was also calculated. The number is crucial because the data may have correlated well and may have been accurate, but the device is beneficial only if the majority of the data was collected.

All devices, except for MIRA (University of Minnesota), provided initial results, as well as results after calibration, upon receiving the core thicknesses. The calibrated results were also correlated to the actual core thicknesses, and the calibrated error was calculated using the adjusted data.

\section{Evaluation of both AC and PCC test locations}

The devices were first evaluated on their performance for both AC and PCC sections. In Table 12, the $\mathrm{R}^{2}$, average error, and percentage of the test locations actually measured are reported. Graphs of the actual core measurements plotted against the device-measured thicknesses are shown in Figure 45 through Figure 55. The error for each test location for all devices can be found in the graphs in Appendix A, and the actual measurements can be found in the tables in Appendix A. The errors for the initial estimates, as well as after calibration, are plotted for comparison. The errors on the graph are limited to $5 \mathrm{in}$. to allow for better comparison among the devices. 
Table 12. Results for all test locations, ranked from highest to lowest $\mathbf{R}^{2}$.

\begin{tabular}{|c|c|c|c|}
\hline Method & $\begin{array}{l}\mathrm{R}^{2} \text { for All } \\
\text { Test } \\
\text { Locations }^{1}\end{array}$ & $\begin{array}{l}\text { Average } \\
\text { Error }{ }^{2} \\
\text { in. }\end{array}$ & $\begin{array}{l}\% \text { of Test } \\
\text { Locations } \\
\text { Measured }\end{array}$ \\
\hline MIRA (University of Minnesota) & 0.98 & 0.51 & 70 \\
\hline Calibrated 1-GHz GSSI Horn Antenna (Infrasense, Inc.) & 0.97 & 0.32 & 73 \\
\hline 1-GHz GSSI Horn Antenna (Infrasense, Inc.) & 0.96 & 0.51 & 73 \\
\hline Calibrated 1-GHz Pulse Radar Horn Antenna (ERDC) & 0.95 & 0.40 & 63 \\
\hline Calibrated MISW (Olson Engineering) & 0.91 & 1.15 & 78 \\
\hline MISW (Olson Engineering) & 0.87 & 2.10 & 78 \\
\hline $\begin{array}{l}\text { Calibrated } 800-\mathrm{MHz}, 1.2-\mathrm{GHz}, 1.6-\mathrm{GHz} \text {, and } 2.3-\mathrm{GHz} \text { ground- } \\
\text { coupled antennas (MALA) }\end{array}$ & 0.85 & 1.28 & 100 \\
\hline 1-GHz Pulse Radar Horn Antenna (ERDC) & 0.80 & 1.05 & 70 \\
\hline $\begin{array}{l}\text { Calibrated Single 1.5-GHz Ground-Coupled GSSI Antenna } \\
\text { (Infrasense, Inc.) }\end{array}$ & 0.71 & 0.87 & 80 \\
\hline Single 1.5-GHz Ground-Coupled GSSI Antenna (Infrasense, Inc.) & 0.68 & 1.10 & 83 \\
\hline Calibrated Impact Echo (Olson Engineering) & 0.51 & 1.82 & 100 \\
\hline Calibrated 3D-Radar & 0.41 & 2.11 & 100 \\
\hline Impact Echo (Olson Engineering) & 0.39 & 2.29 & 90 \\
\hline $\begin{array}{l}\text { Calibrated CMP Method with Two 1.5-GHz Ground-Coupled GSSI } \\
\text { Antennas (Infrasense, Inc.) }\end{array}$ & 0.38 & 1.37 & 80 \\
\hline $\begin{array}{l}\text { 800-MHz, 1.2-GHz, 1.6-GHz, and 2.3-GHz ground-coupled antennas } \\
\text { (MALÅ) }\end{array}$ & 0.38 & 2.37 & 100 \\
\hline $\begin{array}{l}\text { Calibrated 2-GHz Ground-Coupled IDS Aladdin GPR (Olson } \\
\text { Engineering) }\end{array}$ & 0.34 & 2.35 & 100 \\
\hline $\begin{array}{l}\text { CMP Method with Two 1.5-GHz Ground-Coupled GSSI Antennas } \\
\text { (Infrasense, Inc.) }\end{array}$ & 0.31 & 1.68 & 83 \\
\hline $\begin{array}{l}\text { 900-MHz and 1.5-GHz Ground-Coupled GSSI Antennas (Resource } \\
\text { International) }\end{array}$ & 0.22 & 7.19 & 100 \\
\hline $\begin{array}{l}\text { Calibrated 900-MHz and 1.5-GHz Ground-Coupled GSSI Antennas } \\
\text { (Resource International) }\end{array}$ & 0.17 & 2.51 & 100 \\
\hline 3D-Radar & 0.03 & 3.88 & 100 \\
\hline 2-GHz Ground-Coupled IDS Aladdin GPR (Olson Engineering) & 0.03 & 4.48 & 100 \\
\hline
\end{tabular}

${ }^{1}$ Coefficient of Determination calculated using the measured core thicknesses and the measured thickness from the device.

2 Error was calculated as the absolute difference between the thickness measured with the devices and the actual thickness of the core. The errors for all the test locations were averaged for each method.

3 Percentage of both AC and PCC test locations measured because not all of the test locations were measured for each device. 


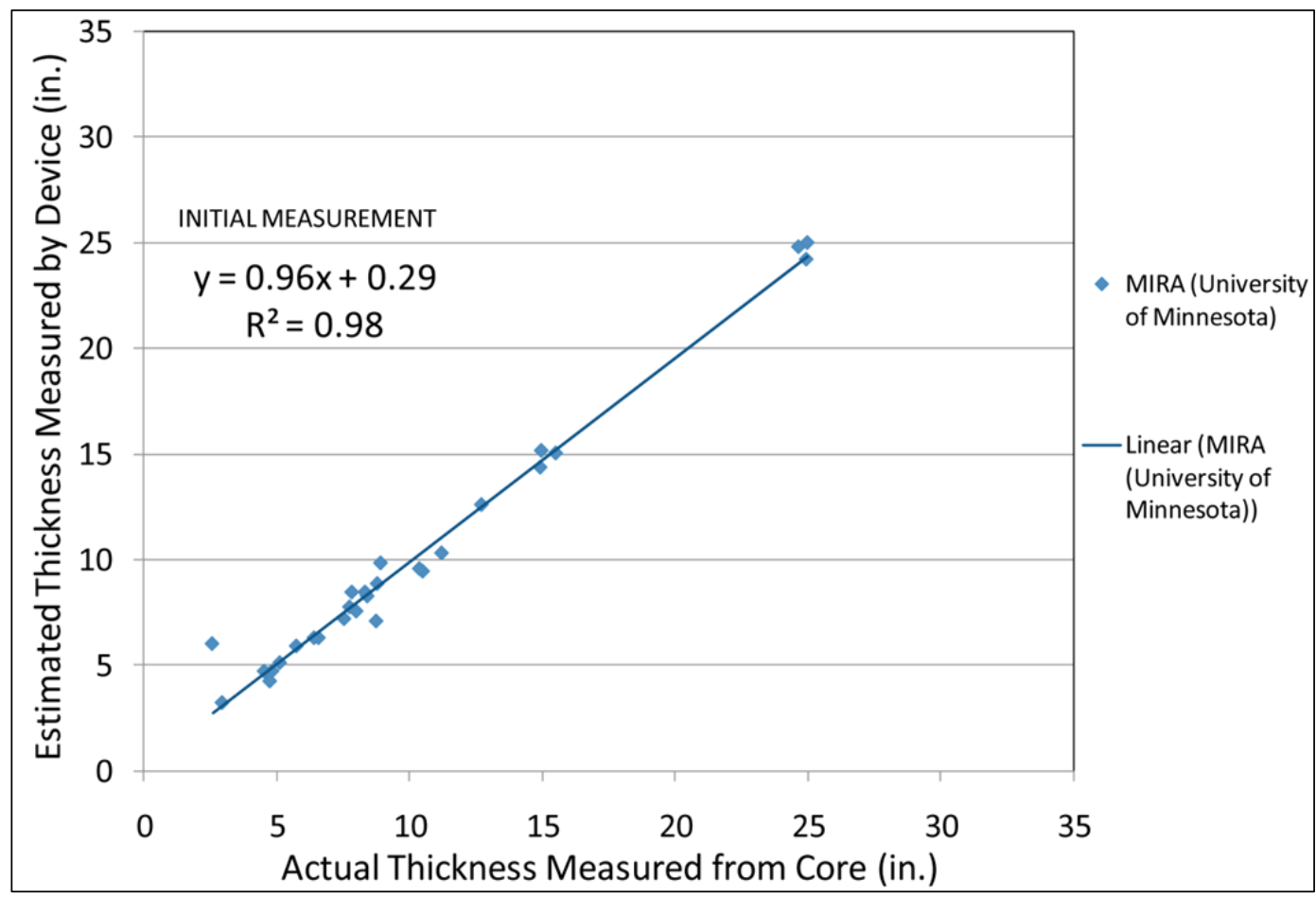

Figure 45. Correlation of actual core thickness and estimated thickness from the MIRA (University of Minnesota).

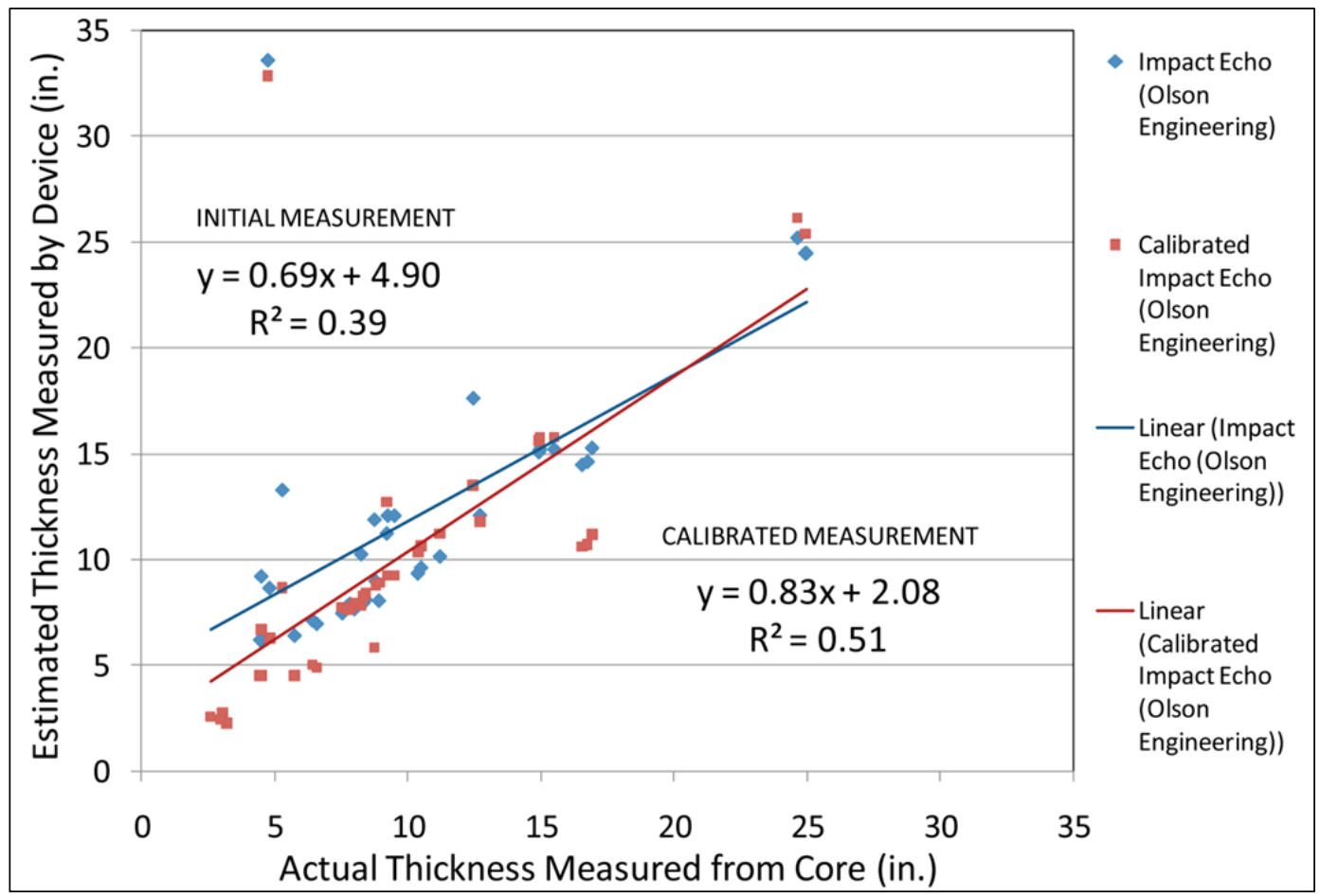

Figure 46. Correlation of actual core thickness and estimated thickness from impact echo (Olson Engineering). 


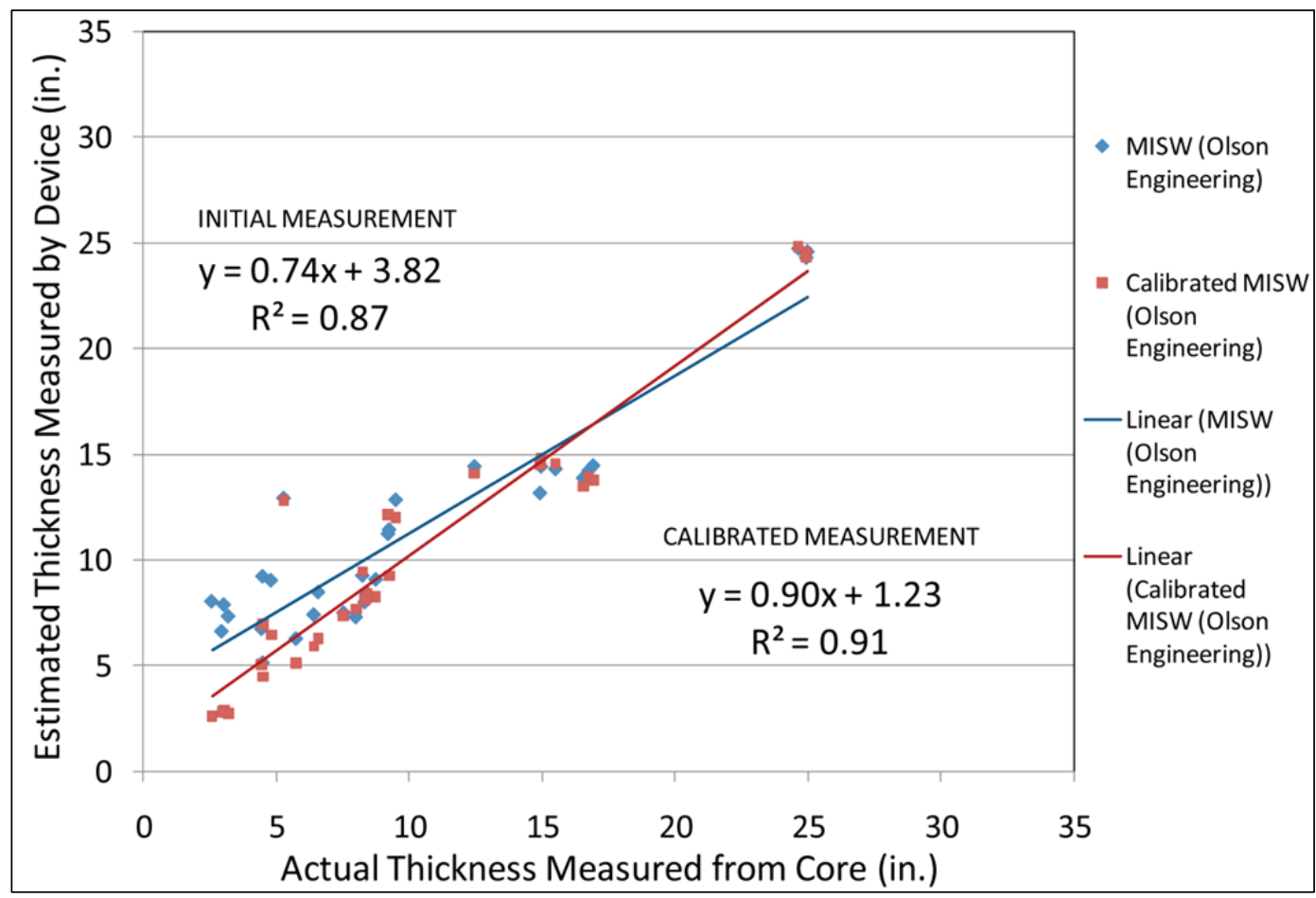

Figure 47. Correlation of actual core thickness and estimated thickness from the MISW (Olson Engineering).

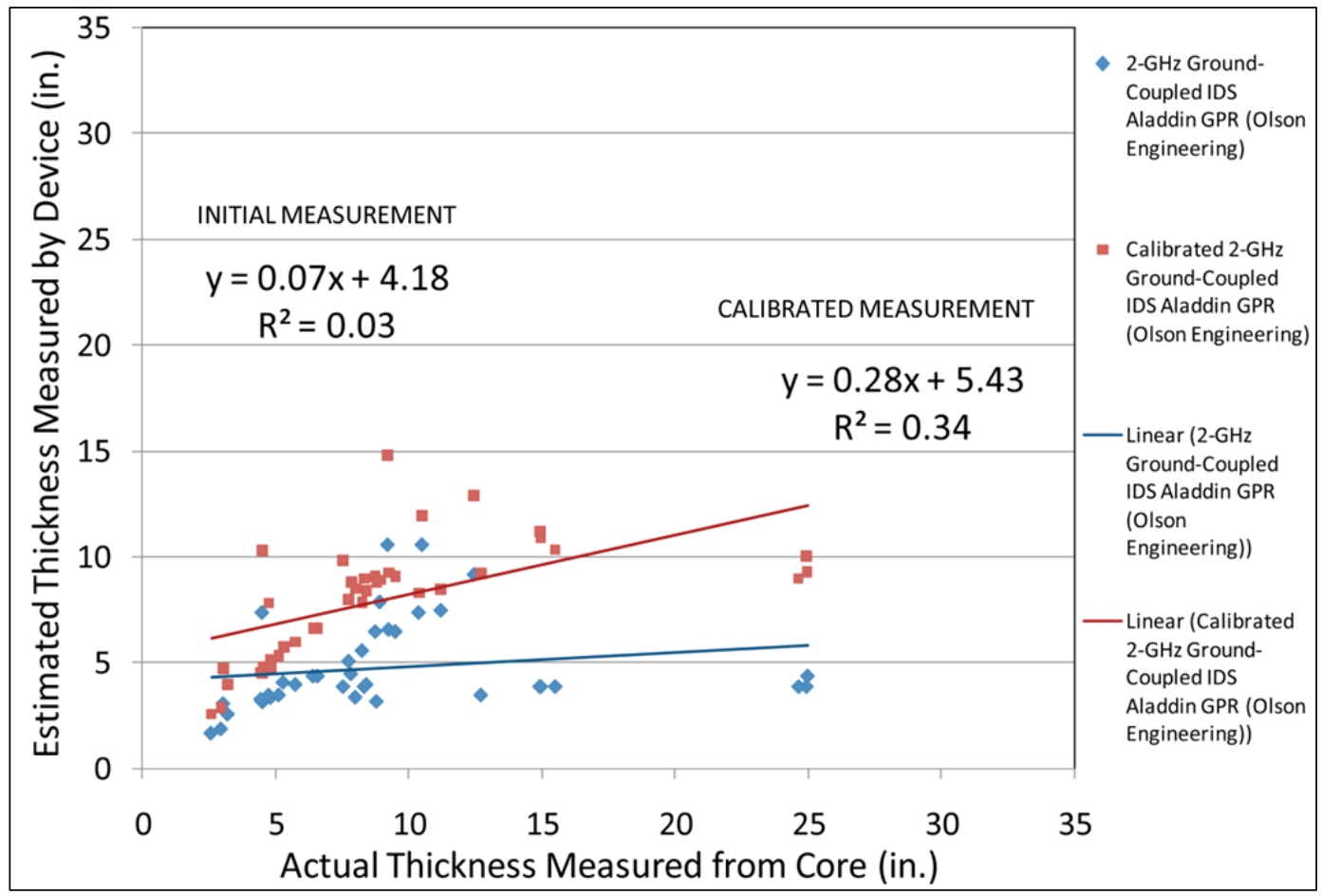

Figure 48. Correlation of actual core thickness and estimated thickness from the 2-GHz ground-coupled IDS Aladdin GPR (Olson Engineering). 


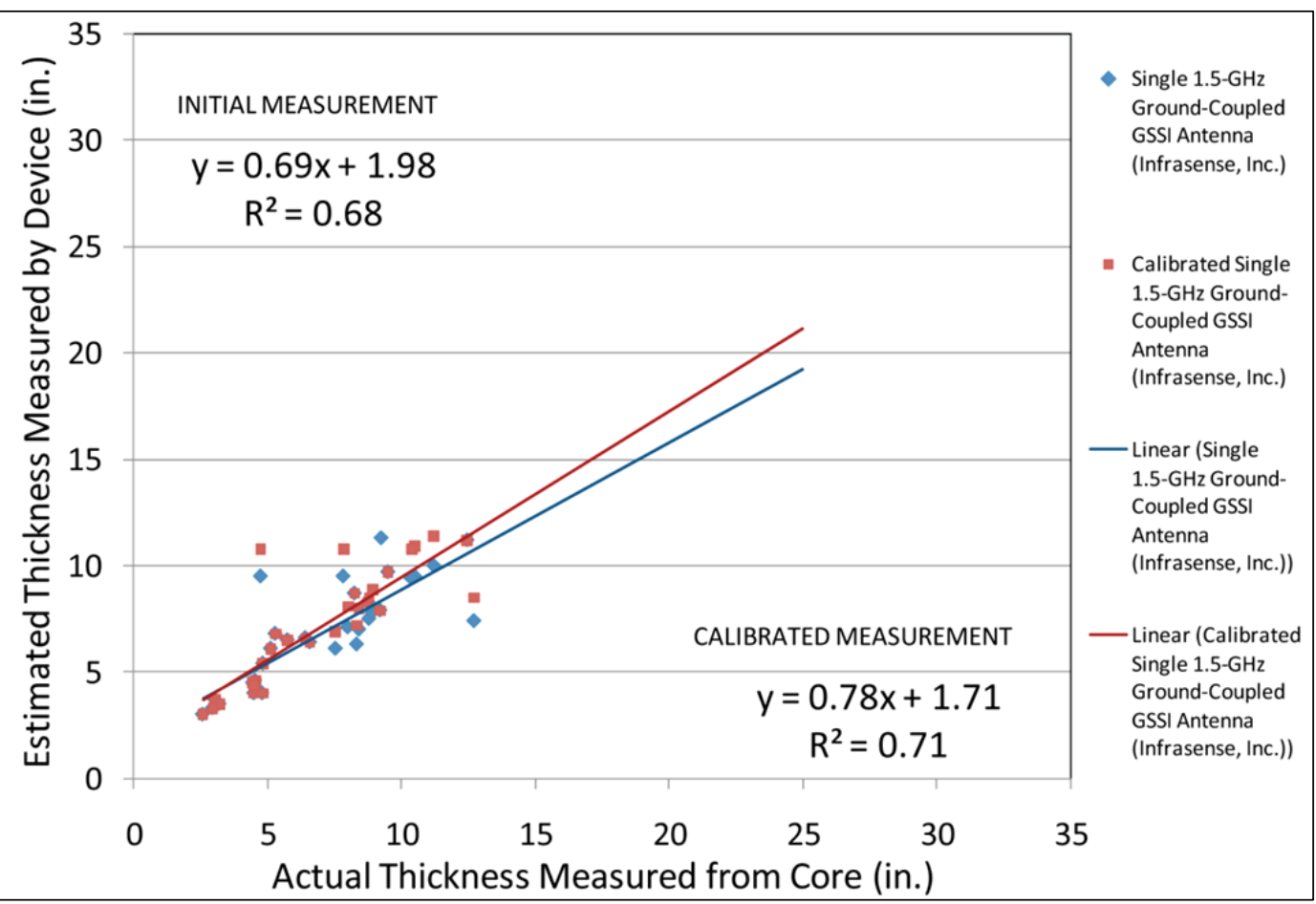

Figure 49. Correlation of actual core thickness and estimated thickness from the single 1.5-GHz ground-coupled GSSI antenna (Infrasense, Inc.).

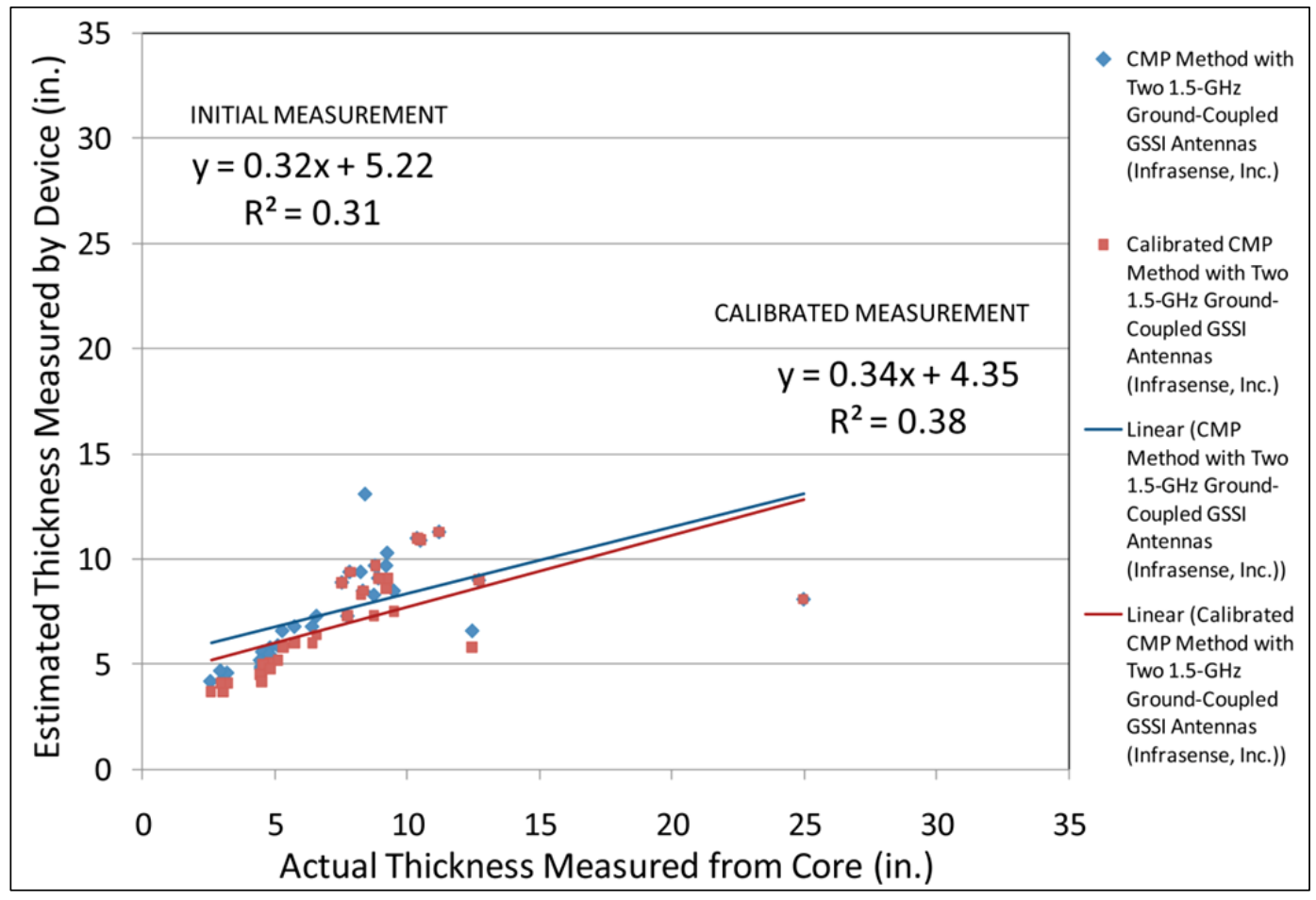

Figure 50. Correlation of actual core thickness and estimated thickness from the CMP method with two 1.5-GHz ground-coupled GSSI antennas (Infrasense, Inc.). 


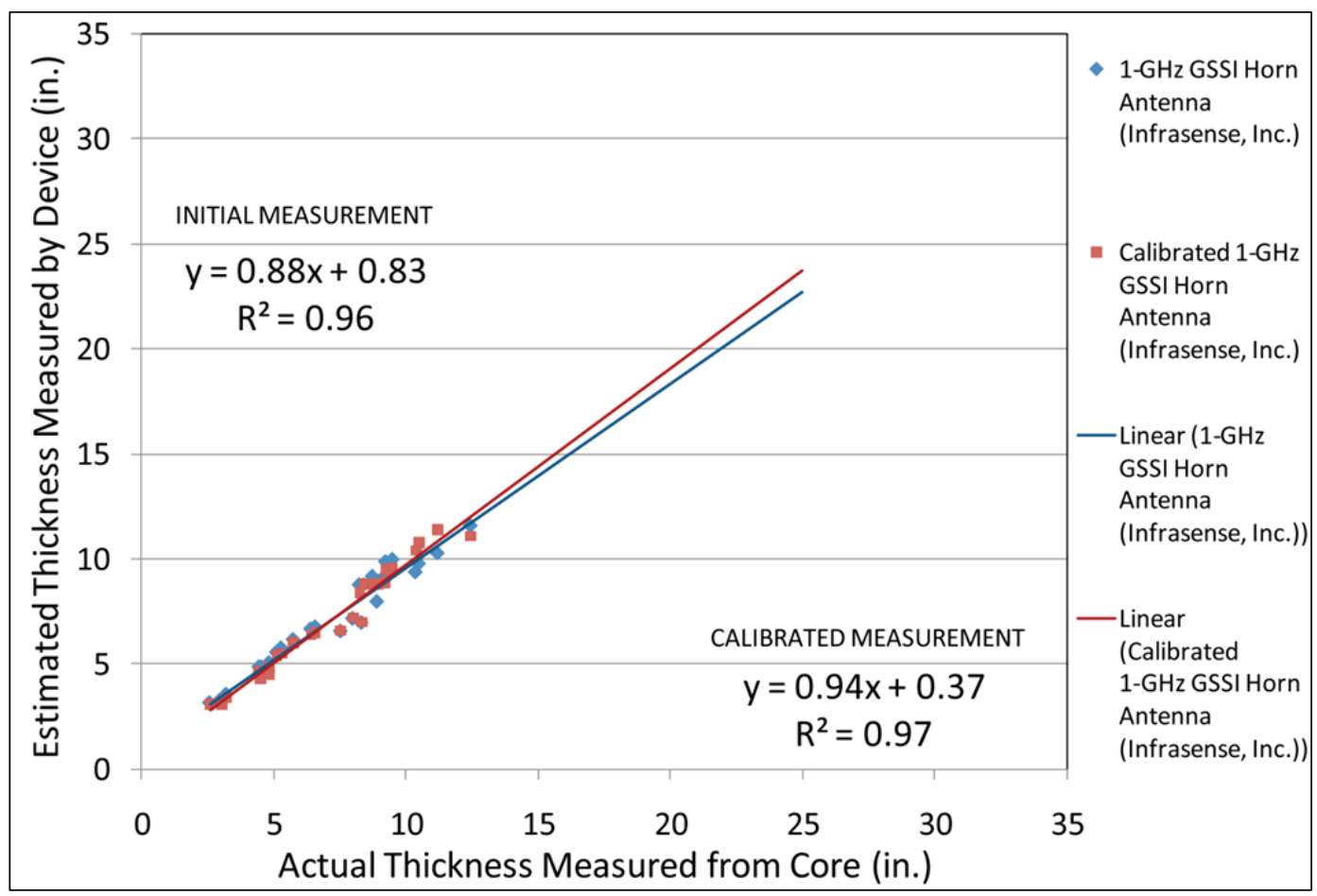

Figure 51. Correlation of actual core thickness and estimated thickness from the 1-GHz GSSI horn antenna (Infrasense, Inc.).

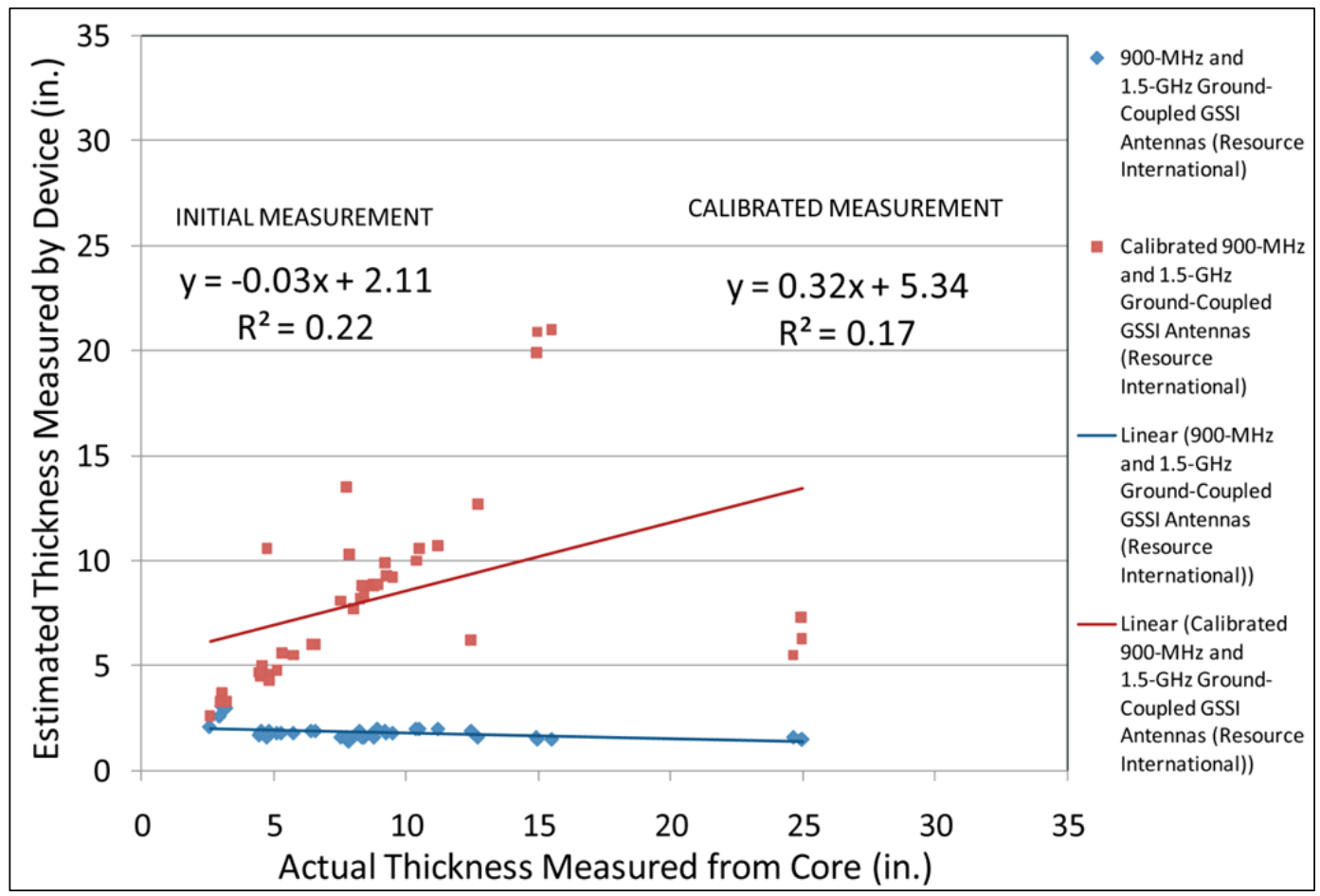

Figure 52. Correlation of actual core thickness and estimated thickness from the $900-\mathrm{MHz}$ and 1.5-GHz ground-coupled GSSI antennas (Resource International). 


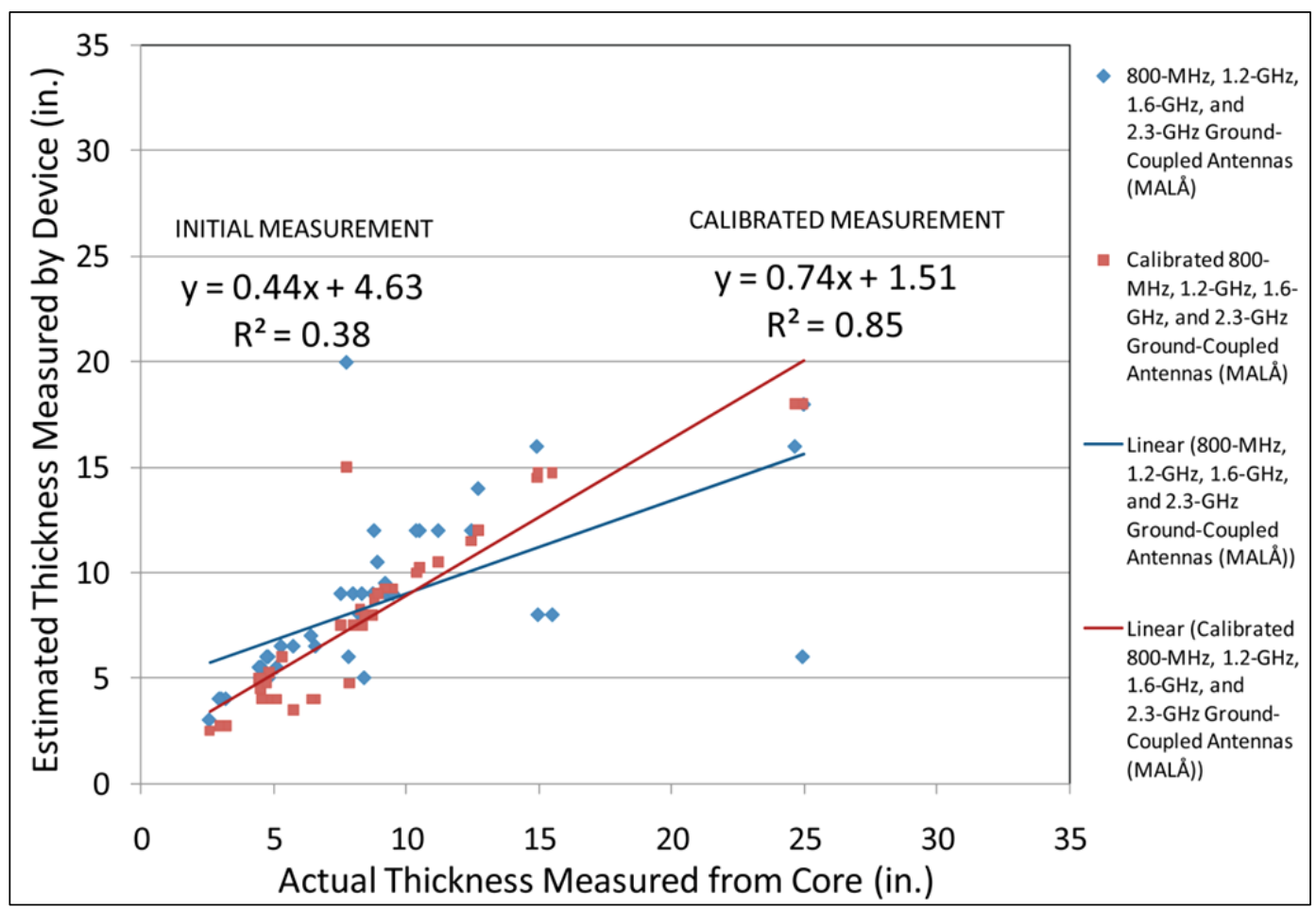

Figure 53. Correlation of actual core thickness and estimated thickness from the $800-\mathrm{MHz}$, 1.2-GHz, 1.6-GHz, and 2.3-GHz ground-coupled antennas (MALÅ).

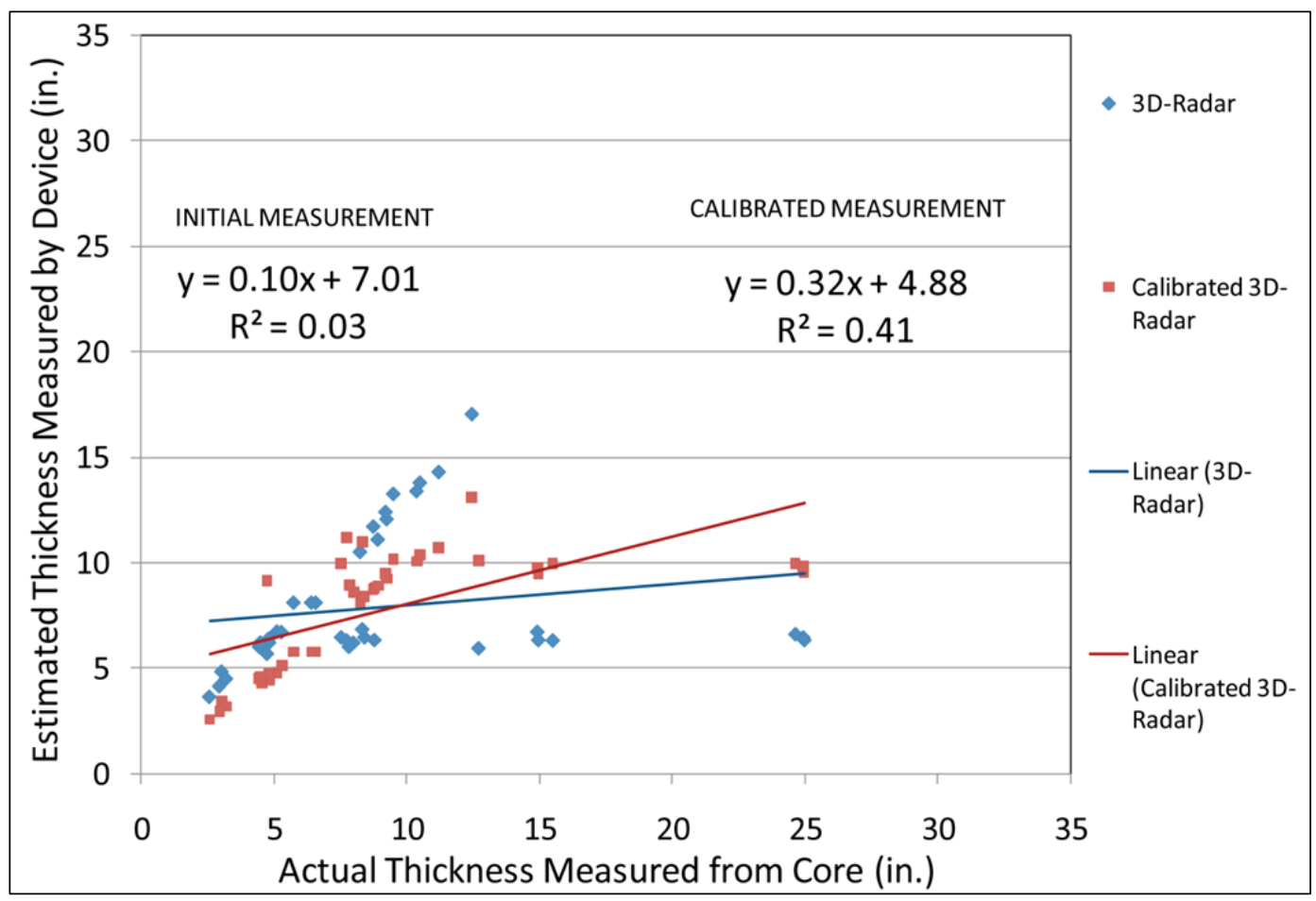

Figure 54. Correlation of actual core thickness and estimated thickness from 3D-Radar's GPR system. 


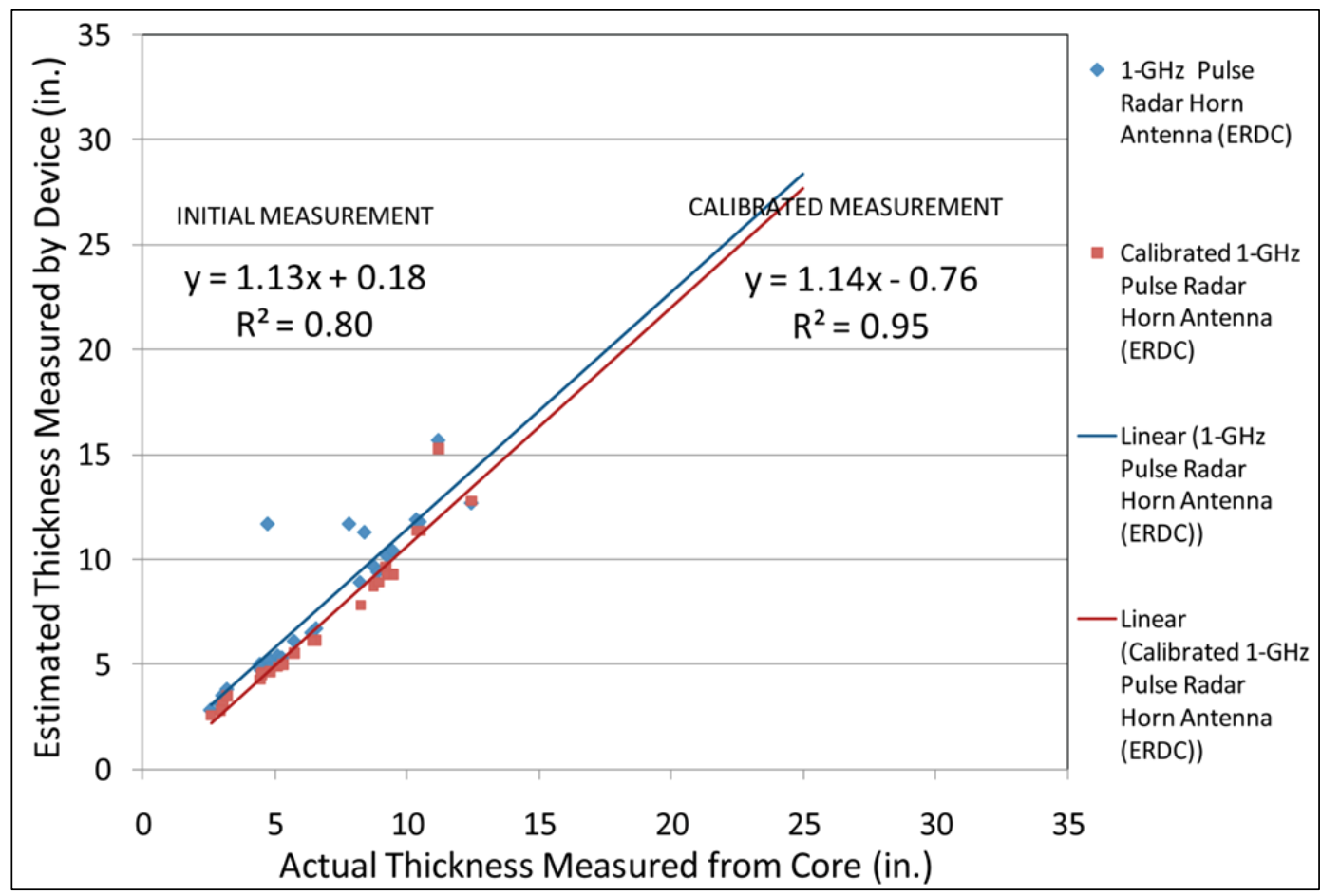

Figure 55. Correlation of actual core thickness and estimated thickness from the 1-GHz Pulse Radar horn antenna (ERDC).

The top four devices listed in Table 12 all performed well, with $\mathrm{R}^{2}$ values ranging from 0.95 to 0.98 and average errors from $0.32 \mathrm{in}$. to $0.51 \mathrm{in}$. The MIRA (University of Minnesota) performed the best overall without calibration, measuring $70 \%$ of the test locations with an average error of $0.51 \mathrm{in}$. The correlation of the device-measured thicknesses to core thicknesses was extremely high, with a $\mathrm{R}^{2}$ of 0.98 . The 1-GHz GSSI horn antenna (Infrasense, Inc.) provided good results, measuring $73 \%$ of the data with calibrated and uncalibrated average errors of $0.32 \mathrm{in.} \mathrm{and}$ 0.51 in., respectively. The calibrated 1-GHz Pulse Radar horn antenna (ERDC) also performed well, with an average error of 0.40 in. and $R^{2}$ of 0.95 , but had a lower percentage of test location measuring $63 \%$.

Many of the devices performed better on one material than the other, i.e. better on AC than PCC, or vice versa. Often, the GPR signal is attenuated in PCC pavements because of the salts and water content within the material, especially in newly placed PCC. The seismic and ultrasonic methods often have difficulty in AC pavements, especially if there is a temperature gradient in the pavement. 


\section{Results of AC sections}

As expected, GPR devices were more accurate for the AC sections, and they were able to measure the majority of the AC test locations. Table 13 lists the results for the AC test locations only, from the smallest error to the highest error. The GPR devices that were able to measure $100 \%$ of the data and have less than $0.5 \mathrm{in}$. error were the calibrated and uncalibrated 1GHz Pulse Radar horn antenna (ERDC), the calibrated 3D-Radar, and the calibrated and uncalibrated 1-GHz GSSI horn antenna (Infrasense, Inc.).

Table 13. Results for AC test locations, ranked from lowest error to highest error.

\begin{tabular}{|c|c|c|}
\hline Method & $\begin{array}{l}\text { Average } \\
\text { Error for } \\
\text { AC }^{1}\end{array}$ & $\begin{array}{l}\% \text { of } A C \\
\text { Test } \\
\text { Locations } \\
\text { Measured }^{2}\end{array}$ \\
\hline Calibrated 1-GHz Pulse Radar Horn Antenna (ERDC) & 0.19 & 100 \\
\hline Calibrated 3D-Radar & 0.24 & 100 \\
\hline Calibrated 1-GHz GSSI Horn Antenna (Infrasense, Inc.) & 0.24 & 100 \\
\hline 1-GHz GSSI Horn Antenna (Infrasense, Inc.) & 0.37 & 100 \\
\hline 1-GHz Pulse Radar Horn Antenna (ERDC) & 0.38 & 100 \\
\hline Calibrated Single 1.5-GHz Ground-Coupled GSSI Antenna (Infrasense, Inc.) & 0.55 & 95 \\
\hline $\begin{array}{l}\text { Calibrated 900-MHz and 1.5-GHz Ground-Coupled GSSI Antennas (Resource } \\
\text { International) }\end{array}$ & 0.58 & 100 \\
\hline 800-MHz, 1.2-GHz, 1.6-GHz, and 2.3-GHz ground-coupled antennas (MALÅ) & 0.62 & 100 \\
\hline Single 1.5-GHz Ground-Coupled GSSI Antenna (Infrasense, Inc.) & 0.62 & 100 \\
\hline MIRA (University of Minnesota) & 0.69 & 43 \\
\hline Calibrated 800-MHz, 1.2-GHz, 1.6-GHz, and 2.3-GHz ground-coupled antennas (MALÅ) & 0.71 & 100 \\
\hline Calibrated 2-GHz Ground-Coupled IDS Aladdin GPR (Olson Engineering) & 0.83 & 100 \\
\hline $\begin{array}{l}\text { Calibrated CMP Method with Two 1.5-GHz Ground-Coupled GSSI Antennas } \\
\text { (Infrasense, Inc.) }\end{array}$ & 0.83 & 100 \\
\hline CMP Method with Two 1.5-GHz Ground-Coupled GSSI Antennas (Infrasense, Inc.) & 1.16 & 100 \\
\hline Calibrated MISW (Olson Engineering) & 1.54 & 100 \\
\hline 2-GHz Ground-Coupled IDS Aladdin GPR (Olson Engineering) & 1.72 & 100 \\
\hline Calibrated Impact Echo (Olson Engineering) & 1.86 & 100 \\
\hline 3D-Radar & 2.03 & 100 \\
\hline Impact Echo (Olson Engineering) & 2.67 & 81 \\
\hline MISW (Olson Engineering) & 2.82 & 100 \\
\hline 900-MHz and 1.5-GHz Ground-Coupled GSSI Antennas (Resource International) & 4.01 & 100 \\
\hline
\end{tabular}

1 Error was calculated as the absolute difference between the thickness measured with the devices and the actual thickness of the core. The errors for all the AC test locations were averaged for each method.

2 Percentage of AC test locations measured because not all of the test locations were measured for each device. 
While the two horn antennas, the 1-GHz Pulse Radar horn antenna (ERDC) and the GSSI horn antenna (Infrasense, Inc.), provided accurate results, they also require post-processing that would have to be executed by a trained user. Additionally, the calibration process, which improved the data marginally, would require a trained user as well. The data could be used without the calibration, as the calibration process only decreased the error by $0.19 \mathrm{in}$. and $0.13 \mathrm{in}$. for the 1-GHz Pulse Radar horn antenna (ERDC) and 1-GHz GSSI horn antenna (Infrasense, Inc.), respectively. The horn antennas, as shown in Figure 27 and Figure 37, are quite large and bulky, and would require at least 30 min of setup time, prior to using. However, once they are set up, they can collect data easily.

The 3D-Radar system, as shown in Figure 36, is extremely large and bulky. The calibrated results were very accurate for the AC pavement section, with an average error of 0.24 in., but the error from the initial data was quite larger (2.03 in.). The post-processing for the thickness data would require a trained user, and the calibration process would be required to achieve an error less than $0.5 \mathrm{in}$.

The ground-coupled antennas did not perform as well as the horn antennas; and if the ground-coupled antennas were used, they would require calibration because dielectric constants are not actively measured by the devices. However, the ground-coupled systems were very small and portable. The Infrasense single ground-coupled antenna and Resource International ground-coupled antennas were actually made by the same manufacturer, GSSI, and also had similar results when calibrated ( $0.55 \mathrm{in}$. for Infrasense, and 0.58 in. for Resource International). Both of these devices were able to measure at least $95 \%$ of the AC test locations. MAL $\AA$, which also used ground-coupled antennas, also had an error close to the other ground-coupled antennas (0.62 in.). The calibration process did not appear to be beneficial, and the error was only 0.09 in. greater for the calibration process.

The seismic methods, as expected, did not perform well on the AC test sections, as the average errors for these methods was at least $0.69 \mathrm{in}$. The MIRA (University of Minnesota) had the lowest error of the seismic and ultrasonic methods, but it was only able to measure $43 \%$ of the AC test locations. The other of these type devices had errors of at least $1.54 \mathrm{in}$. for calibrated and uncalibrated data. 


\section{Results of PCC sections}

MIRA (University of Minnesota) was the only device that was able to measure on all the PCC test locations with a low error (0.43 in.). The MIRA was easy to use, provided real time measurements, and did not require calibration to achieve this accuracy for the PCC test locations.

The calibrated MISW (Olson Engineering) had a very low error of 0.34 in. as well, but only $53 \%$ of the PCC test locations were measured. However, this was not because the system was unable to collect the data, but because the equipment was broken during testing. The uncalibrated MISW (Olson Engineering) had an error of $0.58 \mathrm{in}$., which was only 0.24 in. higher than the calibrated MISW. However, the MISW is quite time and labor intensive for both data collection and processing. Olson has been working on an automated MISW to reduce the effort required to execute the data collection, but it was not available during the time of testing.

The calibrated 1-GHz GSSI horn antenna (Infrasense, Inc) had a relatively low error of $0.51 \mathrm{in}$., but was only able to measure $42 \%$ of the PCC test location. As expected, the GPR signal was attenuated by the PCC pavement material.

The remaining devices had errors that were high and/ or low ability to measure all of the test locations (Table 14).

Table 14. Results for PCC test locations, ranked from lowest error to highest error.

\begin{tabular}{|l|c|c|}
\hline & \multicolumn{1}{|c|}{$\begin{array}{l}\text { of PCC } \\
\text { Test } \\
\text { Locations } \\
\text { Method }\end{array}$} & $\begin{array}{l}\text { Average } \\
\text { Error for } \\
\text { PCC }^{1}\end{array}$ \\
\hline Calibrated MISW (Olson Engineering) & 0.34 & 53 \\
\hline MIRA (University of Minnesota) & 0.43 & 100 \\
\hline Calibrated 1-GHz GSSI Horn Antenna (Infrasense, Inc.) & 0.51 & 42 \\
\hline MISW (Olson Engineering) & 0.58 & 53 \\
\hline 1-GHz GSSI Horn Antenna (Infrasense, Inc.) & 0.87 & 42 \\
\hline Calibrated Single 1.5-GHz Ground-Coupled GSSI Antenna (Infrasense, Inc.) & 1.40 & 63 \\
\hline Calibrated 1-GHz Pulse Radar Horn Antenna (ERDC) & 1.48 & 21 \\
\hline Calibrated Impact Echo (Olson Engineering) & 1.78 & 100 \\
\hline $\begin{array}{l}\text { Calibrated 800-MHz, 1.2-GHz, 1.6-GHz, and 2.3-GHz ground-coupled antennas } \\
\text { (MALA) }\end{array}$ & 1.90 & 100 \\
\hline Single 1.5-GHz Ground-Coupled GSSI Antenna (Infrasense, Inc.) & 1.93 & 63 \\
\hline
\end{tabular}




\begin{tabular}{|l|c|l|}
\hline Method & $\begin{array}{l}\text { Average } \\
\text { Error for } \\
\text { PCC }^{1}\end{array}$ & $\begin{array}{l}\text { \% of PCC } \\
\text { Test } \\
\text { Locations } \\
\text { Measured }^{2}\end{array}$ \\
\hline Impact Echo (Olson Engineering) & 1.94 & 100 \\
\hline $\begin{array}{l}\text { Calibrated CMP Method with Two 1.5-GHz Ground-Coupled GSSI Antennas } \\
\text { (Infrasense, Inc.) }\end{array}$ & 2.39 & 58 \\
\hline CMP Method with Two 1.5-GHz Ground-Coupled GSSI Antennas (Infrasense, Inc.) & 2.58 & 63 \\
\hline 1-GHz Pulse Radar Horn Antenna (ERDC) & 3.07 & 37 \\
\hline Calibrated 2-GHz Ground-Coupled IDS Aladdin GPR (Olson Engineering) & 4.03 & 100 \\
\hline Calibrated 3D-Radar & 4.18 & 100 \\
\hline 800-MHz, 1.2-GHz, 1.6-GHz, and 2.3-GHz ground-coupled antennas (MALÅ) & 4.31 & 100 \\
\hline $\begin{array}{l}\text { Calibrated 900-MHz and 1.5-GHz Ground-Coupled GSSI Antennas (Resource } \\
\text { International) }\end{array}$ & 4.64 & 100 \\
\hline 3D-Radar & 5.93 & 100 \\
\hline 2-GHz Ground-Coupled IDS Aladdin GPR (Olson Engineering) & 7.52 & 100 \\
\hline 900-MHz and 1.5-GHz Ground-Coupled GSSI Antennas (Resource International) & 10.72 & 100 \\
\hline
\end{tabular}

${ }^{1}$ Error was calculated as the absolute difference between the thickness measured with the devices and the actual thickness of the core. The errors for all the test locations were averaged for each method.

2 Percentage of PCC test locations measured because not all of the test locations were measured for each device.

\section{Effect of Calibration}

The calibration process varied slightly from device to device, as discussed earlier in Chapter 4. All of the devices tested in this study provided calibrated data, except for MIRA. The University of Minnesota does have a calibration process, but it is quite intensive and was not deemed necessary in this study.

The calibration process, as a rule, improved the accuracy of the devices. For AC test locations, all of the devices improved with calibration, except for the MALA GPR ground-coupled antennas, as shown in Table 15. With the PCC test locations, all of the devices improved with calibration, as shown in Table 16. 
Table 15. Comparison of estimated data before and after calibration for AC test locations.

\begin{tabular}{|c|c|c|c|c|}
\hline Method & $\begin{array}{l}\text { Initial Error }{ }^{1} \\
\text { for AC Test } \\
\text { Locations } \\
\text { in. }\end{array}$ & $\begin{array}{l}\text { After } \\
\text { Calibration } \\
\text { Error } \\
\text { in. }\end{array}$ & $\begin{array}{l}\text { Difference } \\
\text { between } \\
\text { Initial and } \\
\text { Calibrated } \\
\text { Errors } \\
\text { in. }\end{array}$ & $\begin{array}{l}\text { \% Improve- } \\
\text { ment after } \\
\text { Calibration }\end{array}$ \\
\hline $\begin{array}{l}\text { 900-MHz and } 1.5-\mathrm{GHz} \text { Ground-Coupled GSSI } \\
\text { Antennas (Resource International) }\end{array}$ & 4.01 & 0.58 & 3.43 & 86 \\
\hline 3D-Radar & 2.03 & 0.24 & 1.79 & 88 \\
\hline MISW (Olson Engineering) & 2.82 & 1.54 & 1.29 & 46 \\
\hline $\begin{array}{l}\text { 2-GHz Ground-Coupled IDS Aladdin GPR (Olson } \\
\text { Engineering) }\end{array}$ & 1.72 & 0.83 & 0.89 & 52 \\
\hline Impact Echo (Olson Engineering) & 2.67 & 1.86 & 0.82 & 31 \\
\hline $\begin{array}{l}\text { CMP Method with Two 1.5-GHz Ground-Coupled } \\
\text { GSSI Antennas (Infrasense, Inc.) }\end{array}$ & 1.16 & 0.83 & 0.33 & 29 \\
\hline 1-GHz Pulse Radar Horn Antenna (ERDC) & 0.38 & 0.19 & 0.19 & 49 \\
\hline 1-GHz GSSI Horn Antenna (Infrasense, Inc.) & 0.37 & 0.24 & 0.12 & 34 \\
\hline $\begin{array}{l}\text { Single 1.5-GHz Ground-Coupled GSSI Antenna } \\
\text { (Infrasense, Inc.) }\end{array}$ & 0.62 & 0.55 & 0.07 & 11 \\
\hline $\begin{array}{l}\text { 800-MHz, 1.2-GHz, 1.6-GHz, and 2.3-GHz } \\
\text { ground-coupled antennas (MALÅ) }\end{array}$ & 0.62 & 0.71 & -0.09 & -15 \\
\hline MIRA (University of Minnesota) & 0.69 & N/A & N/A & N/A \\
\hline
\end{tabular}

${ }^{1}$ Error was calculated as the absolute difference between the thickness measured with the devices and the actual thickness of the core. The errors for all the test locations were averaged for each method.

Table 16. Comparison of estimated data before and after calibration for PCC test locations.

\begin{tabular}{|c|c|c|c|c|}
\hline Method & $\begin{array}{l}\text { Initial Error }{ }^{1} \\
\text { for PCC Test } \\
\text { Locations } \\
\text { in. }\end{array}$ & $\begin{array}{l}\text { After } \\
\text { Calibration } \\
\text { Error } \\
\text { in. }\end{array}$ & $\begin{array}{l}\text { Difference } \\
\text { between } \\
\text { Initial and } \\
\text { Calibrated } \\
\text { Errors } \\
\text { in. }\end{array}$ & $\begin{array}{l}\text { \% Improve } \\
\text { ment after } \\
\text { Calibration }\end{array}$ \\
\hline $\begin{array}{l}900-\mathrm{MHz} \text { and } 1.5-\mathrm{GHz} \text { Ground-Coupled GSSI } \\
\text { Antennas (Resource International) }\end{array}$ & 10.72 & 4.64 & 6.07 & 57 \\
\hline $\begin{array}{l}\text { 2-GHz Ground-Coupled IDS Aladdin GPR (Olson } \\
\text { Engineering) }\end{array}$ & 7.52 & 4.03 & 3.49 & 46 \\
\hline $\begin{array}{l}\text { 800-MHz, 1.2-GHz, 1.6-GHz, and 2.3-GHz } \\
\text { ground-coupled antennas (MALÅ) }\end{array}$ & 4.31 & 1.90 & 2.41 & 56 \\
\hline 3D-Radar & 5.93 & 4.18 & 1.74 & 29 \\
\hline 1-GHz Pulse Radar Horn Antenna (ERDC) & 3.07 & 1.48 & 1.59 & 52 \\
\hline
\end{tabular}




\begin{tabular}{|l|l|l|l|l|}
\hline & $\begin{array}{l}\text { Initial Error1 } \\
\text { for PCC Test } \\
\text { Locations } \\
\text { in. }\end{array}$ & $\begin{array}{l}\text { After } \\
\text { Calibration } \\
\text { Error } \\
\text { in. }\end{array}$ & $\begin{array}{l}\text { Difference } \\
\text { between } \\
\text { Initial and } \\
\text { Calibrated } \\
\text { Errors } \\
\text { in. }\end{array}$ & $\begin{array}{l}\text { \% Improve- } \\
\text { ment after } \\
\text { Calibration }\end{array}$ \\
\hline $\begin{array}{l}\text { Single 1.5-GHz Ground-Coupled GSSI Antenna } \\
\text { (Infrasense, Inc.) }\end{array}$ & 1.93 & 1.40 & 0.52 & 27 \\
\hline 1-GHz GSSI Horn Antenna (Infrasense, Inc.) & 0.87 & 0.51 & 0.36 & 41 \\
\hline MISW (Olson Engineering) & 0.58 & 0.34 & 0.24 & 42 \\
\hline $\begin{array}{l}\text { CMP Method with Two 1.5-GHz Ground-Coupled } \\
\text { GSSI Antennas (Infrasense, Inc.) }\end{array}$ & 2.58 & 2.39 & 0.19 & 7 \\
\hline Impact Echo (Olson Engineering) & 1.94 & 1.78 & 0.16 & 8 \\
\hline MIRA (University of Minnesota) & 0.43 & N/A & N/A & N/A \\
\hline
\end{tabular}

${ }^{1}$ Error was calculated as the absolute difference between the thickness measured with the devices and the actual thickness of the core. The errors for all the test locations were averaged for each method.

Generally, the ground-coupled GPR systems improved by a greater margin because the dielectric constants are not measured during the initial data collection, and the amount of improvement depends on how close the assumed dielectric constant was to the actual dielectric constant. If the assumed value is close, then the accuracy of the initial results will be good; however, there is not a way to verify the assumed value without further investigation, such as coring. The horn antennas showed more improvement with calibration in the PCC test sections than in the AC test sections. The seismic methods appeared to have required calibration for the AC test locations more than the PCC test locations for better accuracy. This is probably due to the variability in temperature and modulus in the AC pavement. 


\section{Conclusions and Recommendations}

The ERDC performed field evaluations of nondestructive testing devices to measure pavement thickness. Devices were down-selected during a literature review, and these devices were tested at 40 test locations at the ERDC as a side-by-side comparison. The error, defined as the absolute difference between the deviced measured thickness and actual core thickness, was used to gauge the performance of the devices.

\section{Conclusions}

The following conclusions were derived from the evaluation of selected nondestructive thickness measurement devices:

1. It appears that separate devices are required for accurate thickness prediction on AC and PCC pavement. The devices that work well for AC pavements are the air-coupled GPR devices, but these devices have difficulty penetrating through PCC pavements. Conversely, the devices that work well for PCC pavements are the seismic and ultrasonic ones, but do not perform as well on AC pavements.

2. Generally, calibration, by taking cores and recalculating the thickness data, improved the performance of the device. Coring in onelocation per pavement type is recommended for all devices, except for the MIRA, for optimal accuracy.

3. The MIRA (University of Minnesota) performed the best overall on PCC and AC pavements. MIRA's performance on PCC was very good. The error for MIRA on PCC pavements was low (0.43 in.), and the device was able to measure $100 \%$ of the PCC test locations. The error for AC pavements was only slightly higher at $0.69 \mathrm{in}$., but only $43 \%$ of the AC test locations were measured. The University of Minnesota is currently working on an algorithm to better process the AC pavement data to improve the consistency of data collection on AC pavements. Additionally, testing at night, or during oolder weather, would reduce the temperature gradient and possibly increase data collection on AC with the MIRA. One important benefit to the MIRA device is that no experience is required to collect the data and obtain thickness measurements.

4. The air-coupled horn antenna GPR methods performed well in AC pavements by giving low error thickness measurements, and these could measure data the majority of the time. While calibration with cores 
improved the data, it was not by a high margin; therefore, calibration could be eliminated, if necessary.

5. Ground-coupled GPR antennas required calibration cores to improve the accuracy because their accuracy depended on how close the estimated dielectric constant was to the actual pavement dielectric constant. Determining which ground-coupled frequency to use is difficult because penetration depends on the material. As a general rule, the lower the frequency, the deeper the penetration.

6. The MISW (Olson Engineering) showed good potential in providing accurate data for PCC test locations with low average errors of $0.34 \mathrm{in}$. and 0.58 in. for calibrated and uncalibrated measurements, respectively. However, it was difficult to fully evaluate this device because it required repair beforeall PCC test locations were measured.

7. Ease of use would be extremely important for the implementation of these devices. The MIRA would require the least amount of training and experience. Simply following step-by-step instructions would result in accurate thickness measurements. The GPR methods, both horn antennas and ground-coupled antennas, would require a trained user with experience, especially if the layer interfaces are difficult to detect. The MISW (Olson Engineering) was extremely time intensive, and would require a trained user to post-process the data.

8. Borescopes were not found to be effective at measuring pavement thickness in this evaluation. Use of the borescope is not nondestructive, but it was evaluated as a potential minimally destructive method. However, it is too difficult to create a clean inspection hole to view layer interfaces, and it is difficult to obtain a clear picture with the borescope camera.

\section{Recommendations}

Based on the evaluation described in this report, the following recommendations are provided:

1. For PCC pavements, the MIRA (University of Minnesota) system is recommended. It is a small system that can be easily added to the current evaluation package. It is consistent on PCC pavements and is easy to use.

2. If nondestructive AC pavement thicknesses are desired, then an aircoupled horn antenna is recommended. However, because this system is bulky, small ground-coupled antennas could be beneficial as well, but cores would be required to assure quality data collection. More than one ground-coupled antenna would be recommended to accommodate testing on varying pavement thicknesses. 
3. Additional research to improve the accuracy of ground-coupled GPR systems should be performed.

4. Additional research to simplify or automate the post-processing of GPR data is required to improve the ease of use of those systems. 


\section{References}

Al-Qadi, I. L. and S. Lahouar. 2005. Measuring layer thicknesses with GPR - theory to practice. Construction and Building Materials 19:763-772.

Al-Qadi, I. L., S. Lahouar, K. Jiang, K. K. McGhee, and D. Mokarem. 2005. Accuracy of ground-penetrating radar for estimating rigid and flexible pavement layer thicknesses. Transportation Research Record: J ournal of the Transportation Research Board, Transportation Research Board of the National Academies, Washington, DC 1940: 69-78.

American Society for Testing and Materials. 2003. Standard test method for use of the dynamic cone penetrometer in shallow pavement applications. Designation: D6951, Philadelphia, PA.

. 2010a. Standard test method for compressive strength of cylindrical concrete specimens. Designation: C39/ C39M-10, Philadelphia, PA.

2010b. Standard test method for flexural strength of concrete (using simple beam with third-point loading). Designation: C78/C78M-10, Philadelphia, PA.

2010c. Standard test method for in-place density and water content of soil and soil-aggregate by nuclear methods (shallow depths). Designation: D693810, Philadelphia, PA.

De Souza, T., A. P. Annan, J . D. Redman, and N. Hu. 2004. Monitoring the GPR response of curing concrete. Proc. $16^{\text {th }}$ CDNDT 2004-World Conf. NDT, Montreal, Canada.

Grau, R. 1993. Effects of variable tire pressure on road surfacings, volume I: Design, construction, behavior under traffic, and test results. ERDC Technical Report GL-93-20. Vicksburg, MS: U.S. Army Waterways Experiment Station.

Gopaldas, J., R. B. Lodge, and A. Wright. 2009. Developing a new method for measuring pavement layer thickness. Published Project Report, PPR390. Transport Research Laboratory.

Halabe, U. B., A. Sotoodehnia, K. R. Maser, and E. A. Kausel. 1993. Modeling the electromagnetic properties of concrete. ACI Materials J ournal 90(6):552-563.

Hoegh, K., L. Khazanovich, and H. T. Yu. 2011. Ultrasonic tomography technique for evaluation of concrete pavements. Paper submitted to the Transportation Research Board 88th Annual Meeting, 23-27J anuary 2011.

Infrasense, Inc. 2010. Measuring pavement thickness using ground penetrating radar methods. Final report, submitted to U.S. Army Engineer Research and Development Center on December 29, 2010.

Lahouar, S. and I. L. Al-Qadi. 2008. Automatic detection of multiple pavement layers from GPR data. NDT\&E International 41:69-81. 
MALÅ Geoscience USA, Inc. 2010. USACE Pavement thickness study. Report, submitted to U.S. Army Engineer Research and Development Center on 18 November 2010.

Maser, K. R., T. J . Holland, and R. Roberts. 2002. Nondestructive measurement of layer thickness on newly constructed asphalt pavement. Proc. of the Pavement Evaluation Conference, Roanoke, VA, October 21-25, 2002.

Maser, K. R., J . Holland, R. Roberts, and J . Popovics. 2006. NDE methods for quality assurance of new pavement thickness. International J ournal of Pavement Engineering 7(1):1-10.

Noureldin, S., K. Zhu, D. Harris, and S. Li. 2005. Non-destructive estimation of pavement thickness, structural number and subgrade resilience along INDOT highways, final report. FHWA/IN/J TRP-2004/35, SPR-2408.

Olson, L. D., C. L. Barnes, M. P. Hergert, and P. K. Miller. 2010. Multiple Impact Surface Waves for Determination of Pavement System Moduli for Assessment and Design. Symposium on the Application of Geophysics to Environmental and Engineering Problems (SAGEEP), Keystone, Colorado, April 10-15, 2010.

Olson Engineering. 2001. Non-destructive testing and evaluation slab thickness investigation. Olson Final Report for J ob No. R115, submitted to ERDC on 11 March 2011.

Olson, L. D., and C. C. Wright. 1990. Nondestructive testing for repair and rehabilitation. Concrete International: Design \& Construction, March, 58-64.

Pulse Radar. 1995. Ground penetrating radar for pavement applications. Unpublished technical report. Houston, TX: Pulse Radar.

Sansalone, M. 1997. Impact-echo: the complete story. ACI Structural J ournal 94(6):777786.

Scullion, T., C. Lau, and Y. Chen. 1994. Implementation of the Texas Ground Penetrating Radar System. Research Report 1233-1. College Station, TX: Texas Transportation Institute. 


\section{Appendix A: Testing Results}




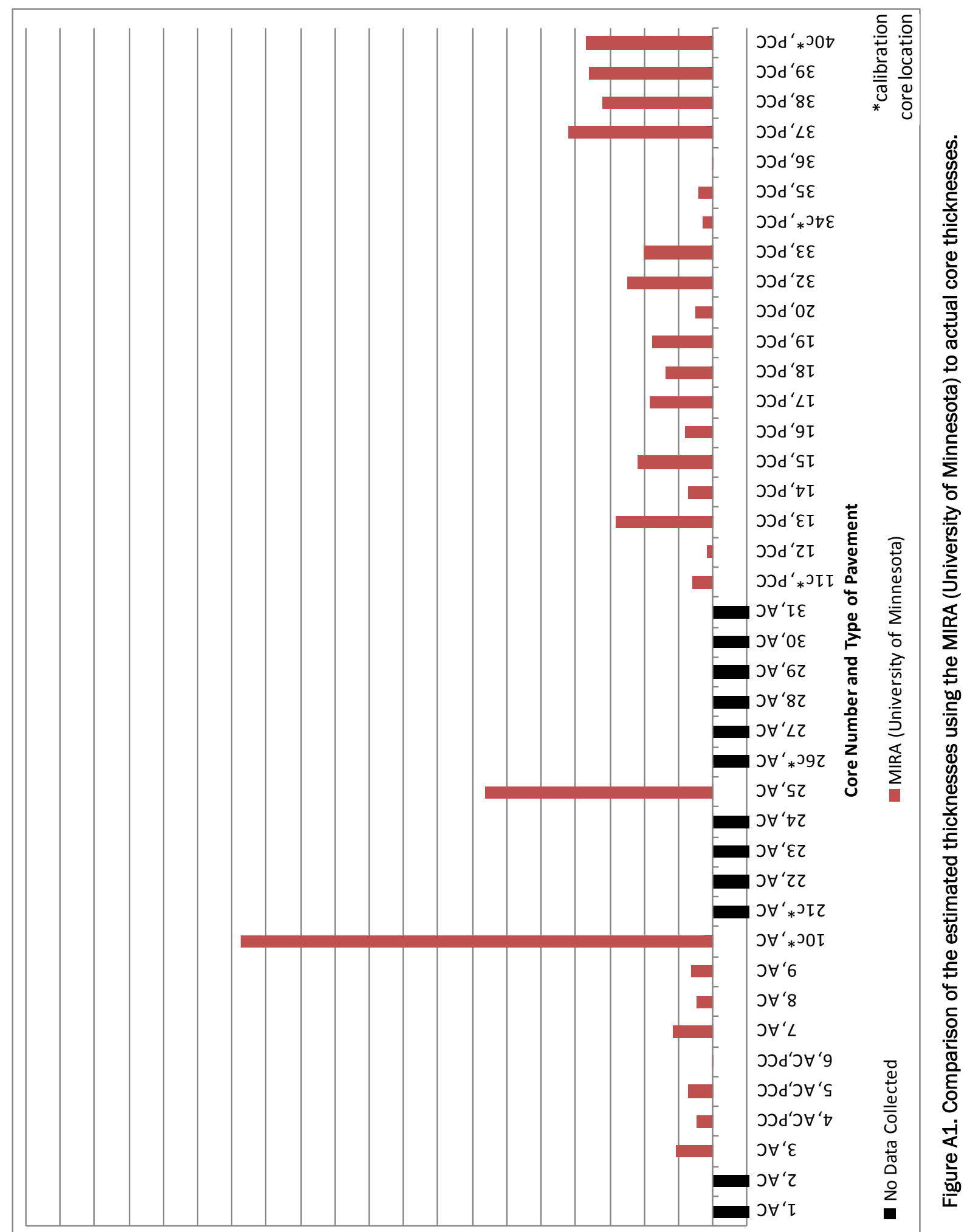

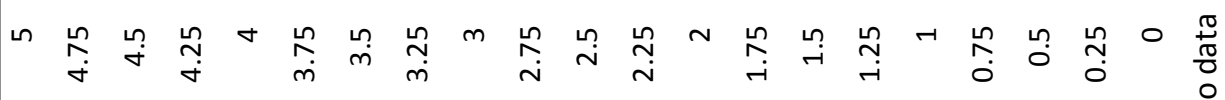

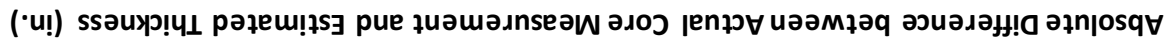




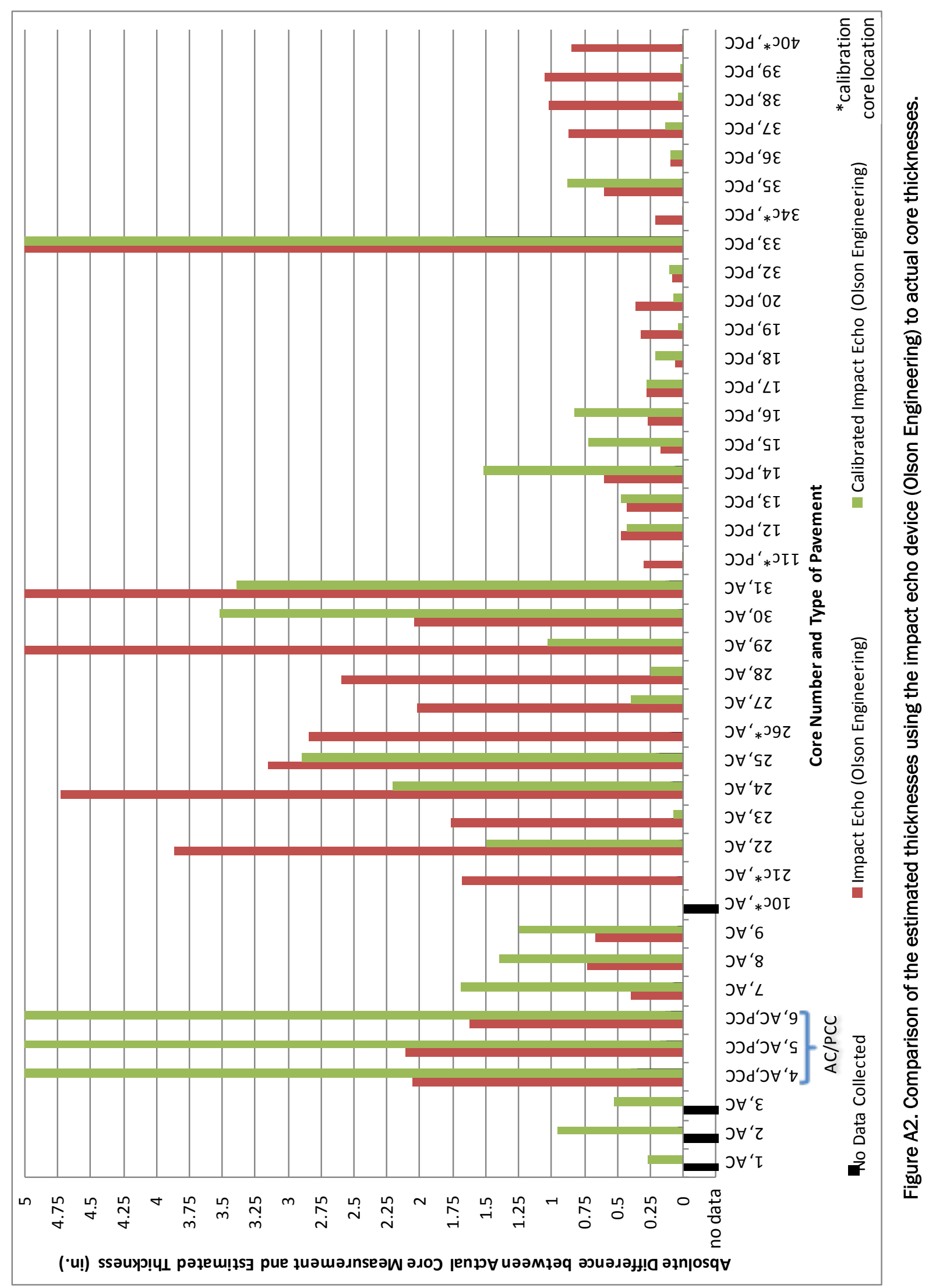




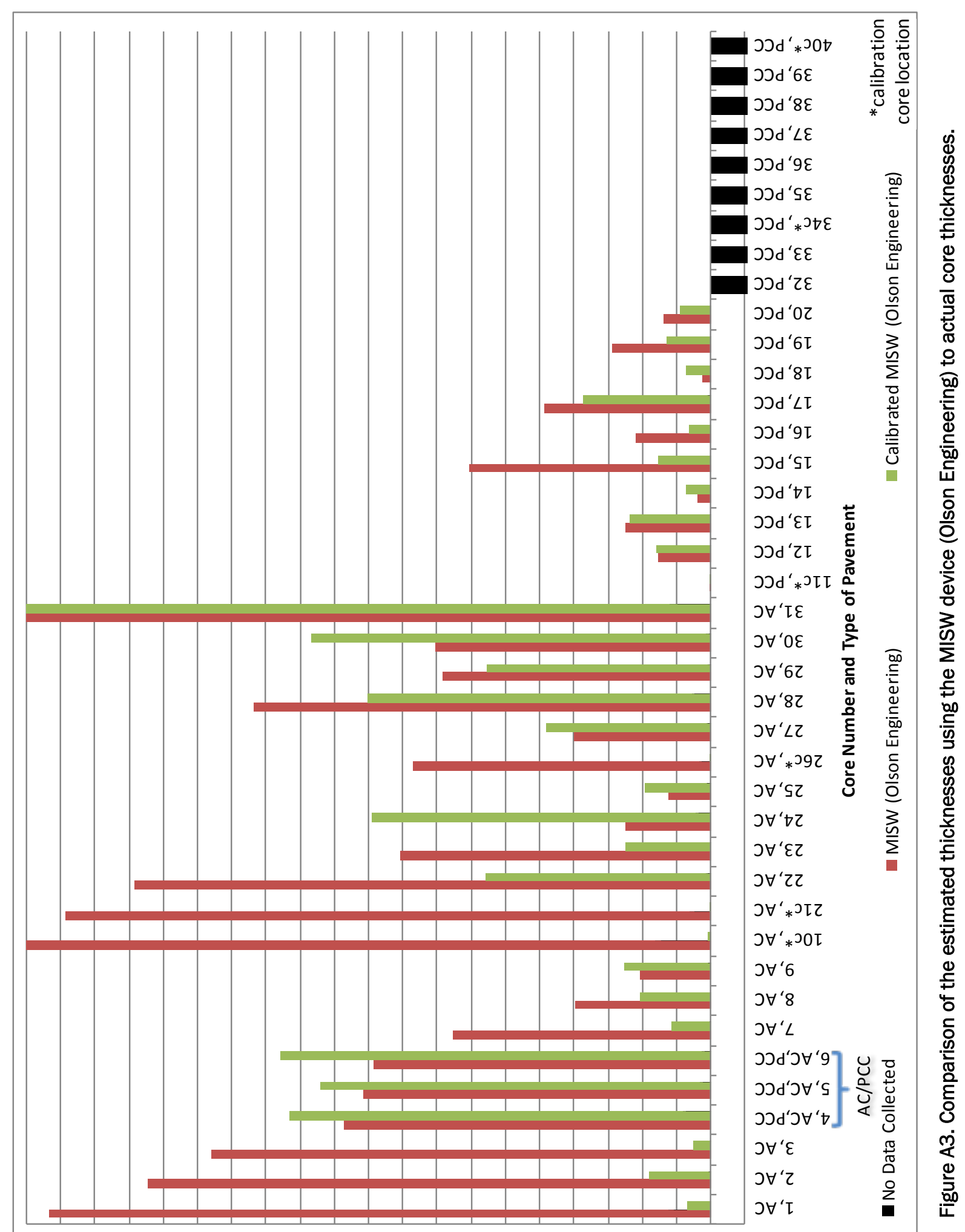

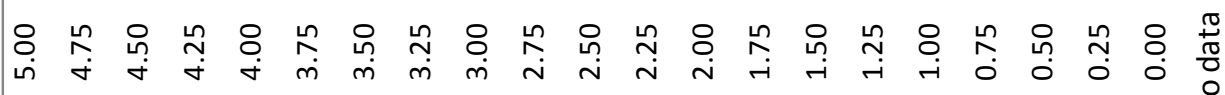

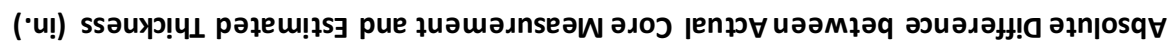




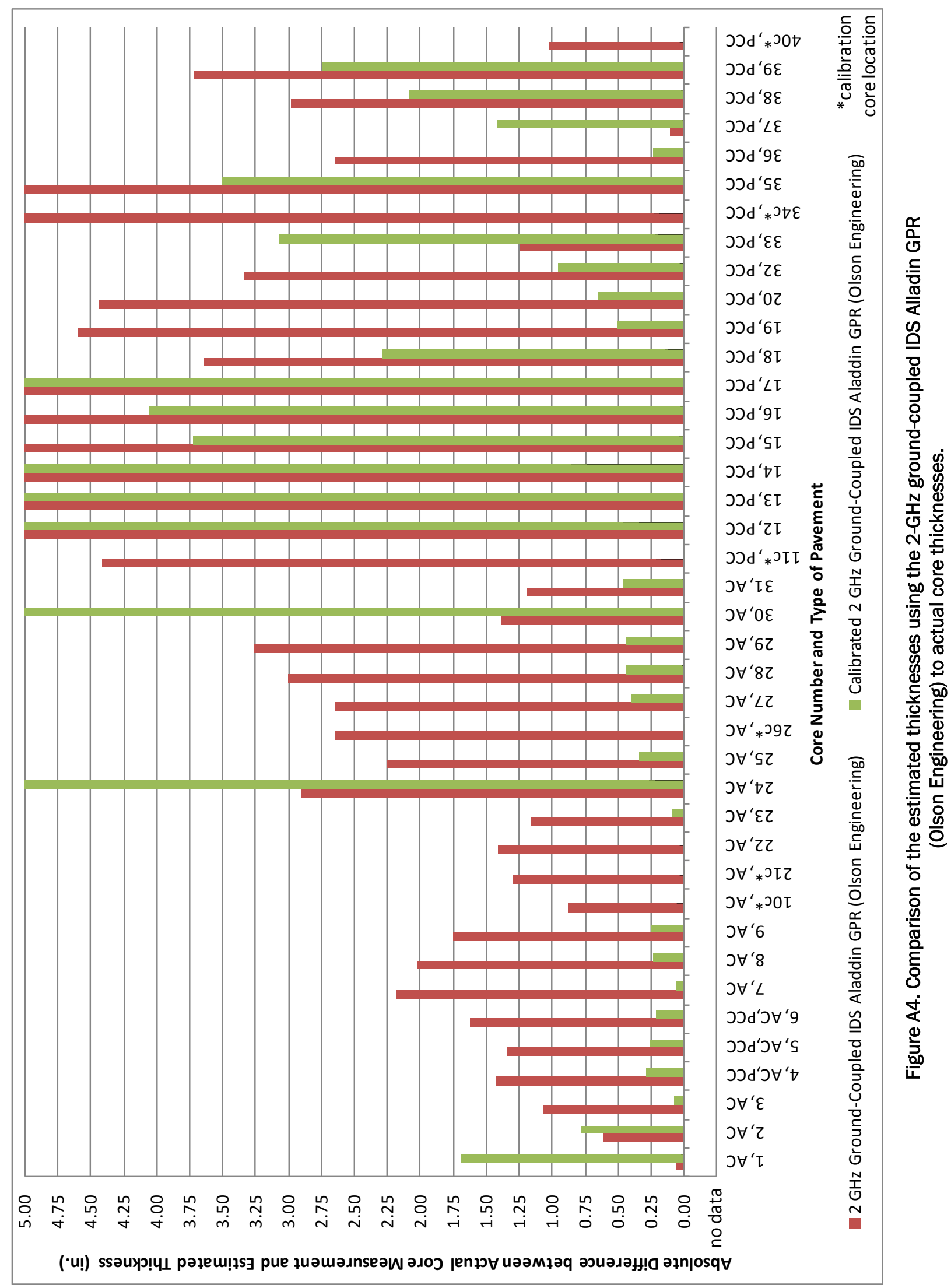




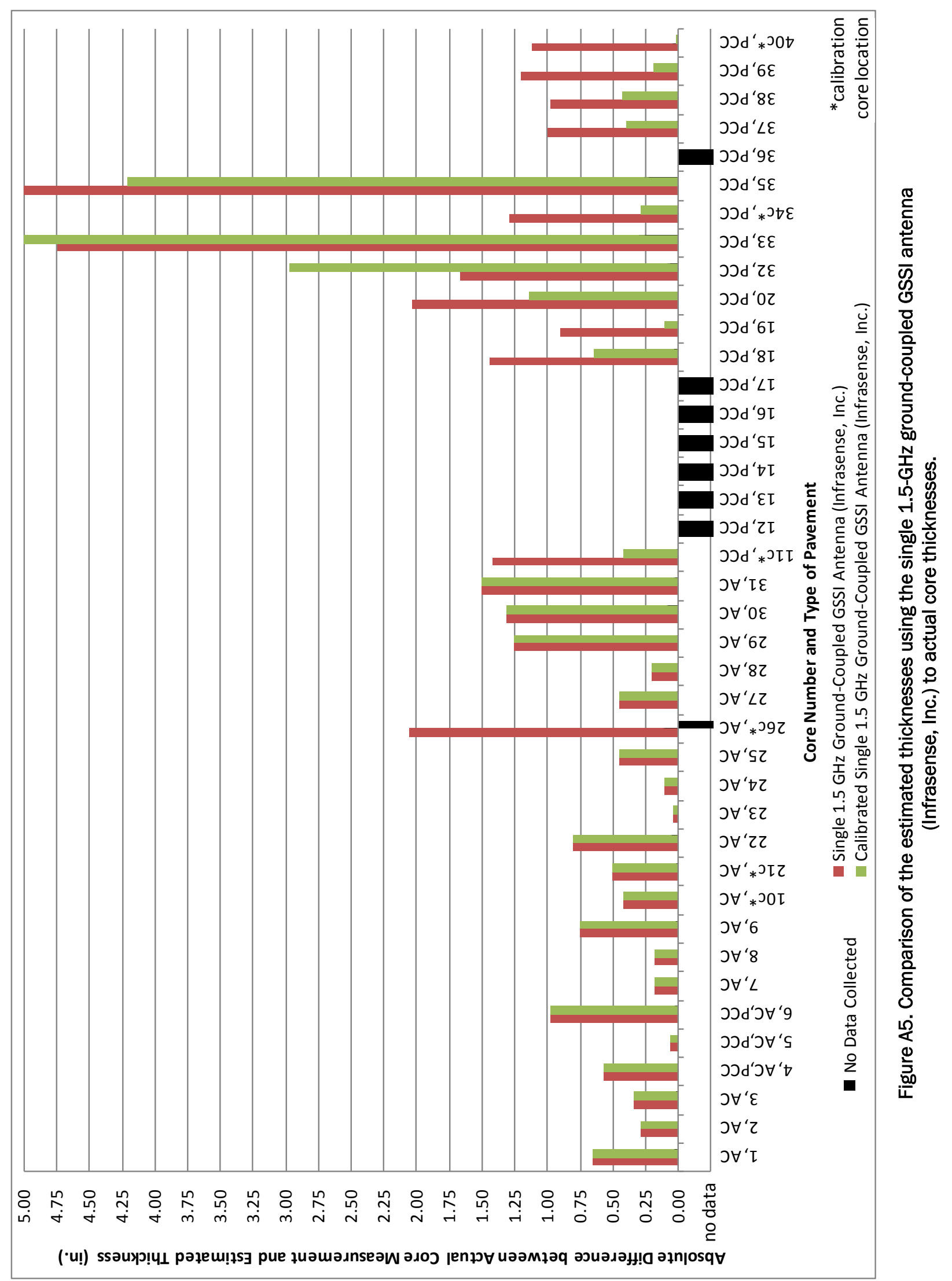




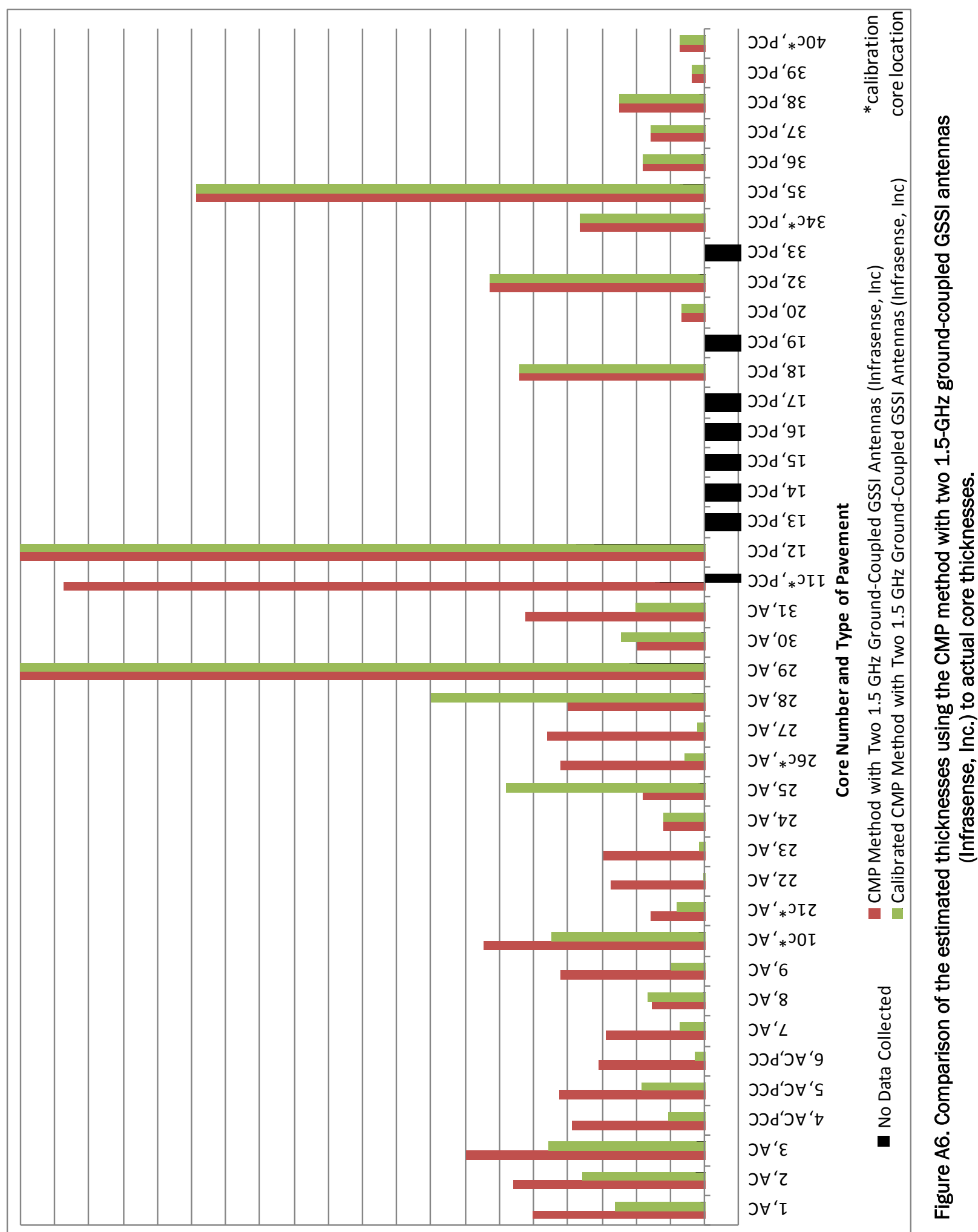

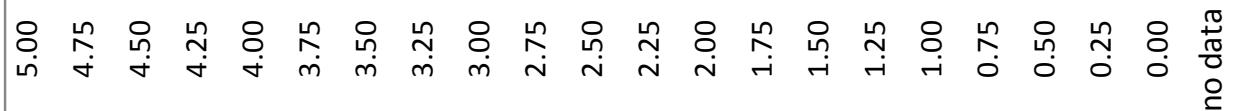

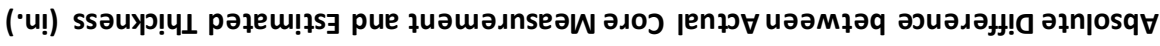




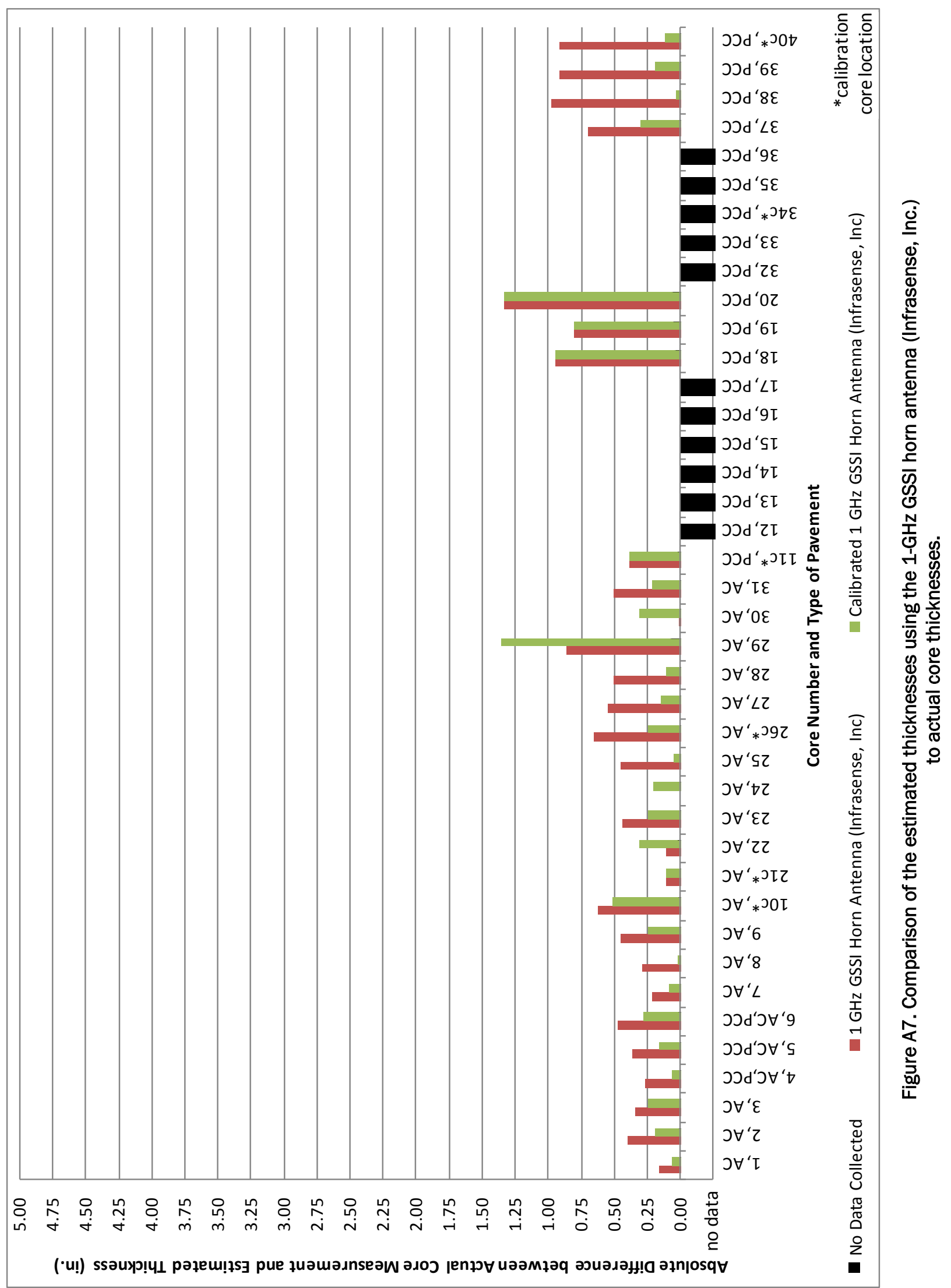




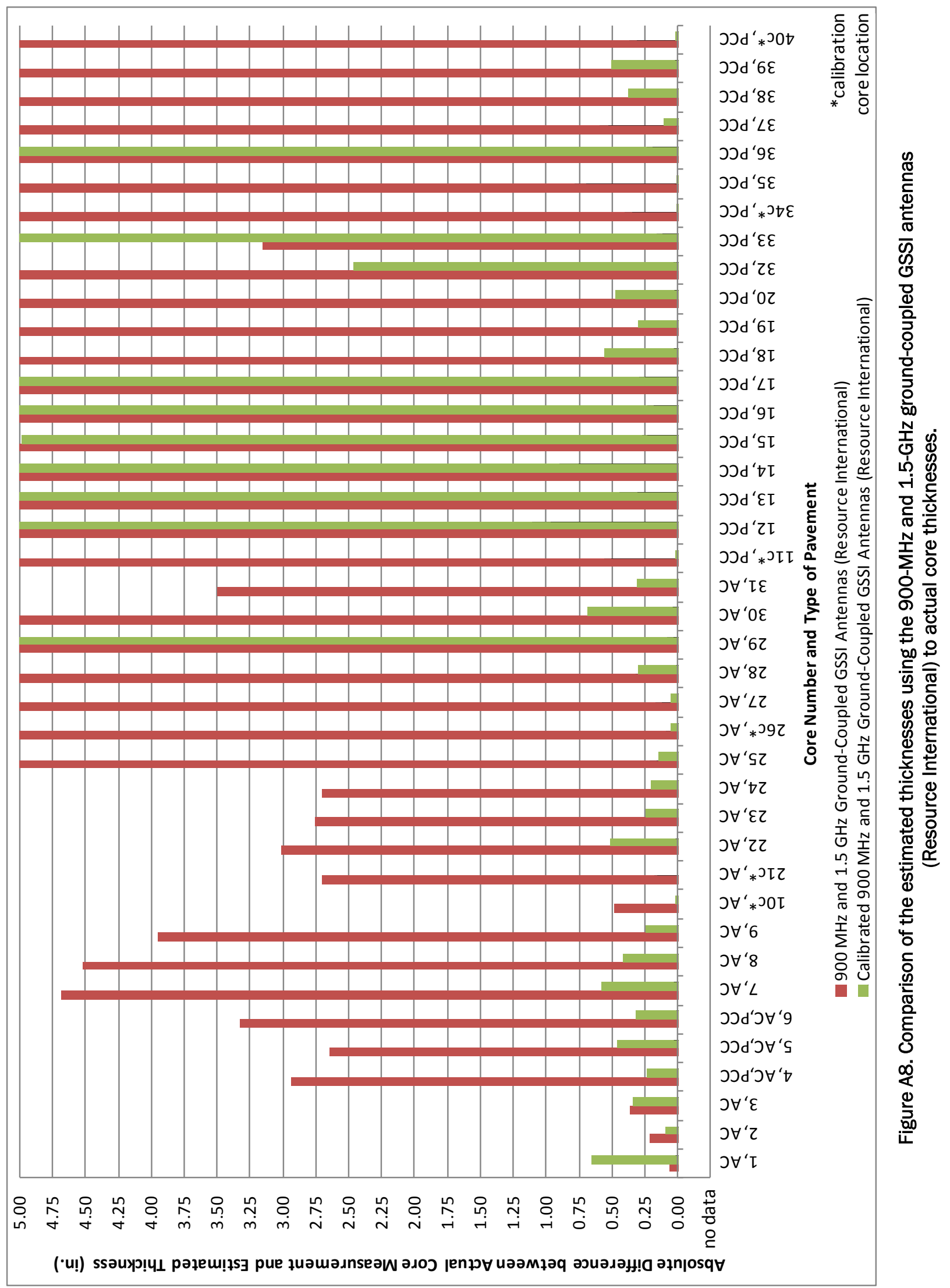




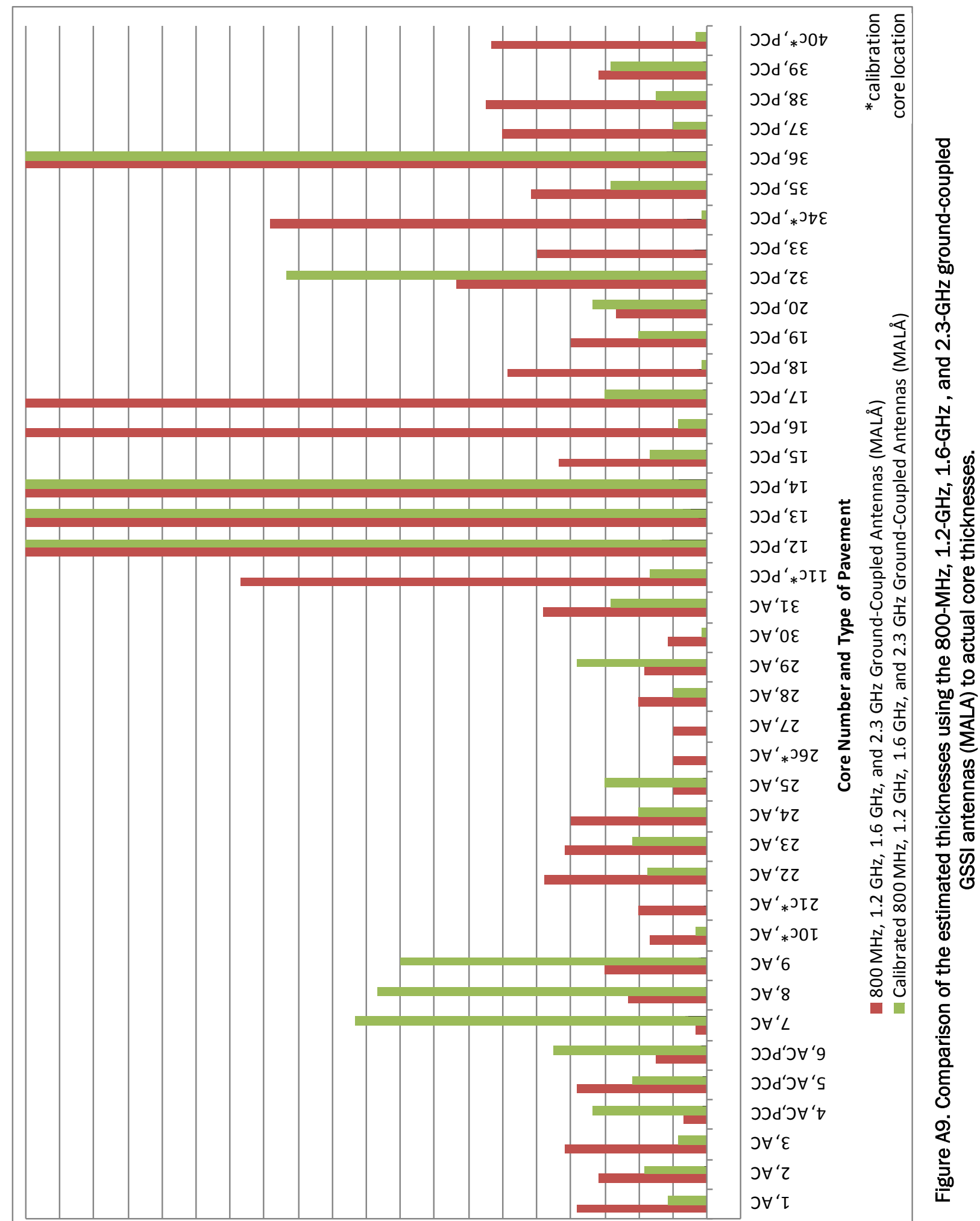

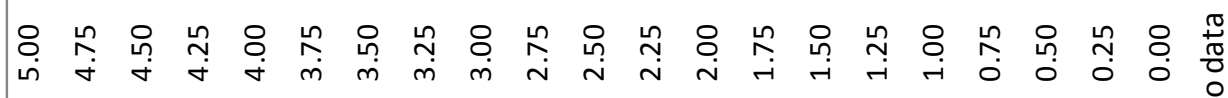

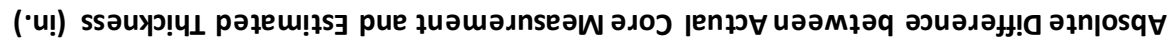




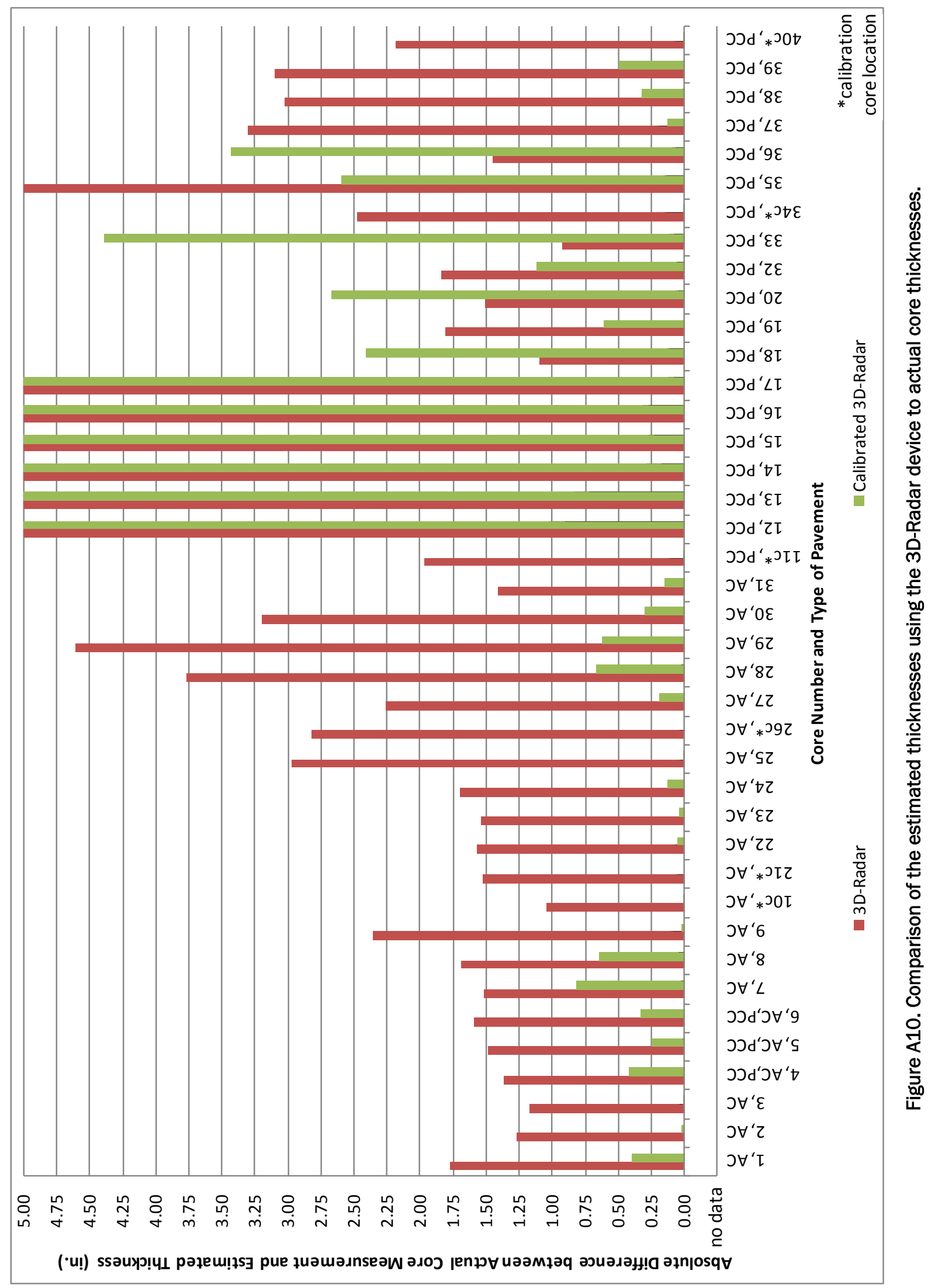




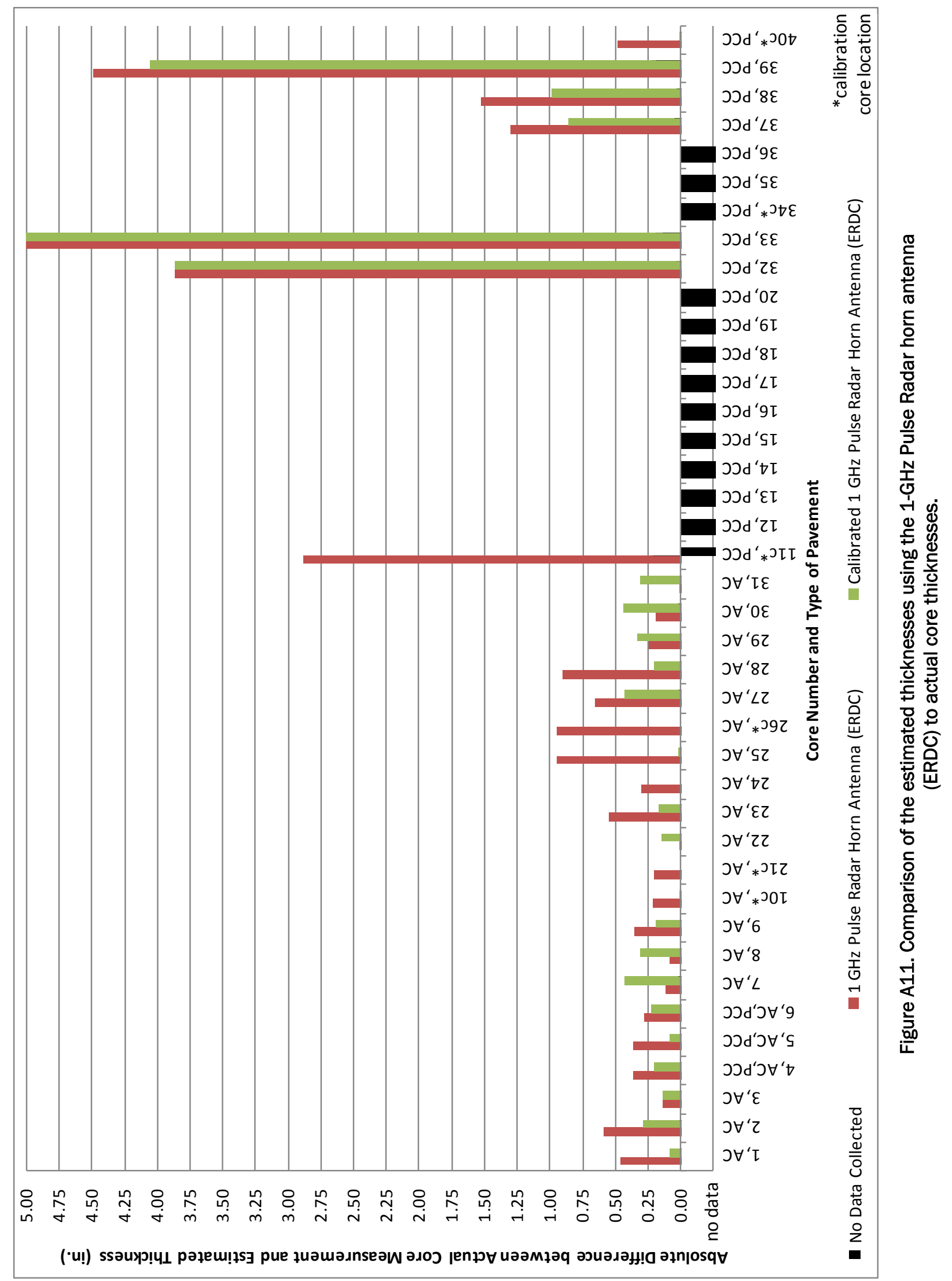


Table A1. Results for MIRA (University of Minnesota).

\begin{tabular}{|c|c|c|c|c|c|}
\hline $\begin{array}{l}\text { Test Location and } \\
\text { Pavement Type }\end{array}$ & $\begin{array}{l}\text { Layer } 1 \text { Actual } \\
\text { Core Thickness } \\
\text { in. }\end{array}$ & $\begin{array}{l}\text { Other Layers } \\
\text { Actual Core } \\
\text { Thicknesses } \\
\text { in. }\end{array}$ & $\begin{array}{l}\text { Sum of Pavement } \\
\text { Layers } \\
\text { in. }\end{array}$ & $\begin{array}{l}\text { Initial Measured } \\
\text { Thickness } \\
\text { in. }\end{array}$ & $\begin{array}{l}\text { Calibrated } \\
\text { Thickness } \\
\text { in. }\end{array}$ \\
\hline $1, A C$ & 3.04 & & 3.04 & $\mathrm{~N} / \mathrm{A}$ & $\mathrm{N} / \mathrm{A}$ \\
\hline $2, A C$ & 3.21 & & 3.21 & $\mathrm{~N} / \mathrm{A}$ & $\mathrm{N} / \mathrm{A}$ \\
\hline $3, A C$ & 2.96 & & 2.96 & 3.23 & $\mathrm{~N} / \mathrm{A}$ \\
\hline 4, AC,PCC & 4.83 & PCC, 11.71 & 16.54 & 4.72 & $\mathrm{~N} / \mathrm{A}$ \\
\hline $5, A C, P C C$ & 4.54 & PCC, 12.21 & 16.75 & 4.72 & $\mathrm{~N} / \mathrm{A}$ \\
\hline 6, AC,PCC & 5.13 & PCC, 11.79 & 16.92 & 5.12 & $\mathrm{~N} / \mathrm{A}$ \\
\hline $7, A C$ & 6.58 & & 6.58 & 6.30 & $\mathrm{~N} / \mathrm{A}$ \\
\hline $8, A C$ & 6.42 & & 6.42 & 6.30 & $\mathrm{~N} / \mathrm{A}$ \\
\hline $9, A C$ & 5.75 & & 5.75 & 5.91 & $\mathrm{~N} / \mathrm{A}$ \\
\hline $10 c^{*}, A C$ & 2.58 & & 2.58 & 6.02 & $\mathrm{~N} / \mathrm{A}$ \\
\hline $21 c^{*}, A C$ & 4.50 & & 4.50 & $N / A$ & $\mathrm{~N} / \mathrm{A}$ \\
\hline $22, A C$ & 4.81 & & 4.81 & $\mathrm{~N} / \mathrm{A}$ & $\mathrm{N} / \mathrm{A}$ \\
\hline $23, A C$ & 4.46 & & 4.46 & $\mathrm{~N} / \mathrm{A}$ & $\mathrm{N} / \mathrm{A}$ \\
\hline $24, A C$ & 4.50 & & 4.50 & $\mathrm{~N} / \mathrm{A}$ & N/A \\
\hline $25, A C$ & 8.75 & & 8.75 & 7.09 & $\mathrm{~N} / \mathrm{A}$ \\
\hline $26 c^{*}, A C$ & 9.25 & & 9.25 & $\mathrm{~N} / \mathrm{A}$ & $\mathrm{N} / \mathrm{A}$ \\
\hline $27, A C$ & 8.25 & & 8.25 & $\mathrm{~N} / \mathrm{A}$ & $\mathrm{N} / \mathrm{A}$ \\
\hline $28, A C$ & 9.50 & & 9.50 & $\mathrm{~N} / \mathrm{A}$ & $\mathrm{N} / \mathrm{A}$ \\
\hline $29, A C$ & 12.46 & & 12.46 & $\mathrm{~N} / \mathrm{A}$ & $\mathrm{N} / \mathrm{A}$ \\
\hline $30, A C$ & 9.21 & & 9.21 & N/A & $\mathrm{N} / \mathrm{A}$ \\
\hline $31, A C, S B$ & 5.29 & SB, $4.75,4.5$ & 14.54 & $\mathrm{~N} / \mathrm{A}$ & $\mathrm{N} / \mathrm{A}$ \\
\hline $11 c^{*}, P C C$ & 8.42 & & 8.42 & 8.27 & $\mathrm{~N} / \mathrm{A}$ \\
\hline $12, \mathrm{PCC}$ & 24.96 & & 24.96 & 25.00 & $\mathrm{~N} / \mathrm{A}$ \\
\hline 13, PCC & 24.92 & & 24.92 & 24.21 & $\mathrm{~N} / \mathrm{A}$ \\
\hline 14, PCC & 24.63 & & 24.63 & 24.80 & N/A \\
\hline 15, PCC & 14.92 & & 14.92 & 14.37 & $\mathrm{~N} / \mathrm{A}$ \\
\hline 16, PCC & 14.96 & & 14.96 & 15.16 & $\mathrm{~N} / \mathrm{A}$ \\
\hline 17, PCC & 15.50 & & 15.50 & 15.04 & $\mathrm{~N} / \mathrm{A}$ \\
\hline 18, PCC & 7.54 & & 7.54 & 7.20 & $\mathrm{~N} / \mathrm{A}$ \\
\hline 19, PCC & 8.00 & & 8.00 & 7.56 & N/A \\
\hline 20, PCC & 8.33 & & 8.33 & 8.46 & N/A \\
\hline $32, \mathrm{PCC}$ & 7.83 & & 7.83 & 8.46 & $\mathrm{~N} / \mathrm{A}$ \\
\hline 33, PCC & 4.75 & & 4.75 & 4.25 & $\mathrm{~N} / \mathrm{A}$ \\
\hline $34 c^{*}, P C C$ & 8.79 & & 8.79 & 8.86 & $\mathrm{~N} / \mathrm{A}$ \\
\hline 35, PCC & 12.71 & & 12.71 & 12.60 & $\mathrm{~N} / \mathrm{A}$ \\
\hline 36, PCC & 7.75 & & 7.75 & 7.76 & $\mathrm{~N} / \mathrm{A}$ \\
\hline $37, \mathrm{PCC}$ & 10.50 & & 10.50 & 9.45 & $\mathrm{~N} / \mathrm{A}$ \\
\hline 38, PCC & 10.38 & & 10.38 & 9.57 & $\mathrm{~N} / \mathrm{A}$ \\
\hline 39, PCC & 11.21 & & 11.21 & 10.31 & N/A \\
\hline $40 c^{*}$, PCC & 8.92 & & 8.92 & 9.84 & $\mathrm{~N} / \mathrm{A}$ \\
\hline
\end{tabular}

$\mathrm{SB}=$ stabilized limestone base, $\mathrm{PCC}=$ portland cement concrete, and $\mathrm{AC}=$ asphalt concrete.

* Denotes a test location used as a calibration point. 
Table A2. Results for impact echo (Olson Engineering).

\begin{tabular}{|c|c|c|c|c|c|}
\hline $\begin{array}{l}\text { Test Location and } \\
\text { Pavement Type }\end{array}$ & $\begin{array}{l}\text { Layer } 1 \text { Actual } \\
\text { Core Thickness } \\
\text { in. }\end{array}$ & $\begin{array}{l}\text { Other Layers } \\
\text { Actual Core } \\
\text { Thicknesses } \\
\text { in. }\end{array}$ & $\begin{array}{l}\text { Sum of Pavement } \\
\text { Layers } \\
\text { in. }\end{array}$ & $\begin{array}{l}\text { Initial Measured } \\
\text { Thickness } \\
\text { in. }\end{array}$ & $\begin{array}{l}\text { Calibrated } \\
\text { Thickness } \\
\text { in. }\end{array}$ \\
\hline $1, A C$ & 3.04 & & 3.04 & $\mathrm{~N} / \mathrm{A}$ & 2.78 \\
\hline $2, A C$ & 3.21 & & 3.21 & $\mathrm{~N} / \mathrm{A}$ & 2.25 \\
\hline $3, A C$ & 2.96 & & 2.96 & $\mathrm{~N} / \mathrm{A}$ & 2.43 \\
\hline 4, AC,PCC & 4.83 & PCC, 11.71 & 16.54 & 14.49 & 10.62 \\
\hline $5, A C, P C C$ & 4.54 & PCC, 12.21 & 16.75 & 14.64 & 10.73 \\
\hline $6, A C, P C C$ & 5.13 & PCC, 11.79 & 16.92 & 15.29 & 11.21 \\
\hline $7, \mathrm{AC}$ & 6.58 & & 6.58 & 6.98 & 4.90 \\
\hline $8, A C$ & 6.42 & & 6.42 & 7.15 & 5.02 \\
\hline $9, A C$ & 5.75 & & 5.75 & 6.42 & 4.50 \\
\hline $10 c^{*}, A C$ & 2.58 & & 2.58 & $\mathrm{~N} / \mathrm{A}$ & 2.58 \\
\hline $21 c^{*}, A C$ & 4.50 & & 4.50 & 6.18 & 4.50 \\
\hline $22, A C$ & 4.81 & & 4.81 & 8.67 & 6.31 \\
\hline $23, A C$ & 4.46 & & 4.46 & 6.22 & 4.53 \\
\hline $24, A C$ & 4.50 & & 4.50 & 9.22 & 6.71 \\
\hline $25, A C$ & 8.75 & & 8.75 & 11.90 & 5.86 \\
\hline $26 c^{*}, A C$ & 9.25 & & 9.25 & 12.09 & 9.25 \\
\hline $27, \mathrm{AC}$ & 8.25 & & 8.25 & 10.27 & 7.86 \\
\hline $28, A C$ & 9.50 & & 9.50 & 12.09 & 9.25 \\
\hline $29, A C$ & 12.46 & & 12.46 & 17.64 & 13.49 \\
\hline $30, A C$ & 9.21 & & 9.21 & 11.25 & 12.73 \\
\hline $31, A C, S B$ & 5.29 & SB, $4.75,4.5$ & 14.54 & 13.30 & 8.68 \\
\hline $11 c^{*}$, PCC & 8.42 & & 8.42 & 8.12 & 8.42 \\
\hline $12, \mathrm{PCC}$ & 24.96 & & 24.96 & 24.49 & 25.38 \\
\hline 13, PCC & 24.92 & & 24.92 & 24.49 & 25.38 \\
\hline 14, PCC & 24.63 & & 24.63 & 25.22 & 26.14 \\
\hline 15, PCC & 14.92 & & 14.92 & 15.09 & 15.64 \\
\hline 16, PCC & 14.96 & & 14.96 & 15.22 & 15.78 \\
\hline 17, PCC & 15.50 & & 15.50 & 15.22 & 15.78 \\
\hline 18, PCC & 7.54 & & 7.54 & 7.48 & 7.75 \\
\hline 19, PCC & 8.00 & & 8.00 & 7.68 & 7.96 \\
\hline 20, PCC & 8.33 & & 8.33 & 7.97 & 8.26 \\
\hline $32, \mathrm{PCC}$ & 7.83 & & 7.83 & 7.92 & 7.73 \\
\hline 33, PCC & 4.75 & & 4.75 & 33.61 & 32.83 \\
\hline $34 c^{*}$, PCC & 8.79 & & 8.79 & 9.00 & 8.79 \\
\hline 35, PCC & 12.71 & & 12.71 & 12.11 & 11.83 \\
\hline 36, PCC & 7.75 & & 7.75 & 7.84 & 7.66 \\
\hline $37, \mathrm{PCC}$ & 10.50 & & 10.50 & 9.63 & 10.64 \\
\hline $38, \mathrm{PCC}$ & 10.38 & & 10.38 & 9.36 & 10.34 \\
\hline 39, PCC & 11.21 & & 11.21 & 10.16 & 11.23 \\
\hline $40 c^{*}$, PCC & 8.92 & & 8.92 & 8.07 & 8.92 \\
\hline
\end{tabular}

$\mathrm{SB}=$ stabilized limestone base, $\mathrm{PCC}=$ portland cement concrete, and $\mathrm{AC}=$ asphalt concrete.

* Denotes a test location used as a calibration point. 
Table A3. Results for MISW (Olson Engineering).

\begin{tabular}{|c|c|c|c|c|c|}
\hline $\begin{array}{l}\text { Test Location and } \\
\text { Pavement Type }\end{array}$ & $\begin{array}{l}\text { Layer } 1 \text { Actual } \\
\text { Core Thickness } \\
\text { in. }\end{array}$ & $\begin{array}{l}\text { Other Layers } \\
\text { Actual Core } \\
\text { Thicknesses } \\
\text { in. }\end{array}$ & $\begin{array}{l}\text { Sum of Pavement } \\
\text { Layers } \\
\text { in. }\end{array}$ & $\begin{array}{l}\text { Initial Measured } \\
\text { Thickness } \\
\text { in. }\end{array}$ & $\begin{array}{l}\text { Calibrated } \\
\text { Thickness } \\
\text { in. }\end{array}$ \\
\hline $1, A C$ & 3.04 & & 3.04 & 7.87 & 2.87 \\
\hline $2, A C$ & 3.21 & & 3.21 & 7.32 & 2.76 \\
\hline $3, A C$ & 2.96 & & 2.96 & 6.61 & 2.83 \\
\hline 4, AC,PCC & 4.83 & PCC, 11.71 & 16.54 & 13.86 & 13.46 \\
\hline 5, AC,PCC & 4.54 & PCC, 12.21 & 16.75 & 14.21 & 13.90 \\
\hline $6, \mathrm{AC}, \mathrm{PCC}$ & 5.13 & PCC, 11.79 & 16.92 & 14.45 & 13.78 \\
\hline $7, \mathrm{AC}$ & 6.58 & & 6.58 & 8.46 & 6.30 \\
\hline $8, A C$ & 6.42 & & 6.42 & 7.40 & 5.91 \\
\hline $9, A C$ & 5.75 & & 5.75 & 6.26 & 5.12 \\
\hline $10 c^{*}, A C$ & 2.58 & & 2.58 & 8.03 & 2.60 \\
\hline $21 c^{*}, A C$ & 4.50 & & 4.50 & 9.21 & 4.49 \\
\hline $22, A C$ & 4.81 & & 4.81 & 9.02 & 6.46 \\
\hline $23, A C$ & 4.46 & & 4.46 & 6.73 & 5.08 \\
\hline $24, A C$ & 4.50 & & 4.50 & 5.12 & 6.97 \\
\hline $25, A C$ & 8.75 & & 8.75 & 9.06 & 8.27 \\
\hline $26 c^{*}, A C$ & 9.25 & & 9.25 & 11.42 & 9.25 \\
\hline $27, A C$ & 8.25 & & 8.25 & 9.25 & 9.45 \\
\hline $28, A C$ & 9.50 & & 9.50 & 12.83 & 12.01 \\
\hline $29, A C$ & 12.46 & & 12.46 & 14.41 & 14.09 \\
\hline $30, A C$ & 9.21 & & 9.21 & 11.22 & 12.13 \\
\hline $31, A C, S B$ & 5.29 & SB, $4.75,4.5$ & 14.54 & 12.91 & 12.83 \\
\hline $11 c^{*}, P C C$ & 8.42 & & 8.42 & 8.43 & 8.43 \\
\hline $12, \mathrm{PCC}$ & 24.96 & & 24.96 & 24.57 & 24.57 \\
\hline 13, PCC & 24.92 & & 24.92 & 24.29 & 24.33 \\
\hline $14, \mathrm{PCC}$ & 24.63 & & 24.63 & 24.72 & 24.80 \\
\hline 15, PCC & 14.92 & & 14.92 & 13.15 & 14.53 \\
\hline 16, PCC & 14.96 & & 14.96 & 14.41 & 14.80 \\
\hline 17, PCC & 15.50 & & 15.50 & 14.29 & 14.57 \\
\hline 18, PCC & 7.54 & & 7.54 & 7.48 & 7.36 \\
\hline 19, PCC & 8.00 & & 8.00 & 7.28 & 7.68 \\
\hline 20, PCC & 8.33 & & 8.33 & 7.99 & 8.11 \\
\hline $32, \mathrm{PCC}$ & 7.83 & & 7.83 & N/A & $\mathrm{N} / \mathrm{A}$ \\
\hline 33, PCC & 4.75 & & 4.75 & $\mathrm{~N} / \mathrm{A}$ & $\mathrm{N} / \mathrm{A}$ \\
\hline $34 c^{*}$, PCC & 8.79 & & 8.79 & $\mathrm{~N} / \mathrm{A}$ & $\mathrm{N} / \mathrm{A}$ \\
\hline 35, PCC & 12.71 & & 12.71 & N/A & $\mathrm{N} / \mathrm{A}$ \\
\hline 36, PCC & 7.75 & & 7.75 & $\mathrm{~N} / \mathrm{A}$ & $\mathrm{N} / \mathrm{A}$ \\
\hline $37, \mathrm{PCC}$ & 10.50 & & 10.50 & $\mathrm{~N} / \mathrm{A}$ & $\mathrm{N} / \mathrm{A}$ \\
\hline 38, PCC & 10.38 & & 10.38 & N/A & N/A \\
\hline 39, PCC & 11.21 & & 11.21 & N/A & N/A \\
\hline $40 c^{*}$, PCC & 8.92 & & 8.92 & $\mathrm{~N} / \mathrm{A}$ & $\mathrm{N} / \mathrm{A}$ \\
\hline
\end{tabular}

$\mathrm{SB}=$ stabilized limestone base, $\mathrm{PCC}=$ portland cement concrete, and $\mathrm{AC}=$ asphalt concrete.

* Denotes a test location used as a calibration point. 
Table A4. Results for the 2-GHz ground-coupled IDS Aladdin GPR (Olson Engineering).

\begin{tabular}{|c|c|c|c|c|c|}
\hline $\begin{array}{l}\text { Test Location and } \\
\text { Pavement Type }\end{array}$ & $\begin{array}{l}\text { Layer } 1 \text { Actual } \\
\text { Core Thickness } \\
\text { in. }\end{array}$ & $\begin{array}{l}\text { Other Layers } \\
\text { Actual Core } \\
\text { Thicknesses } \\
\text { in. }\end{array}$ & $\begin{array}{l}\text { Sum of Pavement } \\
\text { Layers } \\
\text { in. }\end{array}$ & $\begin{array}{l}\text { Initial Measured } \\
\text { Thickness } \\
\text { in. }\end{array}$ & $\begin{array}{l}\text { Calibrated } \\
\text { Thickness } \\
\text { in. }\end{array}$ \\
\hline $1, A C$ & 3.04 & & 3.04 & 3.10 & 4.73 \\
\hline $2, A C$ & 3.21 & & 3.21 & 2.60 & 3.99 \\
\hline $3, A C$ & 2.96 & & 2.96 & 1.90 & 2.88 \\
\hline 4, AC,PCC & 4.83 & PCC, 11.71 & 16.54 & 3.40 & 5.12 \\
\hline $5, \mathrm{AC}, \mathrm{PCC}$ & 4.54 & PCC, 12.21 & 16.75 & 3.20 & 4.79 \\
\hline $6, A C, P C C$ & 5.13 & PCC, 11.79 & 16.92 & 3.50 & 5.34 \\
\hline $7, \mathrm{AC}$ & 6.58 & & 6.58 & 4.40 & 6.65 \\
\hline $8, A C$ & 6.42 & & 6.42 & 4.40 & 6.65 \\
\hline $9, A C$ & 5.75 & & 5.75 & 4.00 & 5.99 \\
\hline $10 c^{*}, A C$ & 2.58 & & 2.58 & 1.70 & 2.58 \\
\hline $21 c^{*}, A C$ & 4.50 & & 4.50 & 3.20 & 4.50 \\
\hline $22, A C$ & 4.81 & & 4.81 & 3.40 & 4.81 \\
\hline $23, A C$ & 4.46 & & 4.46 & 3.30 & 4.55 \\
\hline $24, A C$ & 4.50 & & 4.50 & 7.40 & 10.30 \\
\hline $25, A C$ & 8.75 & & 8.75 & 6.50 & 9.09 \\
\hline $26 c^{*}, A C$ & 9.25 & & 9.25 & 6.60 & 9.25 \\
\hline $27, A C$ & 8.25 & & 8.25 & 5.60 & 7.86 \\
\hline $28, A C$ & 9.50 & & 9.50 & 6.50 & 9.06 \\
\hline $29, A C$ & 12.46 & & 12.46 & 9.20 & 12.89 \\
\hline $30, A C$ & 9.21 & & 9.21 & 10.60 & 14.81 \\
\hline $31, A C, S B$ & 5.29 & SB, 4.75, 4.5 & 14.54 & 4.10 & 5.76 \\
\hline $11 c^{*}, \mathrm{PCC}$ & 8.42 & & 8.42 & 4.00 & 8.42 \\
\hline $12, \mathrm{PCC}$ & 24.96 & & 24.96 & 4.40 & 9.30 \\
\hline $13, \mathrm{PCC}$ & 24.92 & & 24.92 & 3.90 & 10.05 \\
\hline 14, PCC & 24.63 & & 24.63 & 3.90 & 8.97 \\
\hline $15, \mathrm{PCC}$ & 14.92 & & 14.92 & 3.90 & 11.19 \\
\hline $16, \mathrm{PCC}$ & 14.96 & & 14.96 & 3.90 & 10.90 \\
\hline $17, \mathrm{PCC}$ & 15.50 & & 15.50 & 3.90 & 10.35 \\
\hline $18, \mathrm{PCC}$ & 7.54 & & 7.54 & 3.90 & 9.83 \\
\hline $19, \mathrm{PCC}$ & 8.00 & & 8.00 & 3.40 & 8.51 \\
\hline 20, PCC & 8.33 & & 8.33 & 3.90 & 8.98 \\
\hline $32, \mathrm{PCC}$ & 7.83 & & 7.83 & 4.50 & 8.79 \\
\hline 33, PCC & 4.75 & & 4.75 & 3.50 & 7.82 \\
\hline $34 c^{*}$, PCC & 8.79 & & 8.79 & 3.20 & 8.79 \\
\hline 35, PCC & 12.71 & & 12.71 & 3.50 & 9.20 \\
\hline 36, PCC & 7.75 & & 7.75 & 5.10 & 7.99 \\
\hline $37, \mathrm{PCC}$ & 10.50 & & 10.50 & 10.60 & 11.92 \\
\hline 38, PCC & 10.38 & & 10.38 & 7.40 & 8.29 \\
\hline 39, PCC & 11.21 & & 11.21 & 7.50 & 8.47 \\
\hline $40 c^{*}$, PCC & 8.92 & & 8.92 & 7.90 & 8.92 \\
\hline
\end{tabular}

$\mathrm{SB}=$ stabilized limestone base, $\mathrm{PCC}=$ portland cement concrete, and $\mathrm{AC}=$ asphalt concrete.

* Denotes a test location used as a calibration point. 
Table A5. Results for the single 1.5-GHz ground-coupled GSSI antenna (Infrasense, Inc.).

\begin{tabular}{|c|c|c|c|c|c|}
\hline $\begin{array}{l}\text { Test Location and } \\
\text { Pavement Type }\end{array}$ & $\begin{array}{l}\text { Layer } 1 \text { Actual } \\
\text { Core Thickness } \\
\text { in. }\end{array}$ & $\begin{array}{l}\text { Other Layers } \\
\text { Actual Core } \\
\text { Thicknesses } \\
\text { in. }\end{array}$ & $\begin{array}{l}\text { Sum of Pavement } \\
\text { Layers } \\
\text { in. }\end{array}$ & $\begin{array}{l}\text { Initial Measured } \\
\text { Thickness } \\
\text { in. }\end{array}$ & $\begin{array}{l}\text { Calibrated } \\
\text { Thickness } \\
\text { in. }\end{array}$ \\
\hline $1, \mathrm{AC}$ & 3.04 & & 3.04 & 3.70 & 3.70 \\
\hline $2, A C$ & 3.21 & & 3.21 & 3.50 & 3.50 \\
\hline $3, A C$ & 2.96 & & 2.96 & 3.30 & 3.30 \\
\hline 4, AC,PCC & 4.83 & PCC, 11.71 & 16.54 & 5.40 & 5.40 \\
\hline $5, \mathrm{AC}, \mathrm{PCC}$ & 4.54 & PCC, 12.21 & 16.75 & 4.60 & 4.60 \\
\hline $6, \mathrm{AC}, \mathrm{PCC}$ & 5.13 & PCC, 11.79 & 16.92 & 6.10 & 6.10 \\
\hline $7, A C$ & 6.58 & & 6.58 & 6.40 & 6.40 \\
\hline $8, A C$ & 6.42 & & 6.42 & 6.60 & 6.60 \\
\hline $9, A C$ & 5.75 & & 5.75 & 6.50 & 6.50 \\
\hline $10 c^{*}, A C$ & 2.58 & & 2.58 & 3.00 & 3.00 \\
\hline $21 c^{*}, A C$ & 4.50 & & 4.50 & 4.00 & 4.00 \\
\hline $22, A C$ & 4.81 & & 4.81 & 4.00 & 4.00 \\
\hline $23, A C$ & 4.46 & & 4.46 & 4.50 & 4.50 \\
\hline $24, A C$ & 4.50 & & 4.50 & 4.40 & 4.40 \\
\hline $25, A C$ & 8.75 & & 8.75 & 8.30 & 8.30 \\
\hline $26 c^{*}, A C$ & 9.25 & & 9.25 & 11.30 & N/A \\
\hline $27, A C$ & 8.25 & & 8.25 & 8.70 & 8.70 \\
\hline $28, A C$ & 9.50 & & 9.50 & 9.70 & 9.70 \\
\hline $29, A C$ & 12.46 & & 12.46 & 11.20 & 11.20 \\
\hline $30, A C$ & 9.21 & & 9.21 & 7.90 & 7.90 \\
\hline $31, \mathrm{AC}, \mathrm{SB}$ & 5.29 & SB, 4.75, 4.5 & 14.54 & 6.80 & 6.80 \\
\hline $11 c^{*}$, PCC & 8.42 & & 8.42 & 7.00 & 8.00 \\
\hline $12, \mathrm{PCC}$ & 24.96 & & 24.96 & $\mathrm{~N} / \mathrm{A}$ & N/A \\
\hline $13, \mathrm{PCC}$ & 24.92 & & 24.92 & N/A & $\mathrm{N} / \mathrm{A}$ \\
\hline 14, PCC & 24.63 & & 24.63 & $\mathrm{~N} / \mathrm{A}$ & $\mathrm{N} / \mathrm{A}$ \\
\hline $15, \mathrm{PCC}$ & 14.92 & & 14.92 & $\mathrm{~N} / \mathrm{A}$ & $\mathrm{N} / \mathrm{A}$ \\
\hline $16, \mathrm{PCC}$ & 14.96 & & 14.96 & $\mathrm{~N} / \mathrm{A}$ & $\mathrm{N} / \mathrm{A}$ \\
\hline $17, \mathrm{PCC}$ & 15.50 & & 15.50 & $\mathrm{~N} / \mathrm{A}$ & $\mathrm{N} / \mathrm{A}$ \\
\hline 18, PCC & 7.54 & & 7.54 & 6.10 & 6.90 \\
\hline 19, PCC & 8.00 & & 8.00 & 7.10 & 8.10 \\
\hline $20, \mathrm{PCC}$ & 8.33 & & 8.33 & 6.30 & 7.20 \\
\hline $32, \mathrm{PCC}$ & 7.83 & & 7.83 & 9.50 & 10.80 \\
\hline 33, PCC & 4.75 & & 4.75 & 9.50 & 10.80 \\
\hline $34 c^{*}, \mathrm{PCC}$ & 8.79 & & 8.79 & 7.50 & 8.50 \\
\hline 35, PCC & 12.71 & & 12.71 & 7.40 & 8.50 \\
\hline $36, \mathrm{PCC}$ & 7.75 & & 7.75 & N/A & N/A \\
\hline $37, \mathrm{PCC}$ & 10.50 & & 10.50 & 9.50 & 10.90 \\
\hline 38, PCC & 10.38 & & 10.38 & 9.40 & 10.80 \\
\hline 39, PCC & 11.21 & & 11.21 & 10.00 & 11.40 \\
\hline $40 c^{*}, \mathrm{PCC}$ & 8.92 & & 8.92 & 7.80 & 8.90 \\
\hline
\end{tabular}

$\mathrm{SB}=$ stabilized limestone base, $\mathrm{PCC}=$ portland cement concrete, and $\mathrm{AC}=$ asphalt concrete.

* Denotes a test location used as a calibration point. 
Table A6. Results for the CMP Method with two 1.5-GHz ground-coupled GSSI antennas (Infrasense, Inc.).

\begin{tabular}{|c|c|c|c|c|c|}
\hline $\begin{array}{l}\text { Test Location and } \\
\text { Pavement Type }\end{array}$ & $\begin{array}{l}\text { Layer } 1 \text { Actual } \\
\text { Core Thickness } \\
\text { in. }\end{array}$ & $\begin{array}{l}\text { Other Layers } \\
\text { Actual Core } \\
\text { Thicknesses } \\
\text { in. }\end{array}$ & $\begin{array}{l}\text { Sum of Pavement } \\
\text { Layers } \\
\text { in. }\end{array}$ & $\begin{array}{l}\text { Initial Measured } \\
\text { Thickness } \\
\text { in. }\end{array}$ & $\begin{array}{l}\text { Calibrated } \\
\text { Thickness } \\
\text { in. }\end{array}$ \\
\hline $1, A C$ & 3.04 & & 3.04 & 4.30 & 3.70 \\
\hline $2, A C$ & 3.21 & & 3.21 & 4.60 & 4.10 \\
\hline $3, A C$ & 2.96 & & 2.96 & 4.70 & 4.10 \\
\hline 4, AC,PCC & 4.83 & PCC, 11.71 & 16.54 & 5.80 & 5.10 \\
\hline 5, AC,PCC & 4.54 & PCC, 12.21 & 16.75 & 5.60 & 5.00 \\
\hline $6, \mathrm{AC}, \mathrm{PCC}$ & 5.13 & PCC, 11.79 & 16.92 & 5.90 & 5.20 \\
\hline $7, \mathrm{AC}$ & 6.58 & & 6.58 & 7.30 & 6.40 \\
\hline $8, A C$ & 6.42 & & 6.42 & 6.80 & 6.00 \\
\hline $9, A C$ & 5.75 & & 5.75 & 6.80 & 6.00 \\
\hline $10 c^{*}, A C$ & 2.58 & & 2.58 & 4.20 & 3.70 \\
\hline $21 c^{*}, A C$ & 4.50 & & 4.50 & 4.90 & 4.30 \\
\hline $22, A C$ & 4.81 & & 4.81 & 5.50 & 4.80 \\
\hline $23, A C$ & 4.46 & & 4.46 & 5.20 & 4.50 \\
\hline $24, A C$ & 4.50 & & 4.50 & 4.80 & 4.20 \\
\hline $25, A C$ & 8.75 & & 8.75 & 8.30 & 7.30 \\
\hline $26 c^{*}, A C$ & 9.25 & & 9.25 & 10.30 & 9.10 \\
\hline $27, A C$ & 8.25 & & 8.25 & 9.40 & 8.30 \\
\hline $28, A C$ & 9.50 & & 9.50 & 8.50 & 7.50 \\
\hline $29, A C$ & 12.46 & & 12.46 & 6.60 & 5.80 \\
\hline $30, A C$ & 9.21 & & 9.21 & 9.70 & 8.60 \\
\hline $31, A C, S B$ & 5.29 & SB, $4.75,4.5$ & 14.54 & 6.60 & 5.80 \\
\hline $11 c^{*}, P C C$ & 8.42 & & 8.42 & 13.10 & $\mathrm{~N} / \mathrm{A}$ \\
\hline $12, \mathrm{PCC}$ & 24.96 & & 24.96 & 8.10 & 8.10 \\
\hline 13, PCC & 24.92 & & 24.92 & N/A & N/A \\
\hline $14, \mathrm{PCC}$ & 24.63 & & 24.63 & $\mathrm{~N} / \mathrm{A}$ & $\mathrm{N} / \mathrm{A}$ \\
\hline 15, PCC & 14.92 & & 14.92 & N/A & $\mathrm{N} / \mathrm{A}$ \\
\hline 16, PCC & 14.96 & & 14.96 & $\mathrm{~N} / \mathrm{A}$ & $\mathrm{N} / \mathrm{A}$ \\
\hline 17, PCC & 15.50 & & 15.50 & N/A & N/A \\
\hline 18, PCC & 7.54 & & 7.54 & 8.90 & 8.90 \\
\hline 19, PCC & 8.00 & & 8.00 & N/A & N/A \\
\hline 20, PCC & 8.33 & & 8.33 & 8.50 & 8.50 \\
\hline $32, \mathrm{PCC}$ & 7.83 & & 7.83 & 9.40 & 9.40 \\
\hline 33, PCC & 4.75 & & 4.75 & N/A & $\mathrm{N} / \mathrm{A}$ \\
\hline $34 c^{*}$, PCC & 8.79 & & 8.79 & 9.70 & 9.70 \\
\hline 35, PCC & 12.71 & & 12.71 & 9.00 & 9.00 \\
\hline 36, PCC & 7.75 & & 7.75 & 7.30 & 7.30 \\
\hline $37, \mathrm{PCC}$ & 10.50 & & 10.50 & 10.90 & 10.90 \\
\hline $38, \mathrm{PCC}$ & 10.38 & & 10.38 & 11.00 & 11.00 \\
\hline 39, PCC & 11.21 & & 11.21 & 11.30 & 11.30 \\
\hline $40 c^{*}$, PCC & 8.92 & & 8.92 & 9.10 & 9.10 \\
\hline
\end{tabular}

$\mathrm{SB}=$ stabilized limestone base, $\mathrm{PCC}=$ portland cement concrete, and $\mathrm{AC}=$ asphalt concrete.

* Denotes a test location used as a calibration point. 
Table A7. 1-GHz GSSI horn antenna (Infrasense, Inc.).

\begin{tabular}{|c|c|c|c|c|c|}
\hline $\begin{array}{l}\text { Test Location and } \\
\text { Pavement Type }\end{array}$ & $\begin{array}{l}\text { Layer } 1 \text { Actual } \\
\text { Core Thickness } \\
\text { in. }\end{array}$ & $\begin{array}{l}\text { Other Layers } \\
\text { Actual Core } \\
\text { Thicknesses } \\
\text { in. }\end{array}$ & $\begin{array}{l}\text { Sum of Pavement } \\
\text { Layers } \\
\text { in. }\end{array}$ & $\begin{array}{l}\text { Initial Measured } \\
\text { Thickness } \\
\text { in. }\end{array}$ & $\begin{array}{l}\text { Calibrated } \\
\text { Thickness } \\
\text { in. }\end{array}$ \\
\hline $1, A C$ & 3.04 & & 3.04 & 3.20 & 3.10 \\
\hline $2, A C$ & 3.21 & & 3.21 & 3.60 & 3.40 \\
\hline $3, A C$ & 2.96 & & 2.96 & 3.30 & 3.20 \\
\hline 4, AC,PCC & 4.83 & PCC, 11.71 & 16.54 & 5.10 & 4.90 \\
\hline $5, A C, P C C$ & 4.54 & PCC, 12.21 & 16.75 & 4.90 & 4.70 \\
\hline $6, A C, P C C$ & 5.13 & PCC, 11.79 & 16.92 & 5.60 & 5.40 \\
\hline $7, A C$ & 6.58 & & 6.58 & 6.80 & 6.50 \\
\hline $8, A C$ & 6.42 & & 6.42 & 6.70 & 6.40 \\
\hline $9, A C$ & 5.75 & & 5.75 & 6.20 & 6.00 \\
\hline $10 c^{*}, A C$ & 2.58 & & 2.58 & 3.20 & 3.10 \\
\hline $21 c^{*}, A C$ & 4.50 & & 4.50 & 4.60 & 4.40 \\
\hline $22, A C$ & 4.81 & & 4.81 & 4.70 & 4.50 \\
\hline $23, A C$ & 4.46 & & 4.46 & 4.90 & 4.70 \\
\hline $24, A C$ & 4.50 & & 4.50 & 4.50 & 4.30 \\
\hline $25, A C$ & 8.75 & & 8.75 & 9.20 & 8.80 \\
\hline $26 c *, A C$ & 9.25 & & 9.25 & 9.90 & 9.50 \\
\hline $27, A C$ & 8.25 & & 8.25 & 8.80 & 8.40 \\
\hline $28, A C$ & 9.50 & & 9.50 & 10.00 & 9.60 \\
\hline $29, A C$ & 12.46 & & 12.46 & 11.60 & 11.10 \\
\hline $30, A C$ & 9.21 & & 9.21 & 9.20 & 8.90 \\
\hline $31, A C, S B$ & 5.29 & SB, $4.75,4.5$ & 14.54 & 5.80 & 5.50 \\
\hline $11 c^{*}, \mathrm{PCC}$ & 8.42 & & 8.42 & 8.80 & 8.80 \\
\hline $12, \mathrm{PCC}$ & 24.96 & & 24.96 & $\mathrm{~N} / \mathrm{A}$ & $\mathrm{N} / \mathrm{A}$ \\
\hline 13, PCC & 24.92 & & 24.92 & $\mathrm{~N} / \mathrm{A}$ & $\mathrm{N} / \mathrm{A}$ \\
\hline 14, PCC & 24.63 & & 24.63 & N/A & N/A \\
\hline 15, PCC & 14.92 & & 14.92 & $\mathrm{~N} / \mathrm{A}$ & $\mathrm{N} / \mathrm{A}$ \\
\hline 16, PCC & 14.96 & & 14.96 & N/A & $\mathrm{N} / \mathrm{A}$ \\
\hline 17, PCC & 15.50 & & 15.50 & $\mathrm{~N} / \mathrm{A}$ & $\mathrm{N} / \mathrm{A}$ \\
\hline 18, PCC & 7.54 & & 7.54 & 6.60 & 6.60 \\
\hline 19, PCC & 8.00 & & 8.00 & 7.20 & 7.20 \\
\hline 20, PCC & 8.33 & & 8.33 & 7.00 & 7.00 \\
\hline $32, \mathrm{PCC}$ & 7.83 & & 7.83 & N/A & N/A \\
\hline 33, PCC & 4.75 & & 4.75 & $\mathrm{~N} / \mathrm{A}$ & $\mathrm{N} / \mathrm{A}$ \\
\hline $34 c^{*}, \mathrm{PCC}$ & 8.79 & & 8.79 & N/A & $\mathrm{N} / \mathrm{A}$ \\
\hline 35, PCC & 12.71 & & 12.71 & N/A & $\mathrm{N} / \mathrm{A}$ \\
\hline 36, PCC & 7.75 & & 7.75 & $\mathrm{~N} / \mathrm{A}$ & N/A \\
\hline 37, PCC & 10.50 & & 10.50 & 9.80 & 10.80 \\
\hline 38, PCC & 10.38 & & 10.38 & 9.40 & 10.40 \\
\hline 39, PCC & 11.21 & & 11.21 & 10.30 & 11.40 \\
\hline $40 c^{*}$, PCC & 8.92 & & 8.92 & 8.00 & 8.80 \\
\hline
\end{tabular}

$\mathrm{SB}=$ stabilized limestone base, $\mathrm{PCC}=$ portland cement concrete, and $\mathrm{AC}=$ asphalt concrete.

* Denotes a test location used as a calibration point. 
Table A8. Results for the 900-MHz and 1.5-GHz ground-coupled GSSI antennas (Resource International).

\begin{tabular}{|c|c|c|c|c|c|}
\hline $\begin{array}{l}\text { Test Location and } \\
\text { Pavement Type }\end{array}$ & $\begin{array}{l}\text { Layer } 1 \text { Actual } \\
\text { Core Thickness } \\
\text { in. }\end{array}$ & $\begin{array}{l}\text { Other Layers } \\
\text { Actual Core } \\
\text { Thicknesses } \\
\text { in. }\end{array}$ & $\begin{array}{l}\text { Sum of Pavement } \\
\text { Layers } \\
\text { in. }\end{array}$ & $\begin{array}{l}\text { Initial Measured } \\
\text { Thickness } \\
\text { in. }\end{array}$ & $\begin{array}{l}\text { Calibrated } \\
\text { Thickness } \\
\text { in. }\end{array}$ \\
\hline $1, A C$ & 3.04 & & 3.04 & 3.10 & 3.70 \\
\hline $2, A C$ & 3.21 & & 3.21 & 3.00 & 3.30 \\
\hline $3, A C$ & 2.96 & & 2.96 & 2.60 & 3.30 \\
\hline 4, AC,PCC & 4.83 & PCC, 11.71 & 16.54 & 1.90 & 4.60 \\
\hline $5, A C, P C C$ & 4.54 & PCC, 12.21 & 16.75 & 1.90 & 5.00 \\
\hline $6, A C, P C C$ & 5.13 & PCC, 11.79 & 16.92 & 1.80 & 4.80 \\
\hline $7, \mathrm{AC}$ & 6.58 & & 6.58 & 1.90 & 6.00 \\
\hline $8, A C$ & 6.42 & & 6.42 & 1.90 & 6.00 \\
\hline $9, A C$ & 5.75 & & 5.75 & 1.80 & 5.50 \\
\hline $10 c^{*}, A C$ & 2.58 & & 2.58 & 2.10 & 2.60 \\
\hline $21 c^{*}, A C$ & 4.50 & & 4.50 & 1.80 & 4.50 \\
\hline $22, A C$ & 4.81 & & 4.81 & 1.80 & 4.30 \\
\hline $23, A C$ & 4.46 & & 4.46 & 1.70 & 4.70 \\
\hline $24, A C$ & 4.50 & & 4.50 & 1.80 & 4.70 \\
\hline $25, A C$ & 8.75 & & 8.75 & 1.80 & 8.90 \\
\hline $26 c^{*}, A C$ & 9.25 & & 9.25 & 1.80 & 9.30 \\
\hline $27, A C$ & 8.25 & & 8.25 & 1.90 & 8.20 \\
\hline $28, A C$ & 9.50 & & 9.50 & 1.80 & 9.20 \\
\hline $29, A C$ & 12.46 & & 12.46 & 1.90 & 6.20 \\
\hline $30, A C$ & 9.21 & & 9.21 & 1.90 & 9.90 \\
\hline $31, A C, S B$ & 5.29 & SB, 4.75, 4.5 & 14.54 & 1.80 & 5.60 \\
\hline $11 c^{*}, \mathrm{PCC}$ & 8.42 & & 8.42 & 1.60 & 8.40 \\
\hline $12, \mathrm{PCC}$ & 24.96 & & 24.96 & 1.50 & 6.30 \\
\hline $13, \mathrm{PCC}$ & 24.92 & & 24.92 & 1.50 & 7.30 \\
\hline 14, PCC & 24.63 & & 24.63 & 1.60 & 5.50 \\
\hline 15, PCC & 14.92 & & 14.92 & 1.60 & 19.90 \\
\hline $16, \mathrm{PCC}$ & 14.96 & & 14.96 & 1.50 & 20.90 \\
\hline 17, PCC & 15.50 & & 15.50 & 1.50 & 21.00 \\
\hline 18, PCC & 7.54 & & 7.54 & 1.60 & 8.10 \\
\hline 19, PCC & 8.00 & & 8.00 & 1.60 & 7.70 \\
\hline 20, PCC & 8.33 & & 8.33 & 1.60 & 8.80 \\
\hline 32, PCC & 7.83 & & 7.83 & 1.40 & 10.30 \\
\hline $33, \mathrm{PCC}$ & 4.75 & & 4.75 & 1.60 & 10.60 \\
\hline $34 c^{*}, P C C$ & 8.79 & & 8.79 & 1.60 & 8.80 \\
\hline 35, PCC & 12.71 & & 12.71 & 1.60 & 12.70 \\
\hline 36, PCC & 7.75 & & 7.75 & 1.60 & 13.50 \\
\hline 37, PCC & 10.50 & & 10.50 & 2.00 & 10.60 \\
\hline 38, PCC & 10.38 & & 10.38 & 2.00 & 10.00 \\
\hline 39, PCC & 11.21 & & 11.21 & 2.00 & 10.70 \\
\hline $40 c^{*}$, PCC & 8.92 & & 8.92 & 2.00 & 8.90 \\
\hline
\end{tabular}

$\mathrm{SB}=$ stabilized limestone base, $\mathrm{PCC}=$ portland cement concrete, and $\mathrm{AC}=$ asphalt concrete.

* Denotes a test location used as a calibration point. 
Table A9. Results for the 800-MHz, 1.2-GHz, 1.6-GHz, and 2.3-GHz ground-coupled antennas (MALÅ).

\begin{tabular}{|c|c|c|c|c|c|}
\hline $\begin{array}{l}\text { Test Location and } \\
\text { Pavement Type }\end{array}$ & $\begin{array}{l}\text { Layer } 1 \text { Actual } \\
\text { Core Thickness } \\
\text { in. }\end{array}$ & $\begin{array}{l}\text { Other Layers } \\
\text { Actual Core } \\
\text { Thicknesses } \\
\text { in. }\end{array}$ & $\begin{array}{l}\text { Sum of Pavement } \\
\text { Layers } \\
\text { in. }\end{array}$ & $\begin{array}{l}\text { Initial Measured } \\
\text { Thickness } \\
\text { in. }\end{array}$ & $\begin{array}{l}\text { Calibrated } \\
\text { Thickness } \\
\text { in. }\end{array}$ \\
\hline $1, A C$ & 3.04 & & 3.04 & 4.00 & 2.75 \\
\hline $2, A C$ & 3.21 & & 3.21 & 4.00 & 2.75 \\
\hline $3, A C$ & 2.96 & & 2.96 & 4.00 & 2.75 \\
\hline 4, AC,PCC & 4.83 & PCC, 11.71 & 16.54 & 5.00 & 4.00 \\
\hline $5, \mathrm{AC}, \mathrm{PCC}$ & 4.54 & \begin{tabular}{|l|} 
PCC, 12.21 \\
\end{tabular} & 16.75 & 5.50 & 4.00 \\
\hline $6, \mathrm{AC}, \mathrm{PCC}$ & 5.13 & PCC, 11.79 & 16.92 & 5.50 & 4.00 \\
\hline $7, \mathrm{AC}$ & 6.58 & & 6.58 & 6.50 & 4.00 \\
\hline $8, A C$ & 6.42 & & 6.42 & 7.00 & 4.00 \\
\hline $9, A C$ & 5.75 & & 5.75 & 6.50 & 3.50 \\
\hline $10 c^{*}, A C$ & 2.58 & & 2.58 & 3.00 & 2.50 \\
\hline $21 c^{*}, A C$ & 4.50 & & 4.50 & 5.00 & 4.50 \\
\hline $22, A C$ & 4.81 & & 4.81 & 6.00 & 5.25 \\
\hline $23, A C$ & 4.46 & & 4.46 & 5.50 & 5.00 \\
\hline $24, A C$ & 4.50 & & 4.50 & 5.50 & 5.00 \\
\hline $25, A C$ & 8.75 & & 8.75 & 9.00 & 8.00 \\
\hline $26 c^{*}, A C$ & 9.25 & & 9.25 & 9.00 & 9.25 \\
\hline $27, A C$ & 8.25 & & 8.25 & 8.00 & 8.25 \\
\hline $28, A C$ & 9.50 & & 9.50 & 9.00 & 9.25 \\
\hline $29, A C$ & 12.46 & & 12.46 & 12.00 & 11.50 \\
\hline $30, A C$ & 9.21 & & 9.21 & 9.50 & 9.25 \\
\hline $31, A C, S B$ & 5.29 & SB, 4.75, 4.5 & 14.54 & 6.50 & 6.00 \\
\hline $11 c^{*}, \mathrm{PCC}$ & 8.42 & & 8.42 & 5.00 & 8.00 \\
\hline $12, \mathrm{PCC}$ & 24.96 & & 24.96 & 18.00 & 18.00 \\
\hline 13, PCC & 24.92 & & 24.92 & 6.00 & 18.00 \\
\hline $14, \mathrm{PCC}$ & 24.63 & & 24.63 & 16.00 & 18.00 \\
\hline $15, \mathrm{PCC}$ & 14.92 & & 14.92 & 16.00 & 14.50 \\
\hline $16, \mathrm{PCC}$ & 14.96 & & 14.96 & 8.00 & 14.75 \\
\hline $17, \mathrm{PCC}$ & 15.50 & & 15.50 & 8.00 & 14.75 \\
\hline 18, PCC & 7.54 & & 7.54 & 9.00 & 7.50 \\
\hline $19, \mathrm{PCC}$ & 8.00 & & 8.00 & 9.00 & 7.50 \\
\hline 20, PCC & 8.33 & & 8.33 & 9.00 & 7.50 \\
\hline $32, \mathrm{PCC}$ & 7.83 & & 7.83 & 6.00 & 4.75 \\
\hline $33, \mathrm{PCC}$ & 4.75 & & 4.75 & 6.00 & 4.75 \\
\hline $34 c^{*}$, PCC & 8.79 & & 8.79 & 12.00 & 8.75 \\
\hline 35, PCC & 12.71 & & 12.71 & 14.00 & 12.00 \\
\hline 36, PCC & 7.75 & & 7.75 & 20.00 & 15.00 \\
\hline $37, \mathrm{PCC}$ & 10.50 & & 10.50 & 12.00 & 10.25 \\
\hline 38, PCC & 10.38 & & 10.38 & 12.00 & 10.00 \\
\hline 39, PCC & 11.21 & & 11.21 & 12.00 & 10.50 \\
\hline $40 c^{*}, \mathrm{PCC}$ & 8.92 & & 8.92 & 10.50 & 9.00 \\
\hline
\end{tabular}

$\mathrm{SB}=$ stabilized limestone base, $\mathrm{PCC}=$ portland cement concrete, and $\mathrm{AC}=$ asphalt concrete.

* Denotes a test location used as a calibration point. 
Table A10. Results for 3D-Radar.

\begin{tabular}{|c|c|c|c|c|c|}
\hline $\begin{array}{l}\text { Test Location and } \\
\text { Pavement Type }\end{array}$ & $\begin{array}{l}\text { Layer } 1 \text { Actual } \\
\text { Core Thickness } \\
\text { in. }\end{array}$ & $\begin{array}{l}\text { Other Layers } \\
\text { Actual Core } \\
\text { Thicknesses } \\
\text { in. }\end{array}$ & $\begin{array}{l}\text { Sum of Pavement } \\
\text { Layers } \\
\text { in. }\end{array}$ & $\begin{array}{l}\text { Initial Measured } \\
\text { Thickness } \\
\text { in. }\end{array}$ & $\begin{array}{l}\text { Calibrated } \\
\text { Thickness } \\
\text { in. }\end{array}$ \\
\hline $1, A C$ & 3.04 & & 3.04 & 4.82 & 3.44 \\
\hline $2, A C$ & 3.21 & & 3.21 & 4.48 & 3.19 \\
\hline $3, A C$ & 2.96 & & 2.96 & 4.13 & 2.95 \\
\hline 4, AC,PCC & 4.83 & PCC, 11.71 & 16.54 & 6.20 & 4.42 \\
\hline $5, A C, P C C$ & 4.54 & PCC, 12.21 & 16.75 & 6.03 & 4.30 \\
\hline 6, AC,PCC & 5.13 & PCC, 11.79 & 16.92 & 6.72 & 4.79 \\
\hline $7, A C$ & 6.58 & & 6.58 & 8.10 & 5.77 \\
\hline $8, A C$ & 6.42 & & 6.42 & 8.10 & 5.77 \\
\hline $9, A C$ & 5.75 & & 5.75 & 8.10 & 5.77 \\
\hline $10 c^{*}, A C$ & 2.58 & & 2.58 & 3.62 & 2.58 \\
\hline $21 c^{*}, A C$ & 4.50 & & 4.50 & 6.03 & 4.50 \\
\hline $22, A C$ & 4.81 & & 4.81 & 6.38 & 4.76 \\
\hline $23, A C$ & 4.46 & & 4.46 & 6.00 & 4.50 \\
\hline $24, A C$ & 4.50 & & 4.50 & 6.20 & 4.63 \\
\hline $25, A C$ & 8.75 & & 8.75 & 11.72 & 8.74 \\
\hline $26 c *, A C$ & 9.25 & & 9.25 & 12.07 & 9.25 \\
\hline $27, A C$ & 8.25 & & 8.25 & 10.51 & 8.06 \\
\hline $28, A C$ & 9.50 & & 9.50 & 13.27 & 10.17 \\
\hline $29, A C$ & 12.46 & & 12.46 & 17.06 & 13.08 \\
\hline $30, A C$ & 9.21 & & 9.21 & 12.41 & 9.51 \\
\hline $31, A C, S B$ & 5.29 & SB, $4.75,4.5$ & 14.54 & 6.70 & 5.14 \\
\hline $11 c^{*}, \mathrm{PCC}$ & 8.42 & & 8.42 & 6.45 & 8.42 \\
\hline $12, \mathrm{PCC}$ & 24.96 & & 24.96 & 6.32 & 9.57 \\
\hline 13, PCC & 24.92 & & 24.92 & 6.45 & 9.85 \\
\hline 14, PCC & 24.63 & & 24.63 & 6.60 & 9.95 \\
\hline 15, PCC & 14.92 & & 14.92 & 6.71 & 9.76 \\
\hline 16, PCC & 14.96 & & 14.96 & 6.32 & 9.47 \\
\hline 17, PCC & 15.50 & & 15.50 & 6.30 & 9.95 \\
\hline 18, PCC & 7.54 & & 7.54 & 6.45 & 9.95 \\
\hline 19, PCC & 8.00 & & 8.00 & 6.19 & 8.61 \\
\hline 20, PCC & 8.33 & & 8.33 & 6.83 & 11.00 \\
\hline $32, \mathrm{PCC}$ & 7.83 & & 7.83 & 6.00 & 8.95 \\
\hline 33, PCC & 4.75 & & 4.75 & 5.67 & 9.14 \\
\hline $34 c^{*}$, PCC & 8.79 & & 8.79 & 6.32 & 8.79 \\
\hline $35, \mathrm{PCC}$ & 12.71 & & 12.71 & 5.93 & 10.12 \\
\hline 36, PCC & 7.75 & & 7.75 & 6.30 & 11.18 \\
\hline 37, PCC & 10.50 & & 10.50 & 13.80 & 10.37 \\
\hline 38, PCC & 10.38 & & 10.38 & 13.40 & 10.06 \\
\hline 39, PCC & 11.21 & & 11.21 & 14.31 & 10.72 \\
\hline $40 c^{*}$, PCC & 8.92 & & 8.92 & 11.10 & 8.92 \\
\hline
\end{tabular}

$\mathrm{SB}=$ stabilized limestone base, $\mathrm{PCC}=$ portland cement concrete, and $\mathrm{AC}=$ asphalt concrete .

* Denotes a test location used as a calibration point. 
Table A11. Results for the 1-GHz Pulse Radar horn antenna (ERDC).

\begin{tabular}{|c|c|c|c|c|c|}
\hline $\begin{array}{l}\text { Test Location and } \\
\text { Pavement Type }\end{array}$ & $\begin{array}{l}\text { Layer } 1 \text { Actual } \\
\text { Core Thickness } \\
\text { in. }\end{array}$ & $\begin{array}{l}\text { Other Layers } \\
\text { Actual Core } \\
\text { Thicknesses } \\
\text { in. }\end{array}$ & $\begin{array}{l}\text { Sum of Pavement } \\
\text { Layers } \\
\text { in. }\end{array}$ & $\begin{array}{l}\text { Initial Measured } \\
\text { Thickness } \\
\text { in. }\end{array}$ & $\begin{array}{l}\text { Calibrated } \\
\text { Thickness } \\
\text { in. }\end{array}$ \\
\hline $1, A C$ & 3.04 & & 3.04 & 3.50 & 3.13 \\
\hline $2, A C$ & 3.21 & & 3.21 & 3.80 & 3.50 \\
\hline $3, A C$ & 2.96 & & 2.96 & 3.10 & 2.82 \\
\hline 4, AC,PCC & 4.83 & PCC, 11.71 & 16.54 & 5.20 & 4.63 \\
\hline $5, A C, P C C$ & 4.54 & PCC, 12.21 & 16.75 & 4.90 & 4.63 \\
\hline $6, A C, P C C$ & 5.13 & PCC, 11.79 & 16.92 & 5.40 & 4.90 \\
\hline $7, A C$ & 6.58 & & 6.58 & 6.70 & 6.16 \\
\hline $8, A C$ & 6.42 & & 6.42 & 6.50 & 6.11 \\
\hline $9, A C$ & 5.75 & & 5.75 & 6.10 & 5.56 \\
\hline $10 c^{*}, A C$ & 2.58 & & 2.58 & 2.80 & 2.58 \\
\hline $21 c^{*}, A C$ & 4.50 & & 4.50 & 4.70 & 4.50 \\
\hline $22, A C$ & 4.81 & & 4.81 & 4.80 & 4.66 \\
\hline $23, A C$ & 4.46 & & 4.46 & 5.00 & 4.29 \\
\hline $24, A C$ & 4.50 & & 4.50 & 4.80 & 4.50 \\
\hline $25, A C$ & 8.75 & & 8.75 & 9.70 & 8.73 \\
\hline $26 c^{*}, A C$ & 9.25 & & 9.25 & 10.20 & 9.25 \\
\hline $27, A C$ & 8.25 & & 8.25 & 8.90 & 7.82 \\
\hline $28, A C$ & 9.50 & & 9.50 & 10.40 & 9.30 \\
\hline $29, A C$ & 12.46 & & 12.46 & 12.70 & 12.79 \\
\hline $30, A C$ & 9.21 & & 9.21 & 9.40 & 9.65 \\
\hline $31, A C, S B$ & 5.29 & SB, $4.75,4.5$ & 14.54 & 5.30 & 4.98 \\
\hline $11 c^{*}, P C C$ & 8.42 & & 8.42 & 11.30 & $\mathrm{~N} / \mathrm{A}$ \\
\hline $12, \mathrm{PCC}$ & 24.96 & & 24.96 & $\mathrm{~N} / \mathrm{A}$ & $\mathrm{N} / \mathrm{A}$ \\
\hline 13, PCC & 24.92 & & 24.92 & $\mathrm{~N} / \mathrm{A}$ & $\mathrm{N} / \mathrm{A}$ \\
\hline 14, PCC & 24.63 & & 24.63 & $\mathrm{~N} / \mathrm{A}$ & $\mathrm{N} / \mathrm{A}$ \\
\hline 15, PCC & 14.92 & & 14.92 & $\mathrm{~N} / \mathrm{A}$ & $\mathrm{N} / \mathrm{A}$ \\
\hline 16, PCC & 14.96 & & 14.96 & $\mathrm{~N} / \mathrm{A}$ & $\mathrm{N} / \mathrm{A}$ \\
\hline 17, PCC & 15.50 & & 15.50 & $\mathrm{~N} / \mathrm{A}$ & $\mathrm{N} / \mathrm{A}$ \\
\hline 18, PCC & 7.54 & & 7.54 & $\mathrm{~N} / \mathrm{A}$ & $\mathrm{N} / \mathrm{A}$ \\
\hline 19, PCC & 8.00 & & 8.00 & $\mathrm{~N} / \mathrm{A}$ & N/A \\
\hline 20, PCC & 8.33 & & 8.33 & N/A & N/A \\
\hline $32, \mathrm{PCC}$ & 7.83 & & 7.83 & 11.70 & N/A \\
\hline 33, PCC & 4.75 & & 4.75 & 11.70 & $\mathrm{~N} / \mathrm{A}$ \\
\hline $34 c^{*}, \mathrm{PCC}$ & 8.79 & & 8.79 & $\mathrm{~N} / \mathrm{A}$ & $\mathrm{N} / \mathrm{A}$ \\
\hline 35, PCC & 12.71 & & 12.71 & $\mathrm{~N} / \mathrm{A}$ & $\mathrm{N} / \mathrm{A}$ \\
\hline 36, PCC & 7.75 & & 7.75 & N/A & $\mathrm{N} / \mathrm{A}$ \\
\hline $37, \mathrm{PCC}$ & 10.50 & & 10.50 & 11.80 & 11.36 \\
\hline 38, PCC & 10.38 & & 10.38 & 11.90 & 11.36 \\
\hline 39, PCC & 11.21 & & 11.21 & 15.70 & 15.27 \\
\hline $40 c^{*}$, PCC & 8.92 & & 8.92 & 9.40 & 8.92 \\
\hline
\end{tabular}

$\mathrm{SB}=$ stabilized limestone base, $\mathrm{PCC}=$ portland cement concrete, and $\mathrm{AC}=$ asphalt concrete.

* Denotes a test location used as a calibration point. 


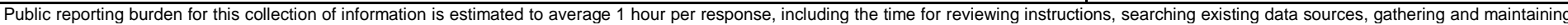

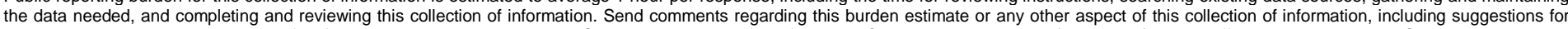

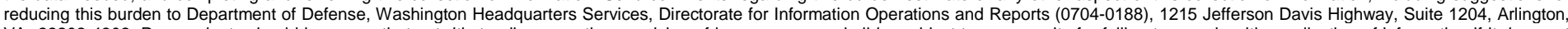

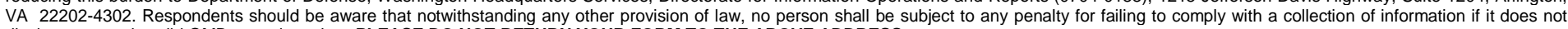
display a currently valid OMB control number. PLEASE DO NOT RETURN YOUR FORM TO THE ABOVE ADDRESS.
1. REPORT DATE (DD-MM-YYYY)
2. REPORT TYPE
3. DATES COVERED (From - To)

September 2011

Final report

\section{TITLE AND SUBTITLE}

Evaluation of Nondestructive Methods for Determining Pavement Thickness

5a. CONTRACT NUMBER

bb. GRANT NUMBER

5c. PROGRAM ELEMENT NUMBER

\section{AUTHOR(S)}

Lulu Edwards and Quint Mason

5d. PROJECT NUMBER

5e. TASK NUMBER

5f. WORK UNIT NUMBER

\section{PERFORMING ORGANIZATION NAME(S) AND ADDRESS(ES)}

8. PERFORMING ORGANIZATION REPORT NUMBER

U.S. Army Engineer Research and Development Center

Geotechnical and Structures Laboratory

ERDC/GSL TR-11-41

3909 Halls Ferry Road, Vicksburg, MS 39180-6199

9. SPONSORING I MONITORING AGENCY NAME(S) AND ADDRESS(ES)

10. SPONSOR/MONITOR'S ACRONYM(S)

Headquarters, Air Force Civil Engineer Support Agency

139 Barnes Avenue, Suite 1

Tyndall AFB, FL 32403-5319

11. SPONSOR/MONITOR'S REPORT NUMBER(S)

\section{DISTRIBUTION I AVAILABILITY STATEMENT}

Approved for public release; distribution is unlimited.

\section{SUPPLEMENTARY NOTES}

\section{ABSTRACT}

The ERDC was tasked by the U.S. Air Force to evaluate emerging nondestructive thickness measuring devices to determine their ability to accurately estimate the pavement surface thickness without requiring large footprint equipment or repairs. Companies with products using nondestructive technology were down-selected to participate in a study requiring them to estimate the thickness of 40 asphalt and concrete locations with nondestructive devices. For each of the different pavement types, a single core was extracted to provide vendors with calibration points. Vendors provided initial thickness estimates, and upon receiving the calibration core thicknesses, vendors provided final thickness estimates. The results were compared to determine the accuracy and feasibility of the devices tested.

\section{SUBJECT TERMS}

Ground-penetrating radar Nondestructive testing 16. SECURITY CLASSIFICATION OF:

\begin{tabular}{l|l}
\hline $\begin{array}{l}\text { a. REPORT } \\
\text { UNCLASSIFIED }\end{array}$ & $\begin{array}{l}\text { b. ABSTRACT } \\
\text { UNCLASSIFIED }\end{array}$
\end{tabular}

Pavement thickness

Seismic
17. LIMITATION OF ABSTRACT
18. NUMBER OF PAGES

c. THIS PAGE

UNCLASSIFIED 19a. NAME OF RESPONSIBLE PERSON

19b. TELEPHONE NUMBER (include

104 area code) 